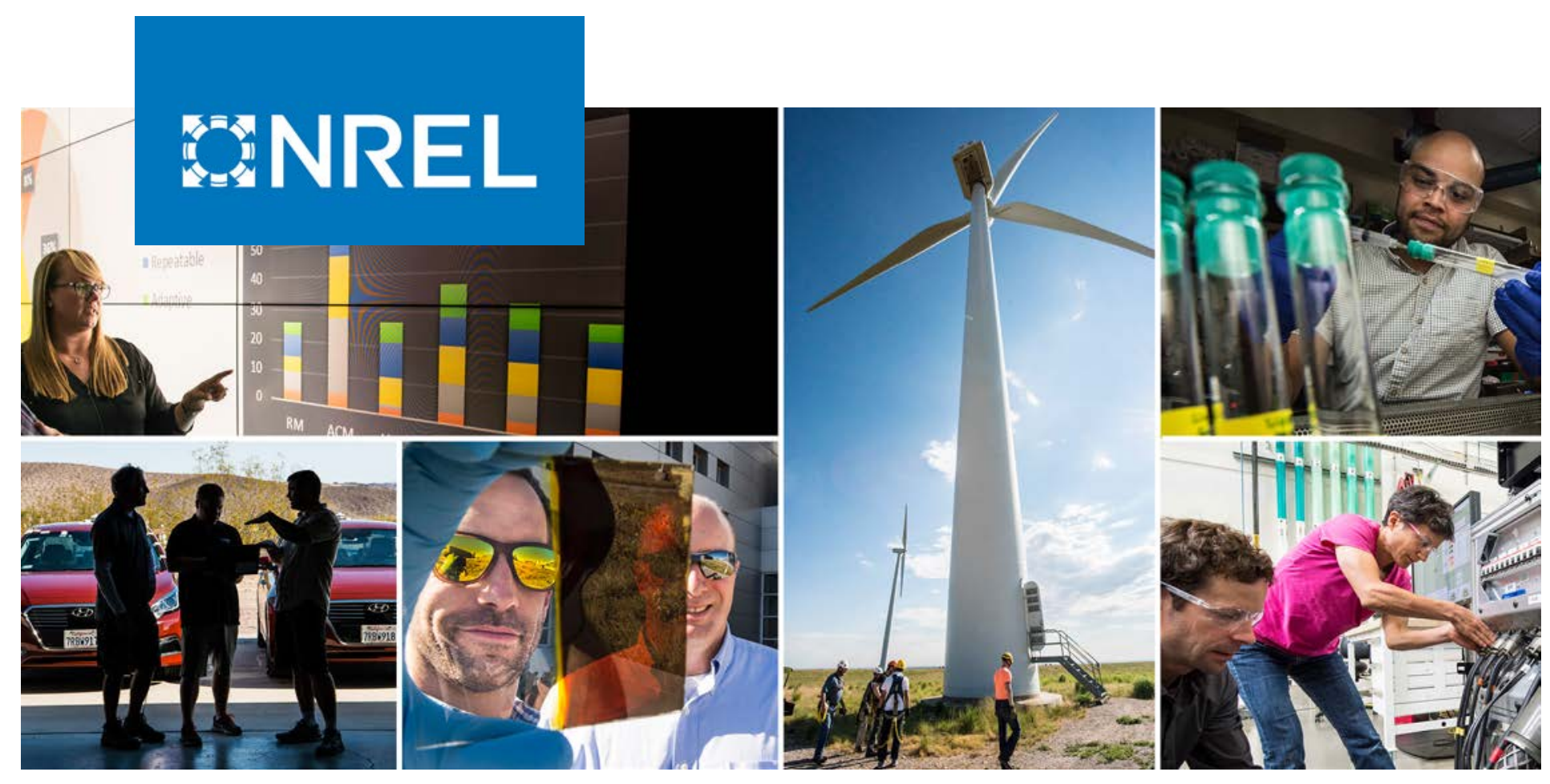

\title{
CSP Systems Analysis - Final Project Report
}

Craig S. Turchi, Matthew Boyd, Devon Kesseli, Parthiv Kurup, Mark Mehos, Ty Neises, Prashant Sharan, Michael Wagner, and Timothy Wendelin

National Renewable Energy Laboratory

NREL is a national laboratory of the U.S. Department of Energy

Office of Energy Efficiency \& Renewable Energy

Operated by the Alliance for Sustainable Energy, LLC

This report is available at no cost from the National Renewable Energy Laboratory (NREL) at www.nrel.gov/publications.

\section{Technical Report}

NREL/TP-5500-72856

May 2019 


\section{GANREL}

\section{CSP Systems Analysis - Final Project Report}

Craig S. Turchi, Matthew Boyd, Devon Kesseli, Parthiv Kurup, Mark Mehos, Ty Neises, Prashant Sharan, Michael Wagner, and Timothy Wendelin

National Renewable Energy Laboratory

\section{Suggested Citation}

Turchi, Craig S., Matthew Boyd, Devon Kesseli, Parthiv Kurup, Mark Mehos, Ty Neises, Prashant Sharan, Michael Wagner, Timothy Wendelin. 2019. CSP Systems Analysis - Final Project Report. Golden, CO: National Renewable Energy Laboratory. NREL/TP-5500-72856.

https://www.nrel.gov/docs/fy19osti/72856.pdf.

NREL is a national laboratory of the U.S. Department of Energy Office of Energy Efficiency \& Renewable Energy Operated by the Alliance for Sustainable Energy, LLC

This report is available at no cost from the National Renewable Energy Laboratory (NREL) at www.nrel.gov/publications.

Contract No. DE-AC36-08GO28308
Technical Report NREL/TP-5500-72856 May 2019

National Renewable Energy Laboratory 15013 Denver West Parkway Golden, CO 80401

303-275-3000 • www.nrel.gov 


\section{NOTICE}

This work was authored by the National Renewable Energy Laboratory, operated by Alliance for Sustainable Energy, LLC, for the U.S. Department of Energy (DOE) under Contract No. DE-AC36-08G028308. Funding provided by.S. Department of Energy Office of Energy Efficiency and Renewable Energy Solar Energy Technologies Office. The views expressed herein do not necessarily represent the views of the DOE or the U.S. Government.

This report is available at no cost from the National Renewable Energy Laboratory (NREL) at www.nrel.gov/publications.

U.S. Department of Energy (DOE) reports produced after 1991 and a growing number of pre-1991 documents are available free via www.OSTI.gov.

Cover Photos by Dennis Schroeder: (clockwise, left to right) NREL 51934, NREL 45897, NREL 42160, NREL 45891, NREL 48097, NREL 46526.

NREL prints on paper that contains recycled content. 


\section{Final Technical Report (FTR)}

Project Title:

Project Period:

Submission Date:

Recipient:

Address:

Website:

Award Number:

Project Team:

Principal Investigator:

Business Contact:

Technology Manager:

Project Officer:
CSP Systems Analysis

Summary Results of Cost Analysis and Analysis-Tool

Development

10/01/15 - 09/30/18

$11 / 15 / 2018$

National Renewable Energy Laboratory (NREL)

15013 Denver West Parkway

Golden, CO 80401

www.nrel.gov

NREL-1651

NREL

Craig Turchi

Phone: 303-384-7565

Email: craig.turchi@nrel.gov

Mark Mehos

Phone: 303-384-7458

Email: mark.mehos@nrel.gov

Mark Lausten

Christine Bing 


\section{Executive Summary}

The CSP Systems Analysis project was a three-year effort supporting the Concentrating Solar Power (CSP) Subprogram within the Solar Energy Technologies Office of the U.S. Department of Energy (DOE). The goal of the CSP Systems Analysis project was to provide timely and accurate CSP cost data to the DOE and project performance and cost for emerging technologies to inform research directions and industry investment. The project consisted of six, mostly independent tasks. Major accomplishments over the three-year period of performance were as follows.

- The NREL team maintained current cost estimates for CSP technologies through annual updates to the cost input parameters within NREL's System Advisor Model (SAM). SAM is a performance and cost simulation software that includes technology models for the primary CSP technologies. During the period from 2016 to 2018, the estimated levelized cost of energy (LCOE) for SAM's default CSP molten-salt power tower technology dropped from 13.0 to $11.1 \phi / \mathrm{kWh}$ (real dollars without incentives).

- Power cycle models for the supercritical carbon dioxide $\left(\mathrm{sCO}_{2}\right)$ Brayton Cycle were developed and made an option within SAM's molten-salt power tower model. These models were subsequently used to evaluate the cost reduction potential of alternative salts. The partial-cooling model was found to provide the greatest cost-reduction potential due to its combination of efficiency and temperature differential across the turbine and thermal energy storage (TES) system. These studies were documented in two journal articles.

- NREL's optical modeling software SolTrace and SolarPILOT were made more versatile and released as open-source software to the CSP community. These tools help researchers and developers to model and optimize the optical performance of CSP collector systems. The new features were highlighted in a recorded webinar that can be accessed from the NREL SAM website (https://sam.nrel.gov).

- New models for solar-thermal systems, that is, applications for solar industrial process heat, were developed, validated, and installed within SAM. The analysis includes a 2018 review of linear collectors in the market that are tailored for solar process heat applications. In 2018 the NREL team also developed an annual simulation for a direct steam generation system integrated with a latent-heat thermal energy storage (TES) system. This analysis was submitted for journal publication.

- The NREL team continued to support the exchange of information and development of CSP guidelines within the international CSP community of SolarPACES. Much of the work under this project was presented at SolarPACES, including the development of a modeling checklist to help CSP stakeholders standardize the models used for estimating CSP performance and cost.

The CSP Systems Analysis project also supported DOE requests for tracking and reporting programmatic targets for the CSP Subprogram. 


\section{Contents}

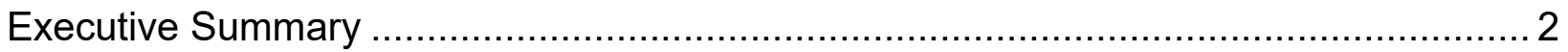

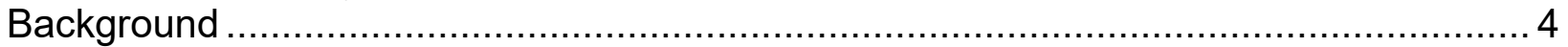

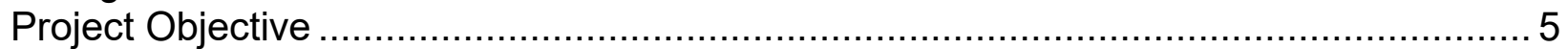

Task 1 - CSP Cost Tracking ……................................................................ 5

Task 2 - Supercritical $\mathrm{CO}_{2}\left(\mathrm{sCO}_{2}\right)$ Power Cycle Modeling …................................ 5

Task 3 - Optical Modeling of Power Tower Systems ............................................ 5

Task 4 - Thermal-Application Modeling Tools for SAM …..................................... 6

Task 5 - IEA SolarPACES Task I Operation Agent ............................................. 6

Task 6 - Assessment of Advanced CSP systems in the $600^{\circ} \mathrm{C}$ to $650^{\circ} \mathrm{C}$ temp. range 6

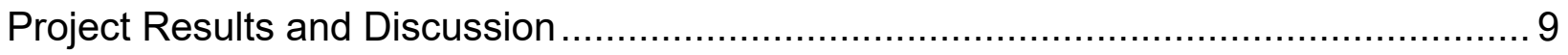

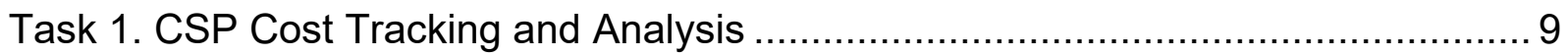

SAM 2018 Updates for Power Towers and Parabolic Troughs ........................... 12

Solar Field Costs ............................................................................................. 13

Heliostat Solar Field Installed Costs........................................................... 13

Parabolic Trough Solar Field Installed Costs .................................................... 15

Power Block and Balance of Plant Costs ......................................................... 17

Thermal Energy Storage (TES) tanks and costs .......................................... 19

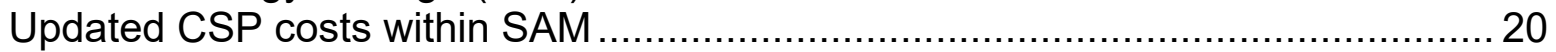

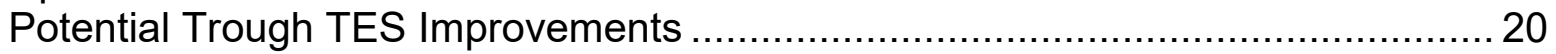

Task 2. Supercritical $\mathrm{CO}_{2}\left(\mathrm{sCO}_{2}\right)$ Power Cycle Modeling .................................... 21

Preprocessor boosts computation speed for $\mathrm{sCO}_{2}$ Power Cycle Modeling ............ 21

The $\mathrm{SCO}_{2}$ recompression model user interface updated within SAM .................. 22

Development of the Partial-cooling $\mathrm{SCO}_{2}$ Cycle within SAM ........................... 25

Comparing Annual System Performance with SAM's sCO 2 Power Cycle Models . 30

Task 3. Optical Modeling of Power Tower Systems................................................ 31

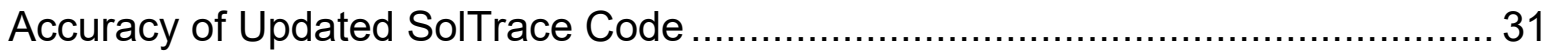

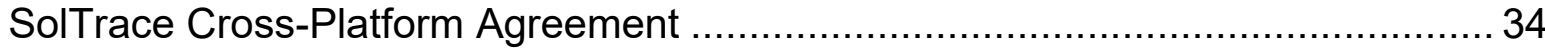

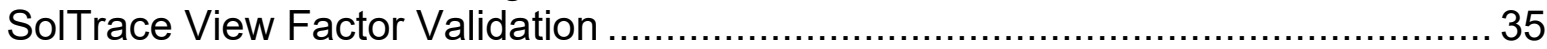

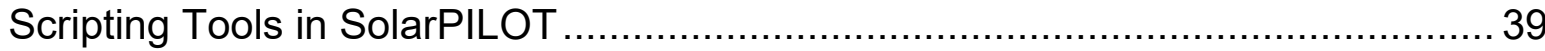

Open-Source Code Release of SolarPILOT and SolTrace ................................. 44

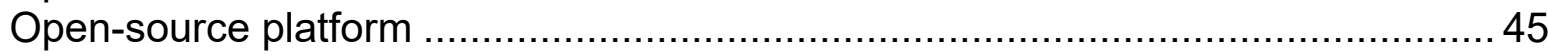

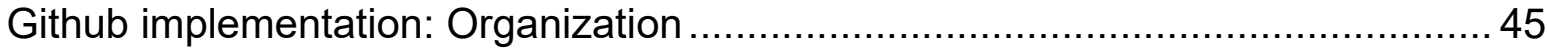

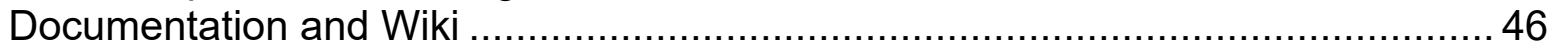

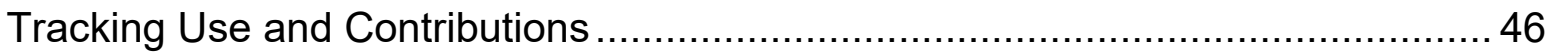

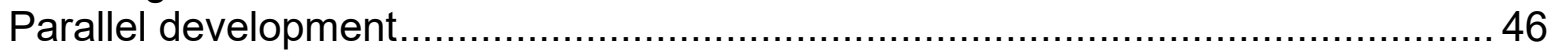

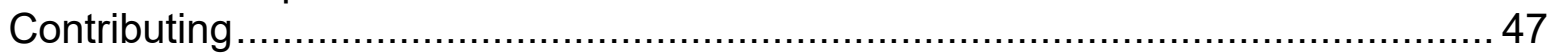

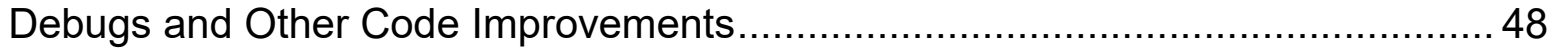

Task 4. Thermal-Application Modeling Tools for SAM ........................................ 49

Validation of New Solar Industrial Process Heat (IPH) Models in SAM - Trough

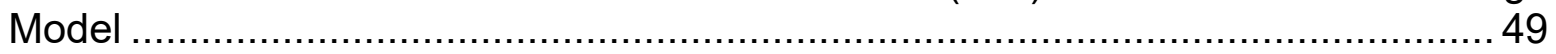


Validation of New Solar IPH Models in SAM - Direct Steam Generation (DSG) Model

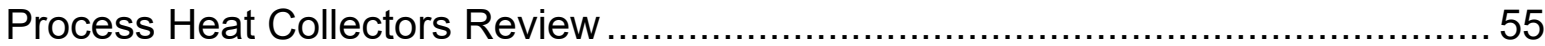

Brewery Integration Case Study .............................................................. 71

Modeling Solar Process Heat with PCM Storage ............................................. 73

Task 5. SolarPACES Task I Status Updates .................................................. 74

Task 6. Assessment of Advanced CSP Systems in the $600^{\circ} \mathrm{C}$ to $650^{\circ} \mathrm{C}$ Temperature

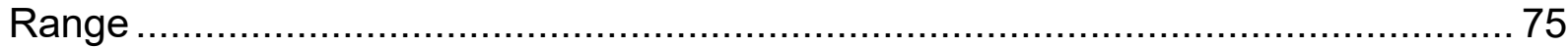

Inventions, Patents, Publications, and Other Results................................................. 76

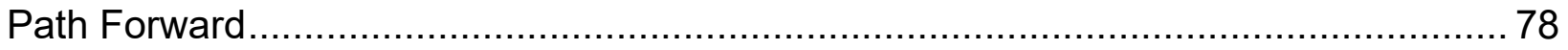

References

\section{Background}

The goal of the CSP Systems Analysis project is to provide timely and accurate CSP cost data to the DOE and project performance and cost for emerging technologies to inform research directions and industry investment. Much of NREL's activity in CSP Systems Analysis is directed toward expanding the capabilities of NREL's System Advisor Model (SAM). SAM is a performance and financial model designed to facilitate decision making for people involved in the renewable energy industry and includes simulation models for photovoltaic (PV), wind, geothermal, CSP and other power systems. SAM makes performance estimates and levelized cost of energy (LCOE) estimates for grid-connected power projects based on installation and operating costs and system design parameters that the user specifies as inputs to the model.

SAM includes CSP models for trough, linear Fresnel, dish/engine, and power tower technologies, as well as linear-collector (trough and Fresnel) process heat models. SAM automatically populates input variables with a set of default values for the type of project. It is the responsibility of the user to review and modify all of the input data as appropriate for each analysis. Information about a project's location, the type of equipment in the system, the cost of installing and operating the system, and financial and incentives assumptions can be selected. To describe the renewable energy resource and weather conditions at a project location, SAM requires a weather data file. Depending on the kind of system being modeling, one can either choose a weather data file from a list, download one from the Internet, or create the file using one's own weather data.

SAM's CSP models have performed well in comparisons with other CSP estimation software and modeling guidelines (Wagner et al. 2011; Kesseli et al. 2018), and SAM has become the preeminent simulation package for estimating the performance and cost of solar energy technologies for NREL and the DOE Solar Energy Technologies Office. For example, SAM was used by NREL to help DOE develop the SunShot targets that have become the basic metrics for DOE's CSP technology development portfolio (Mehos et al. 2016). SAM also serves CSP stakeholders in the research, industrial, and financial sectors by providing a sophisticated, objective, and freely available tool for assessing the performance and cost of CSP systems. 
SAM includes several technology models for different CSP configurations and relies on NREL-developed algorithms for modeling collector optical and thermal performance, power-cycle efficiency and behavior, and system dispatch (i.e., when to discharge storage to maximize revenue and minimize system operating costs), among others. Much of the work under the Systems Analysis project is directed toward improving the accuracy and utility of these subroutines.

SolTrace and SolarPILOT are two such codes that were originally developed by NREL as stand-alone software for optical modeling and were partially integrated into SAM as part of this project. These two, formerly NREL-internal codes, were reviewed, cleaned, and documented and then released as open-source software.

\section{Project Objective}

Objectives under the CSP Systems Analysis project include enhancing the accuracy, speed and utility of NREL's CSP models, including those models within SAM; providing new functionality in SAM; and using SAM and other tools to model CSP systems for specific analyses. The project also responds to specific DOE requests for CSP cost analyses. Six tasks were defined throughout the three-year period of performance:

\section{Task 1 - CSP Cost Tracking}

- Track and assess CSP component and system costs as reported by the industry

- Update SAM's CSP cost values

\section{Task 2 - Supercritical $\mathrm{CO}_{2}\left(\mathrm{sCO}_{2}\right)$ Power Cycle Modeling}

- Increase simulation speed and accuracy to make $\mathrm{sCO}_{2}$ cycle model codes compatible with NREL's SAM framework,

- Address off-design operation and turbomachinery scaling so that the $\mathrm{sCO}_{2}$ power cycle models are consistent with constraints for CSP subsystems and dispatch optimization algorithms,

- Examine $\mathrm{sCO}_{2}$ cycle performance and associated system cost impact as a function of the temperature differential $(\Delta \mathrm{T})$ across a 2-tank thermal energy storage (TES) system,

- Compare annual performance of two common $\mathrm{sCO}_{2}$ cycle configurationsrecompression and partial-cooling - within SAM's molten-salt power tower (MSPT) model. Advise industry related to the selection and operating mode of $\mathrm{sCO}_{2}$ power cycles for CSP applications.

\section{Task 3 - Optical Modeling of Power Tower Systems}

- Develop and implement SolTrace performance and interface enhancements, enabling new analysis capabilities, and transfer SolarPILOT and SolTrace model capabilities to industry and researchers via a SAM webinar.

- Implement a method within the SolTrace engine to calculate view factors for multiple surfaces within selected stages. Availability of these data will significantly improve the efficiency of post-SolTrace radiative exchange analysis using thermal analysis codes.

- Develop and consolidate scripting functionality among SAM, SolTrace, and SolarPILOT under SAM's LK language.

- Update and release SolarPILOT as open-source code consistent with the open-source version of SAM. This will enable users to create custom geometry configurations (the 
former milestone) as well as other user-specific functions within SolarPILOT. Host informational webinar for user community.

\section{Task 4 - Thermal-Application Modeling Tools for SAM}

- Separate SAM's linear collector performance models from constraints associated with power conversion systems,

- Simplify and clarify SAM's user interface for simulations of thermal-only systems,

- Validate performance estimates from a SAM thermal-system model versus experimental data,

- Perform a case study to highlight the potential of solar industrial process heat to promote early adopters,

- Analyze DSG+TES system for industrial steam production, showcasing the collector, TES, and project costs that lead to heat supply at lower cost than natural gas. Emphasis placed on the design and operation of the DSG system and TES to reduce cost and provide reliable steam delivery.

\section{Task 5 - IEA SolarPACES Task I Operation Agent}

- This task supports NREL's Mark Mehos as the SolarPACES Task I Operating Agent. SolarPACES Task I addresses the design, testing, demonstration, evaluation, and application of CSP systems, and supports an international project database for commercial CSP systems as well as the development of acceptance test procedures and standards for CSP systems. The active international market provides valuable markets for U.S. CSP developers and knowledge that can be applied to systems in the United States.

\section{Task 6 - Assessment of Advanced CSP systems in the $600^{\circ} \mathrm{C}$ to $650^{\circ} \mathrm{C}$ temp. range}

- Evaluate potential pathways and cost advantages of increasing power tower operating temperatures to $600-650^{\circ} \mathrm{C}$ as a prelude to later evolution to $\geq 700^{\circ} \mathrm{C}$ conditions. The task leverages prior studies by NREL, Sandia, and others and assesses construction material and thermal energy storage (TES) options. 


\section{The project milestones are outlined in Table 1.}

Table 1. Project evaluation criteria (PEC) for the three-year scope. Page numbers refer to the initial page where information can be found in this report.

\begin{tabular}{|c|c|c|c|c|c|}
\hline & Metric Definition & Success Value & $\begin{array}{c}\text { Measured } \\
\text { Value }\end{array}$ & $\begin{array}{c}\text { Assessment Tool } \\
\text { (Quality Assurance) }\end{array}$ & $\begin{array}{l}\text { Goal } \\
\text { Met? }\end{array}$ \\
\hline$\underset{\text { in }}{-1}$ & $\begin{array}{l}\text { Update to CSP technology } \\
\text { costs in SAM }\end{array}$ & $\begin{array}{l}\text { Report and presentation } \\
\text { to DOE documenting the } \\
\text { updated costs for CSP } \\
\text { subsystems and overall } \\
\text { plant cost within SAM }\end{array}$ & $\mathrm{n} / \mathrm{a}$ & $\begin{array}{c}\text { Referenced data sources } \\
\text { with at least three survey } \\
\text { responses for each cost } \\
\text { category }\end{array}$ & $\begin{array}{c}\text { Yes, } \\
\text { but } \\
\text { superseded by } \\
\text { PEC } 3.1\end{array}$ \\
\hline 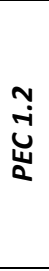 & $\begin{array}{l}\text { Increase computation speed } \\
\text { of the recompression code } \\
\text { while retaining accuracy }\end{array}$ & $\begin{array}{l}\text { Convergence of hourly, } \\
\text { annual simulations in less } \\
\text { than } 25 \% \text { of current } \\
\text { system (SAM 2015-06-30) } \\
\text { runtime }\end{array}$ & $\begin{array}{l}\text { Achieved in } \\
\sim 1 \% \text { of } \\
\text { current } \\
\text { runtime }\end{array}$ & $\begin{array}{l}\text { At least five different use } \\
\text { cases will be evaluated; for } \\
\text { all five, the deviation in } \\
\text { annual generation and } \\
\text { hourly generation RMS } \\
\text { error from non-interpolated } \\
\text { results will be }<5 \%\end{array}$ & $\begin{array}{l}\text { Yes, } \\
\text { pg. } 21\end{array}$ \\
\hline 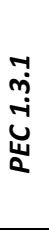 & $\begin{array}{l}\text { SolTrace simulation speed } \\
\text { improvement } \\
\qquad \Delta_{\text {sim }}=\frac{t_{s i m}^{0}}{t_{s i m}}\end{array}$ & $\Delta_{\text {sim }} \geq 20$ & $>300$ & $\begin{array}{l}\text { Among population of } \geq 5 \\
\text { heliostat field test cases, } \\
\text { improvement mean } \\
\Delta_{\text {sim }} \geq 20 \text { with } 90 \% \\
\text { confidence }\end{array}$ & $\begin{array}{l}\text { Yes, } \\
\text { pg. } 31\end{array}$ \\
\hline$\underset{\text { m̧ }}{\stackrel{\sim}{u}}$ & $\begin{array}{l}\text { Deviation between ray- } \\
\text { trace and analytical view } \\
\text { factors } \\
\qquad \Delta f=\left|\frac{f_{a n}-f_{r t}}{f_{a n}}\right|\end{array}$ & $\Delta f_{\max } \leq 0.02$ & $<0.012$ & $\begin{array}{l}\text { Max. error from set of } \geq 7 \\
\text { analytical view factor } \\
\text { solutions in Nellis \& Klein } \\
\text { (2009) F3D_X library }\end{array}$ & $\begin{array}{l}\text { Yes, } \\
\text { pg. } 31\end{array}$ \\
\hline 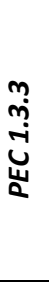 & $\begin{array}{l}\text { Cross-platform simulation } \\
\text { agreement } \\
\begin{aligned} e r r_{\text {max }} & =\left|\frac{m_{p}-m_{\text {ref }}}{m_{\text {ref }}}\right| \\
m & =\left\{\begin{array}{c}\dot{q}_{\text {peak }} \\
\dot{q}_{\text {ave }} \\
n_{\text {ray,int }}\end{array}\right.\end{aligned}\end{array}$ & 0.001 & $<0.001$ & $\begin{array}{c}\text { Among population of } \geq 5 \\
\text { heliostat field test cases, } \\
\text { max error less than success } \\
\text { value }\end{array}$ & $\begin{array}{l}\text { Yes, } \\
\text { pg. } 34\end{array}$ \\
\hline 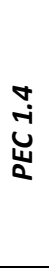 & $\begin{array}{l}\text { Validated, publicly available } \\
\text { code to simulate trough, } \\
\text { DSG trough, and Fresnel } \\
\text { system performance for } \\
\text { thermal applications. }\end{array}$ & $\begin{array}{l}\text { Comparison of each new } \\
\text { model with experimental } \\
\text { data validating model } \\
\text { energy-generation } \\
\text { estimate within } 90 \% \\
\text { confidence interval for } \\
\text { test period. }\end{array}$ & $\begin{array}{l}\text { Agreement } \\
\text { within 2\% } \\
\text { (trough) } \\
\text { and } \\
\text { approx. 3\% } \\
\text { (DSG) }\end{array}$ & Computational validation & $\begin{array}{l}\text { Yes, } \\
\text { pg. } 49\end{array}$ \\
\hline
\end{tabular}


NREL-1651

CSP Systems Analysis

\begin{tabular}{|c|c|c|c|c|c|}
\hline & Metric Definition & Success Value & $\begin{array}{c}\text { Measured } \\
\text { Value }\end{array}$ & $\begin{array}{c}\text { Assessment Tool } \\
\text { (Quality Assurance) }\end{array}$ & $\begin{array}{l}\text { Goal } \\
\text { Met? }\end{array}$ \\
\hline$\underset{N}{N}$ & $\begin{array}{l}\text { MSPT/sCO2 recompression } \\
\text { cycle model functionality } \\
\text { and agreement across the } \\
\text { following ranges: } \\
\text { Capacity: } 10-200 \mathrm{MW} \\
\text { Load: } 40-105 \% \\
\text { Turbine Inlet: } 550-750^{\circ} \mathrm{C} \\
\text { Ambient: Temp. }-10-50^{\circ} \mathrm{C}\end{array}$ & $\begin{array}{l}\text { MSPT/sCO2 model } \\
\text { converges, is } \\
\text { reproducible, and avoids } \\
\text { HTF mass flowrate and } \\
\text { power generation } \\
\text { excursions outside } \\
\text { specified bounds. } \\
\text { Dispatch optimization } \\
\text { improves upon level } \\
\text { dispatch. }\end{array}$ & TBD & $\begin{array}{l}\text { Simulations show that hourly } \\
\text { HTF mass flowrate and cycle } \\
\text { power do not violate } \\
\text { equipment or operational } \\
\text { constraints for annual } \\
\text { simulations of } 10 \text { different } \\
\text { designs. }\end{array}$ & $\begin{array}{l}\text { Yes, } \\
\text { pg. } 22\end{array}$ \\
\hline 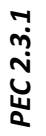 & $\begin{array}{l}\text { Demonstration of custom } \\
\text { geometry configurations for } \\
\text { heliostat and receiver }\end{array}$ & 2 cases each & TBD & $\begin{array}{l}\text { Cases and functionality } \\
\text { demonstrated in a SAM } \\
\text { webinar }\end{array}$ & $\begin{array}{l}\text { No, } \\
\text { replaced by } \\
\text { PEC } 3.3\end{array}$ \\
\hline 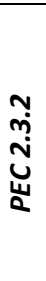 & $\begin{array}{l}\text { Deviation between ray-trace } \\
\text { and analytical view factors } \\
\text { for multiple surfaces on } \\
\text { stage-by-stage basis } \\
\qquad \Delta F_{i, j}=\left|\frac{F_{i, j, a n}-F_{i, j, r t}}{F_{i, j, a n}}\right|\end{array}$ & $\Delta F_{i, j, \max } \leq 0.02$ & $<0.02$ & $\begin{array}{c}\text { Criteria satisfied for } \geq 2 \\
\text { different cavity receiver } \\
\text { geometries consisting of } 5 \\
\text { different surfaces. }\end{array}$ & $\begin{array}{l}\text { Yes, } \\
\text { pg. } 35\end{array}$ \\
\hline$\underset{\substack{m \\
m}}{\stackrel{m}{u}}$ & $\begin{array}{l}\text { Scripting functionality } \\
\text { replicates fraction of } \\
\text { interface actions }\end{array}$ & $80 \%$ & $95 \%$ & $\begin{array}{c}\text { SolarPILOT \& SolTrace } \\
\text { interfaces }\end{array}$ & $\begin{array}{l}\text { Yes, } \\
\text { pg. } 39\end{array}$ \\
\hline 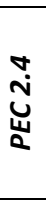 & $\begin{array}{l}\text { Case study report defining } \\
\text { conditions where NPV }>0\end{array}$ & $\begin{array}{l}\text { Define a region of positive } \\
\text { net present value based } \\
\text { on parametric assessment } \\
\text { of key design and financial } \\
\text { parameters. }\end{array}$ & $\mathrm{n} / \mathrm{a}$ & $\begin{array}{l}\text { Partner letter supporting the } \\
\text { analysis methodology and } \\
\text { primary assumptions }\end{array}$ & $\begin{array}{l}\text { Yes, } \\
\text { pg. } 71\end{array}$ \\
\hline 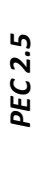 & $\begin{array}{c}\text { SolarPACES Task I status } \\
\text { updates }\end{array}$ & $\begin{array}{l}\text { Keep DOE apprised of } \\
\text { activities within the } \\
\text { international CSP } \\
\text { community. }\end{array}$ & $\begin{array}{l}\text { Quarterly } \\
\text { activity } \\
\text { report }\end{array}$ & $\begin{array}{c}\text { Summary of Task publications } \\
\text { with relevance and benefit to } \\
\text { U.S. CSP interests }\end{array}$ & $\begin{array}{l}\text { Yes, } \\
\text { pg. } 74\end{array}$ \\
\hline 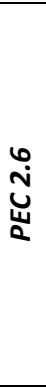 & $\begin{array}{l}\text { DOE milestone report } \\
\text { documenting the estimated } \\
\text { performance and cost of } \\
\text { MSPT systems operating at } \\
600 \text { to } 650^{\circ} \mathrm{C}\end{array}$ & $\begin{array}{c}\text { Estimated LCOE at least } \\
10 \% \text { less than the baseline } \\
\text { design operating at } 565^{\circ} \mathrm{C} \\
\text { with solar salt }\end{array}$ & $10-12 \%$ & $\begin{array}{l}\text { Standardized financial } \\
\text { parameters and a } \\
\text { conceptually similar design } \\
\text { will facilitate an accurate } \\
\text { relative-cost evaluation. } \\
\mathrm{SCO}_{2} \text { performance estimates } \\
\text { based on engineering } \\
\text { correlations of system } \\
\text { performance through the } \\
\text { range of temperature }\end{array}$ & $\begin{array}{l}\text { Yes, } \\
\text { pg. } 75\end{array}$ \\
\hline
\end{tabular}


NREL-1651

CSP Systems Analysis

\begin{tabular}{|c|c|c|c|c|c|}
\hline & Metric Definition & Success Value & $\begin{array}{c}\text { Meas'd } \\
\text { Value }\end{array}$ & $\begin{array}{c}\text { Assessment Tool } \\
\text { (Quality Assurance) }\end{array}$ & $\begin{array}{l}\text { Goal } \\
\text { Met? }\end{array}$ \\
\hline$\bigcup_{\substack{n \\
a}}^{-1}$ & $\begin{array}{l}\text { Update CSP technology } \\
\text { costs in SAM }\end{array}$ & $\begin{array}{c}\text { Presentation to DOE } \\
\text { documenting the updated } \\
\text { costs for CSP subsystems } \\
\text { and overall plant cost } \\
\text { within SAM }\end{array}$ & $\mathrm{n} / \mathrm{a}$ & $\begin{array}{c}\text { Referenced data sources with } \\
\text { at least three survey } \\
\text { responses for each cost } \\
\text { category }\end{array}$ & $\begin{array}{l}\text { Yes, } \\
\text { pg. } 12\end{array}$ \\
\hline 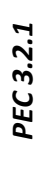 & $\begin{array}{l}\text { Partial-cooling } \mathrm{s}-\mathrm{CO}_{2} \text { option } \\
\quad \text { for SAM MSPT Model }\end{array}$ & $\begin{array}{l}\text { Public release to SAM; } \\
\text { comparison with } \\
\text { recompression and simple } \\
\mathrm{s}-\mathrm{CO}_{2} \text { cycles. }\end{array}$ & $\mathrm{n} / \mathrm{a}$ & $\begin{array}{l}\text { NREL report comparing } \\
\text { performance metrics between } \\
\text { partial-cooling and } \\
\text { recompression model }\end{array}$ & $\begin{array}{l}\text { Yes, } \\
\text { pg. } 25\end{array}$ \\
\hline 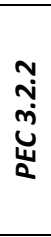 & $\begin{array}{c}\mathrm{sCO}_{2} \text { Power Cycle } \\
\text { Optimization for Sensible } \\
\text { TES }\end{array}$ & $\begin{array}{c}\text { Sensitivity analysis of } \mathrm{sCO}_{2} \\
\text { cycle performance and } \\
\text { associated system cost } \\
\text { impact as a function of } \Delta \mathrm{T} \\
\text { across a 2-tank TES } \\
\text { system }\end{array}$ & $\mathrm{n} / \mathrm{a}$ & Peer-reviewed publication & $\begin{array}{l}\text { Yes, } \\
\text { pg. } 30\end{array}$ \\
\hline 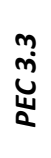 & $\begin{array}{l}\text { Open-source code release } \\
\text { of SolarPILOT to promote } \\
\text { greater customization of } \\
\text { heliostat/receiver modeling }\end{array}$ & $\begin{array}{l}\text { Update code and release } \\
\text { as open-source }\end{array}$ & $\mathrm{n} / \mathrm{a}$ & $\begin{array}{l}\text { Release of open-source } \\
\text { SolarPILOT and host } \\
\text { informational webinar }\end{array}$ & $\begin{array}{l}\text { Yes, } \\
\text { pg. } 44\end{array}$ \\
\hline 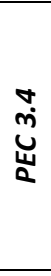 & $\begin{array}{l}\text { Analysis and optimization of } \\
\text { linear collector system } \\
\text { +thermal storage for } \\
\text { industrial steam production }\end{array}$ & $\begin{array}{l}\text { One or more scenarios } \\
\text { illustrating solar-thermal } \\
\text { levelized cost of heat } \\
\text { (LCOH) less than cost from } \\
\text { an industry standard fossil } \\
\text { alternative }\end{array}$ & $\mathrm{n} / \mathrm{a}$ & $\begin{array}{c}\text { Comparison to industry } \\
\text { standard (fossil boiler cost). } \\
\text { Define a market sector (based } \\
\text { on steam conditions, system } \\
\text { capacity and DNI) where solar } \\
\text { LCOH is less than natural gas } \\
\text { boiler }\end{array}$ & $\begin{array}{l}\text { Yes, } \\
\text { pg. } 73\end{array}$ \\
\hline$\overbrace{\tilde{m}}^{n}$ & $\begin{array}{c}\text { SolarPACES Task I status } \\
\text { updates }\end{array}$ & $\begin{array}{l}\text { Keep DOE appraised of } \\
\text { activities within the } \\
\text { international CSP } \\
\text { community. }\end{array}$ & n/a- & $\begin{array}{c}\text { Summary of Task publications } \\
\text { with relevance and benefit to } \\
\text { U.S. CSP interests }\end{array}$ & $\begin{array}{l}\text { Yes, } \\
\text { pg. } 74\end{array}$ \\
\hline
\end{tabular}

\section{Project Results and Discussion}

\section{Task 1. CSP Cost Tracking and Analysis}

This task feeds new cost information into the latest release of SAM. Work in year three focused on developing a better understanding of the capital expenditure (CAPEX) and key cost drivers for global CSP power tower and parabolic trough projects. 2017 and 2018 had reported bids for CSP projects significantly lower than in previous years (Shemer 2018b; Lilliestam et al. 2017), and levelized costs of electricity (LCOE), as low as $\$ 50 / \mathrm{MWh}$ in Chile were reported (Shemer 2018a).

Cost and project information were gathered from: (i) public sources of information (e.g., news sites related to CSP such as New Energy Update, CSP Focus and CSP Plaza), (ii) conference and journal articles, (iii) financing documents, e.g., from the World Bank (WB) and the Asian Development Bank (ADB), (iv) subscription access to the CSP Today Global Tracker which tracks projects globally, and $(v)$ discussions with developers such as SolarReserve, Solar Dynamics and SUPCON Solar. SUPCON Solar is an emerging Chinese CSP technology developer and engineering, procurement and construction (EPC) services provider. 
Table 2 summarizes power tower and parabolic trough plants where overall CAPEX has been determined. CSP and PV hybrid plants such as Cerro Dominador (SolarPACES 2018) have been excluded if costs are not distinguished by technology. Table 2 highlights eleven power tower and eight parabolic trough projects, which use a variety of technologies such as molten salt tower (MS Tower), oil-heat transfer fluid (HTF) or MS parabolic trough.

Table 2. Chinese and other CSP plant projects that are active as of Sept. 2018.

\begin{tabular}{|c|c|c|c|c|c|c|c|c|}
\hline$\#$ & Country & $\begin{array}{l}\text { Project } \\
\text { Name }\end{array}$ & $\begin{array}{l}\text { Capacity } \\
\text { (MW) }\end{array}$ & $\begin{array}{l}\text { Technology } \\
\text { Configuration }\end{array}$ & $\begin{array}{c}\text { Total } \\
\text { Investment } \\
\text { (\$M) }\end{array}$ & $\begin{array}{c}\text { Total } \\
\text { Investment } \\
\text { per kW } \\
(\$ / \mathrm{kW}) \\
\end{array}$ & $\begin{array}{c}\text { TES } \\
\text { Capacity } \\
\text { (h) }\end{array}$ & Source \\
\hline \multicolumn{9}{|c|}{ Power Tower } \\
\hline 1 & China & $\begin{array}{l}\text { Qinghai } \\
\text { Delingha }\end{array}$ & 50 & MS Tower & $\$ 163$ & $\$ 3,260$ & 6 & \multirow{6}{*}{$\begin{array}{l}\text { (Shemer 2018b; } \\
\text { Yang, Zhu, and } \\
\text { Guo 2018) }\end{array}$} \\
\hline 2 & China & $\begin{array}{l}\text { Shouhang } \\
\text { Dunhuang }\end{array}$ & 100 & MS Tower & $\$ 472$ & $\$ 4,720$ & 11 & \\
\hline 3 & China & $\begin{array}{l}\text { Qinghai } \\
\text { Gonghe }\end{array}$ & 50 & MS Tower & $\$ 190$ & $\$ 3,800$ & 6 & \\
\hline 4 & China & CPECC Hami & 50 & MS Tower & $\$ 245$ & $\$ 4,910$ & 8 & \\
\hline 5 & China & Gansu Jinta & 100 & MS Tower & $\$ 388$ & $\$ 3,880$ & 8 & \\
\hline 6 & China & $\begin{array}{c}\text { Yumen } \\
\text { Xinneng } \\
\end{array}$ & 50 & Beam down & $\$ 278$ & $\$ 5,560$ & 12 & \\
\hline 7 & China & Shangyi & 50 & MS Tower & $\$ 245$ & $\$ 4,890$ & 6 & $\begin{array}{c}\text { (CSP Focus } \\
\text { 2017c; Yang, Zhu, } \\
\text { and Guo 2018) }\end{array}$ \\
\hline 8 & Australia & Aurora & 150 & MS Tower & $\$ 650$ & $\$ 4,333$ & 8 & \multirow[b]{2}{*}{$\begin{array}{l}\text { (Shemer 2018b; } \\
\text { Lilliestam and } \\
\text { Pitz-Paal 2018) }\end{array}$} \\
\hline 9 & $\begin{array}{c}\text { United Arab } \\
\text { Emirates } \\
\text { (UAE) }\end{array}$ & $\begin{array}{l}\text { DEWA IV } \\
\text { (tower } \\
\text { portion) } \\
\end{array}$ & 100 & MS Tower & $\begin{array}{c}\$ 553 \\
\text { (tower } \\
\text { portion) } \\
\end{array}$ & $\begin{array}{r}\$ 5,500 \\
\text { (for } 700- \\
\text { MW site) } \\
\end{array}$ & 15 & \\
\hline 10 & Chile & Tamarugal & 450 & MS Tower & $\$ 2,700$ & $\$ 6,000$ & 13 & \multirow{2}{*}{ (Shemer 2018b) } \\
\hline 11 & Chile & Likana & 390 & MS Tower & $\$ 2,400$ & $\$ 6,154$ & 13 & \\
\hline \multicolumn{9}{|c|}{ Parabolic Trough } \\
\hline 1 & China & $\begin{array}{l}\text { Royal Tech } \\
\text { Yumen }\end{array}$ & 50 & Oil-Trough & $\$ 209$ & $\$ 4,180$ & 9 & \multirow{7}{*}{$\begin{array}{c}\text { (Shemer 2018b; } \\
\text { Yang, Zhu, and } \\
\text { Guo 2018; NREL } \\
\text { and SolarPaces } \\
\text { 2016) }\end{array}$} \\
\hline 2 & China & $\begin{array}{l}\text { Rayspower } \\
\text { Yumen }\end{array}$ & 50 & Oil-Trough & Undisclosed & Unknown & 9 & \\
\hline 3 & China & Urat & 100 & Oil-Trough & $\$ 435$ & $\$ 4,350$ & 10 & \\
\hline 4 & China & $\begin{array}{c}\text { CGN } \\
\text { Delingha }\end{array}$ & 50 & Oil-Trough & $\$ 301$ & $\$ 6,020$ & 9 & \\
\hline 5 & China & $\begin{array}{l}\text { Gansu } \\
\text { Gulang } \\
\end{array}$ & 100 & Oil-Trough & Undisclosed & Unknown & 7 & \\
\hline 6 & China & $\begin{array}{l}\text { Gansu } \\
\text { Akesai }\end{array}$ & 50 & MS Trough & $\$ 309$ & $\$ 6,170$ & 15 & \\
\hline 7 & China & Zhangjiakou & 64 & MS Trough & $\$ 280$ & $\$ 4,370$ & 16 & \\
\hline 8 & UAE & $\begin{array}{l}\text { DEWA IV } \\
\text { (Parabolic } \\
\text { trough } \\
\text { portion) } \\
\end{array}$ & 600 & Oil-Trough & $\begin{array}{l}\$ 3,317 \\
\text { (parabolic } \\
\text { trough } \\
\text { portion) }\end{array}$ & $\begin{array}{l}\$ 5,500 \\
\text { (for } 700- \\
\text { MW site) }\end{array}$ & 11 & $\begin{array}{c}\text { (Shemer 2018b; } \\
\text { Lilliestam and } \\
\text { Pitz-Paal 2018) }\end{array}$ \\
\hline
\end{tabular}


Table 2 includes the seven power tower and seven parabolic trough Chinese plants that are currently expected to finish as part of the Chinese Phase 1 demonstration projects. As previously highlighted, at least four of the original 20 projects have been stopped (HelioCSP 2018; Wang et al. 2017). The calculated CAPEX (in \$M) of the active Chinese projects has used an exchange rate of 6.4364 Chinese Yuan (RMB) to \$1 USD as of June 15, 2018 (XE.com 2018a).

As seen in Table 2, the power tower investment range is approximately $\$ 3,300 / \mathrm{kW}$ to $\$ 6,200 / \mathrm{kW}$, even including the first commercial beam-down project (Yumen Xinneng). These projects include 6 to 15 hours of thermal storage, which will influence the cost per $\mathrm{kW}$. It is reported that the Shangyi 50-MW power tower project has been switched from direct steam generation (DSG) tower to MS tower with 6 hours of storage (CSP Focus 2017c). Most power towers in construction or progressed development are less than $\$ 5,500 / \mathrm{kW}$. Contrast this with the U.S. Crescent Dunes MS power tower plant, which came online in 2015 at $\$ 8,960 / \mathrm{kW}$ (NREL 2017a). The Chinese CAPEX range is slightly lower than the UAE and Chilean sites, although that can be at least partially attributed to lesser storage hours at the Chinese plants.

The parabolic trough investment range highlighted in Table 2 is $\$ 4,200$ to $\$ 6,200 / \mathrm{kW}$, even including two ongoing MS parabolic trough plants. The overall CAPEX bids for the Rayspower Yumen (50 MW oil-trough), and the Gansu Gulang (100 MW oil-trough) are undisclosed, but with the go-ahead to finish construction, it can be expected the investment is of the same order. Table 2 illustrates technology diversity within the Chinese program, not only MS power towers and oil-HTF troughs, but also a beam-down tower, and two MS parabolic troughs in the first set of demonstration projects. Aalborg, a key supplier of CSP MS steam generators, has been awarded the contract to supply two trains of MS steam generator for the Gansu Akesai 50-MW MS trough project in China (Aalborg CSP 2017).

This tracking work shows that overall CAPEX and power purchase agreements (PPAs) for CSP plants outside the U.S. has sharply decreased. There are several factors for this including the strong development of new markets like China and UAE, and very large capacity plants being built. Important factors in the CAPEX and PPA reduction include:

- Long financing and PPA durations. The PPA at the DEWA $700 \mathrm{MW}$ site extends to 35 years (Government of Dubai 2018). Had the period been 20 years like in other plants, the PPA price could have been $\$ 0.106 / \mathrm{kWh}$ instead of $\$ 0.073 / \mathrm{kWh}$ i.e., more than a $2 \phi$ difference (Lilliestam and Pitz-Paal 2018). Another related important factor at DEWA, is the large amounts of storage capacity at each of the four plants, that then allows for very high energy generation and capacity factors. For example each of the parabolic trough plants have 11 hours of storage and could have for over 5,000 full load hours per year (Pitz-Paal 2017). Other important factors at DEWA include very low financing costs (e.g., interest rate) and very good financing conditions. For example, when the overall CAPEX ( $\$ 3.9$ billion), the 35-year PPA life, and the $80 \%$ debt financing are considered (PR Newswire 2018a), it can be estimated that the Weighted Average Cost of Capital (WACC) is potentially only $4.8 \%$ with an internal rate of return (IRR) of $2.8 \%$ (Pitz-Paal 2017). This level of beneficial financing conditions supports the low reported PPA price.

- Alternative revenue streams outside of the PPA, i.e., the plant can sell electricity at different times to supplement the PPA. For Aurora, as part of the business model, the 
plant can sell electricity at market prices during the evening peak times when electricity prices are significantly higher (Lilliestam and Pitz-Paal 2018).

- Cost-effective local suppliers. Low CAPEX costs are possible, for example though local heliostat manufacturing, automation and sourcing, rather than exclusively using low-cost labor countries. In Australia, which has labor costs similar in magnitude to the United States, SolarReserve has signed an agreement for the manufacture of at least 13,000 heliostats needed for the Aurora project (CSP Plaza 2018b). This manufacturing capacity may then also be leveraged for other plants.

\section{SAM 2018 Updates for Power Towers and Parabolic Troughs}

Table 3 and Table 4 show the SAM 2017 and the updated 2018 cost values. The key areas that are discussed further for each technology are: Solar fields (both heliostats and parabolic troughs); Power Cycle and Balance of Plant (BOP); and the Thermal Energy Storage (TES). O\&M and other cost inputs are not updated in the SAM 2018 update.

Table 3. Update of SAM 2017 to 2018 values of key parameters for the Molten Salt Power Tower ( $\mathrm{n} / \mathrm{c}=$ no change).

\begin{tabular}{|c|c|c|c|c|}
\hline $\begin{array}{l}\text { Power Tower } \\
\text { (Molten Salt and DSG) }\end{array}$ & units & $\begin{array}{l}\text { SAM } \\
2017 \\
\end{array}$ & $\begin{array}{l}\text { SAM } \\
2018 \\
\end{array}$ & Comments \\
\hline Site Improvements & $\$ / m^{2}$ & 16 & $\mathrm{n} / \mathrm{c}$ & \\
\hline Heliostat Field & $\$ / m^{2}$ & 145 & 140 & $\begin{array}{l}\text { Few data on real plants. } \$ / \mathrm{m}^{2} \\
\text { estimate created for China and then } \\
\text { labor shifted to the U.S. }\end{array}$ \\
\hline Tower cost formula & & & $\mathrm{n} / \mathrm{c}$ & \\
\hline Receiver cost formula & & & $\mathrm{n} / \mathrm{c}$ & \\
\hline Thermal Energy Storage (TES) & $\$ / k W h-t$ & 24 & 22 & $\begin{array}{l}\text { Calculations based on recent } \\
\text { developer tank-cost estimates and } \\
\text { SQM salt quote }\end{array}$ \\
\hline Power cycle & $\$ / k W e$ & 1,100 & 1,040 & $\begin{array}{l}\text { Adjusted learning rate for overall CSP } \\
\text { plants and CEPCI }\end{array}$ \\
\hline Balance of plant (BOP) & $\$ / k W e$ & 340 & 290 & $\begin{array}{l}\text { Adjusted learning rate for overall CSP } \\
\text { plants and CEPCl }\end{array}$ \\
\hline Contingency & $\%$ & 7 & $\mathrm{n} / \mathrm{c}$ & \\
\hline EPC \& Owners Cost & $\%$ & 13 & $\mathrm{n} / \mathrm{c}$ & \\
\hline Sales Tax & $\%$ & 5 & $\mathrm{n} / \mathrm{c}$ & Applied to $80 \%$ of total direct costs \\
\hline O\&M Fixed cost by capacity (MS) & $\$ / k W-y$ & 66 & $\mathrm{n} / \mathrm{c}$ & \\
\hline O\&M Fixed cost by capacity (DSG) & $\$ / k W-y$ & 55 & $\mathrm{n} / \mathrm{c}$ & \\
\hline Variable cost O\&M (both) & $\$ / M W h$ & 3.5 & $\mathrm{n} / \mathrm{c}$ & \\
\hline Property Tax & $\%$ & 0.0 & $\mathrm{n} / \mathrm{c}$ & \\
\hline Insurance & $\%$ & 0.5 & $\mathrm{n} / \mathrm{c}$ & \\
\hline
\end{tabular}


Table 4. Update of SAM 2017 to 2018 values of key parameters for the for the Physical and Empirical Parabolic Trough models ( $\mathrm{n} / \mathrm{c}=$ no change).

\begin{tabular}{|l|c|c|c|l|}
\hline $\begin{array}{l}\text { Trough } \\
\text { (Physical and Empirical) }\end{array}$ & Units & $\begin{array}{c}\text { SAM } \\
\mathbf{2 0 1 7}\end{array}$ & $\begin{array}{c}\text { SAM } \\
\mathbf{2 0 1 8}\end{array}$ & Comments \\
\hline Site Improvements & $\$ / \mathrm{m}^{2}$ & 25 & $\mathrm{n} / \mathrm{c}$ & \\
\hline Solar Field & $\$ / \mathrm{m}^{2}$ & 150 & $\mathrm{n} / \mathrm{c}$ & \\
\hline HTF System & $\$ / \mathrm{m}^{2}$ & 60 & $\mathrm{n} / \mathrm{c}$ & \\
\hline Thermal Energy Storage (TES) & $\$ / \mathrm{kWh}-\mathrm{t}$ & 65 & 62 & $\begin{array}{l}\text { Calculations based on recent } \\
\text { developer tank-cost estimates and } \\
\text { SQM salt quote }\end{array}$ \\
\hline Power Plant & $\$ / \mathrm{kWe}$ & 930 & 910 & $\begin{array}{l}\text { Adjusted learning rate for overall } \\
\text { CSP plants and CEPCl }\end{array}$ \\
\hline Balance of Plant (BOP) & $\$ / \mathrm{kWe}$ & 120 & 90 & $\begin{array}{l}\text { Adjusted learning rate for overall } \\
\text { CSP plants and CEPCl }\end{array}$ \\
\hline Contingency & $\%$ & 7 & $\mathrm{n} / \mathrm{c}$ & \\
\hline EPC \& Owners Cost & $\%$ & 11 & $\mathrm{n} / \mathrm{c}$ & \\
\hline Sales Tax & $\%$ & 5 & $\mathrm{n} / \mathrm{c}$ & Applied to 80\% of total direct costs \\
\hline O\&M Fixed cost by capacity & $\$ / \mathrm{kW}-\mathrm{y}$ & 66 & $\mathrm{n} / \mathrm{c}$ & \\
\hline O\&M Variable cost by generation & $\$ / \mathrm{MWh}$ & 4 & $\mathrm{n} / \mathrm{c}$ & \\
\hline Property Tax & $\%$ & 0 & $\mathrm{n} / \mathrm{c}$ & \\
\hline Insurance & $\%$ & 0.5 & $\mathrm{n} / \mathrm{c}$ & \\
\hline
\end{tabular}

\section{Solar Field Costs}

A review of relevant published papers, project bids and discussions on the solar field costs (e.g., $\$ / \mathrm{m}^{2}$ ) has been completed for available heliostats and the parabolic troughs. Part of the challenge when dealing with reported system costs or bids is discerning details on subsystem costs, for example, the $\$ / \mathrm{m}^{2}$ for the solar field. Normally only a small amount of detail is available, e.g., an overall solar field bid, rather than a detailed breakdown.

\section{Heliostat Solar Field Installed Costs}

Task 1 compiled estimated, bid, installed and aspirational heliostat costs. Figure 1 shows the spread of estimated solar field costs for available data. The variation results from a combination of different heliostat designs and estimating teams. The R\&D based heliostat installed costs (shown as cross-hatched column) are mainly found in scientific journals (e.g., new low-cost heliostat designs) and have not been built or realized. As such, they are excluded from the SAM 2018 heliostat cost update. The SAM 2017 value for the installed cost of heliostats is $\$ 145 / \mathrm{m}^{2}$. 


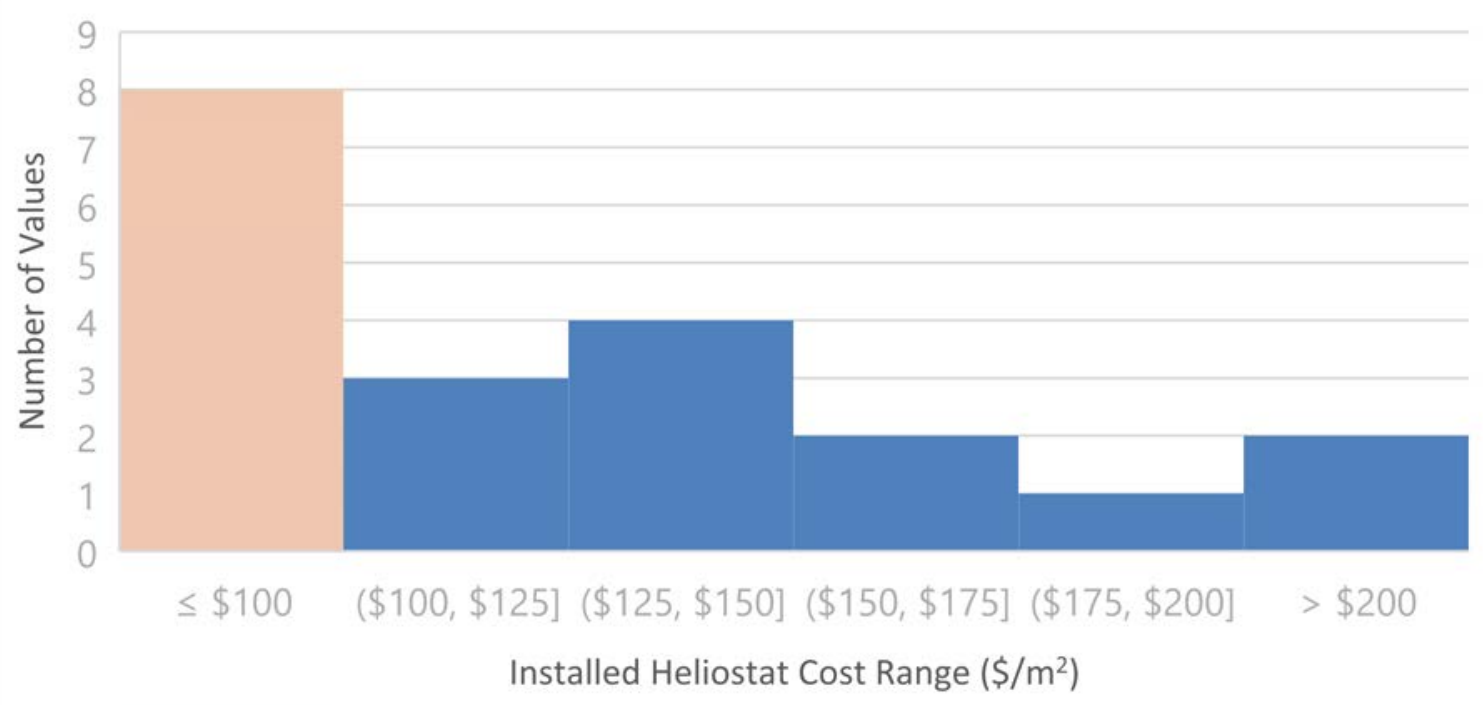

Figure 1. Estimated heliostat installed solar field cost spread (in $\left.\$ / \mathrm{m}^{2}\right)$. Cross-hatched bar shows R\&D-based values.

The recently published Australian Solar Thermal Research Initiative (ASTRI) 2016 report, highlighted that "The actual cost of heliostats is presently estimated to be in the range 150-200 USD/m" (Coventry et al. 2016). The evidence in Figure 1 also shows that most expected or installed heliostats are less than $\$ 200 / \mathrm{m}^{2}$. Our review has found anecdotal evidence that heliostat costs have decreased; however, until more data on constructed solar fields are found, the SAM estimates-which are conceptually based on current year bid prices-will remain conservative.

As seen in Figure 1, the current sample size (of estimated or reported) installed solar fields for the power tower is 20 , of which 8 are considered R\&D-based projections at $\$ 75$ $100 / \mathrm{m}^{2}$. There is one further R\&D data point ascertained with confidential discussions with a solar developer who expects to build a solar field using their new design at $\$ 125 / \mathrm{m}^{2}$ in the U.S.

The lowest reported solar field bid was from SUPCON Solar, where an installed heliostat field was bid at approximately $\$ 180 \mathrm{M}$ or $\$ 105 / \mathrm{m}^{2}$ (HelioCSP 2017; CSP Focus 2017b). This was for the Luneng Haixi 50-MW molten salt power tower plant in China.

The Shouhang Dunhuang project in China (100-MW molten salt project) heliostat field is estimated at $\$ 224 / \mathrm{m}^{2}$, for a solar field of approximately $1,380,000 \mathrm{~m}^{2}$ (CSP Focus 2018a). It must be noted that the Shouhang Dunhuang plant includes the receiver as part of the solar field in its reported subsystem CAPEX (CSP Focus 2018a), though the estimated value of $\left(\$ 224 / \mathrm{m}^{2}\right)$ has attempted to exclude the receiver from the $\$ / \mathrm{m}^{2}$ cost.

For this cost update, an important plant to highlight is the CPECC Hami 50-MW molten salt power tower which is expected to use the low-cost heliostat developed by the Stellio Consortium, known as the Stellio (HelioCSP 2017; CSP Focus 2017b; SBP 2016). The estimated bid cost of an installed Stellio heliostat field in China is $\$ 124 / \mathrm{m}^{2}$. The Stellio heliostat has been reported as the solar field for the CPECC Hami site and the Redstone 100-MW plant in South Africa (ACWA Power 2017; Shemer 2017). As such, Stellio represents a suitable 
surrogate for a state-of-the-art heliostat design and the SAM update uses the Stellio as a reference for the cost estimate.

Using the detailed SAM molten salt power tower cost models (Turchi and Heath 2013), we estimate the labor portion of the solar field at $11 \%$ of the total installed solar field cost. Thus, the CPECC Hami installed cost of $\$ 124 / \mathrm{m}^{2}$ can be broken into: $\sim \$ 14 / \mathrm{m}^{2}$ for labor and $\sim \$ 110 / \mathrm{m}^{2}$ for non-labor (i.e., materials). To shift the Chinese plant to the United States., one must account for the difference between U.S. and Chinese labor cost and productivity. It is assumed that the same amount of tools and construction equipment are used.

In 2017 in China, construction workers earn approximately 18 Chinese Yuan (CNY) per hour, or approximately 38,400 CNY/year (Economic Research Institute 2018). In dollars that would be $\$ 2.70 / \mathrm{h}$ or $\$ 5,775 / \mathrm{yr}$ as of $29^{\text {th }}$ September 2017 (X-Rates 2018a). As a comparison, the hourly and yearly average construction labor wage for 'Electric Power Generation' in the U.S. as of 2017 was $\$ 24.55 / \mathrm{h}$ and $\$ 51,060 / \mathrm{yr}$ (BLS 2017). This is approximately 9.1 times more in the U.S. than in China for construction labor. If cheaper U.S. construction labor is used, e.g. approximately $\$ 15 / \mathrm{h}$ (PayScale 2018), the hourly rate for U.S. construction labor is approximately 5.8 times more than Chinese construction labor.

China as of 2017 , had an estimated labor productivity of $\$ 14 / \mathrm{h}$ (Statista 2018a). If this is used as comparable for the construction industry, a China-to-USA productivity measure can be derived. Effectively it can be expected that for every 1.75 hours worked in China, $1 \mathrm{~h}$ can be attributed to the U.S. labor (i.e., $\$ 24.55$ of value in USA $\div \$ 14$ value in China $=1.75$ ). Taking the estimated Stellio labor requirement of $\$ 14 / \mathrm{m}^{2}$ in China, this can be shifted to the U.S. as $\left(\$ 14 / \mathrm{m}^{2}\right)^{\star}(5.8$ to 9.1$) / 1.75=46$ to $73 \$ / \mathrm{m}^{2}$. When the materials cost of $\$ 110 / \mathrm{m}^{2}$ is added, the estimated installed Stellio field cost is $\$ 156 / \mathrm{m}^{2}$ to $\$ 183 / \mathrm{m}^{2}$ for the USA. The non-labor portion of the Stellio heliostat cost estimate is left unchanged, assuming globally sourced components and no tariffs.

If a similar installed cost estimate is undertaken using the installed heliostat costs for the Luneng Haixi plant (i.e., $\$ 105 / \mathrm{m}^{2}$ ), a lower U.S. estimate can be determined. Through similar calculation, it can be determined that the U.S. equivalent to install the Luneng Haixi heliostat field could be $\sim \$ 133 / \mathrm{m}^{2}$ (i.e., $\left[\$ 12 / \mathrm{m}^{2} * 5.8\right] / 1.75+\$ 93 / \mathrm{m}^{2}$ for non-labor costs). As such there is some evidence to suggest a $\$ 140 / \mathrm{m}^{2}$ installed cost heliostat in the U.S. (assuming the lower US-labor rate of $\$ 15 / \mathrm{h}$ ) can be used for SAM 2018. For the SAM 2018 update, a heliostat cost of $\$ 140 / \mathrm{m}^{2}$ is recommended based on reported Chinese-project costs and near-term R\&D projections.

\section{Parabolic Trough Solar Field Installed Costs}

The installed solar field costs for the parabolic trough, as of SAM 2017 was $\$ 150 / \mathrm{m}^{2}$. Figure 2 shows the spread of estimated parabolic trough installed costs to date, including the number of aspirational R\&D-based values (cross-hatched column) indicating potential of installing the solar field at less than $\$ 100 / \mathrm{m}^{2}$. 


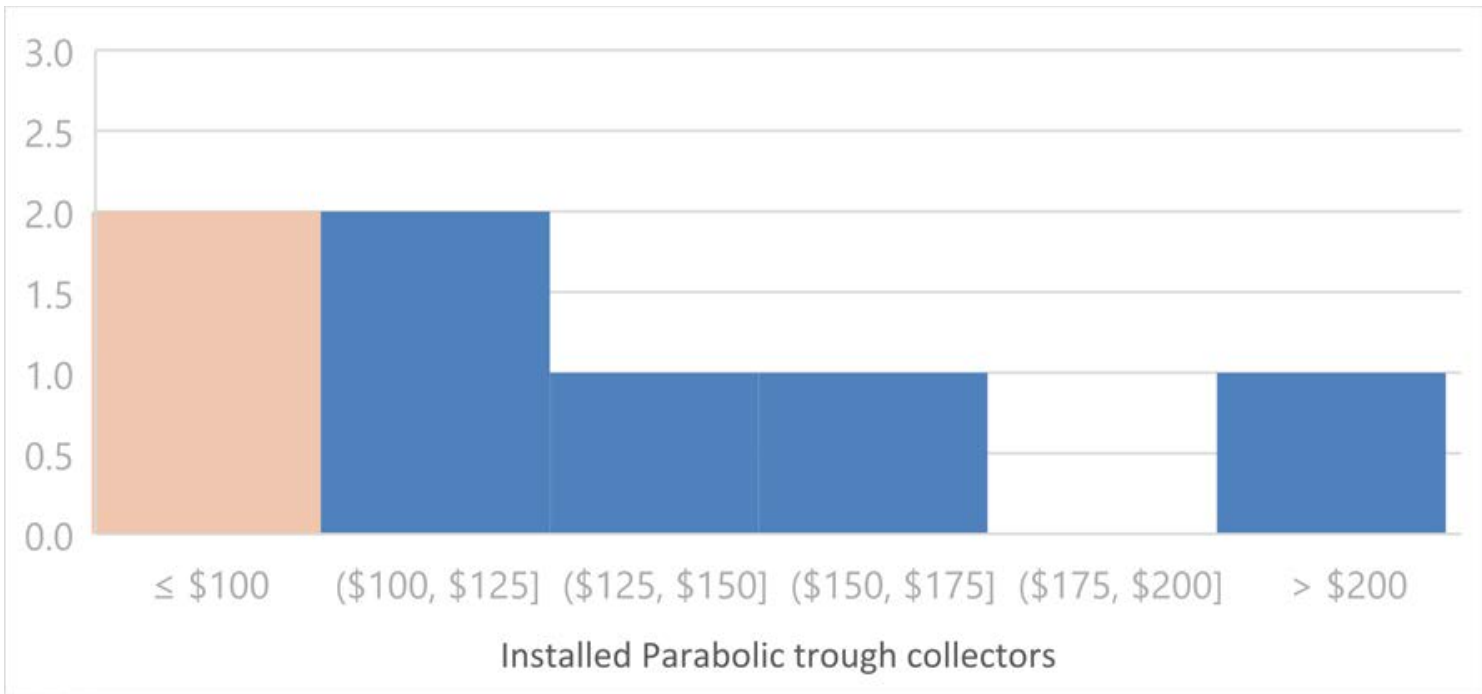

Figure 2. Estimated parabolic trough installed solar field cost spread (in $\$ / \mathrm{m}^{2}$ ). Values reported as R\&D-based are shown crosshatched.

The CGN Delingha 50-MW, oil-trough plant, which was the first grid-connected CSP plant in China in June 2018 and is expected to be fully operational by the end of September 2018 (CSP Focus 2018b). ADB proposed loan documents have allowed the solar field installed cost to be estimated at $\$ 231 / \mathrm{m}^{2}$ in $\$ 2018$ (ADB 2013), as such it is classified as $>\$ 200 / \mathrm{m}^{2}$. Even though the CGN Delingha solar field has an estimated installed cost of $\$ 231 / \mathrm{m}^{2}$, which is higher than the current SAM 2017 value of $\$ 150 / \mathrm{m}^{2}$, the use of the EuroTrough (the most deployed parabolic trough in the market) is a significant step forward for the Chinese CSP market. Future deployments of such an established trough technology may lead to reduced installed solar field costs.

The most significant parabolic trough estimate is for the installed cost of the 600-MW DEWA solar fields, which is estimated to be $\$ 105 / \mathrm{m}^{2}$. As mentioned, NREL has estimated the installed cost of the DEWA solar fields based on available project information, SAM parabolic trough breakdowns, and discussions with trough developer Solar Dynamics (who have experience with Abengoa collectors). The estimated installed cost was found to be $\$ 105 / \mathrm{m}^{2}$ (Pizá de Silva 2018; Abengoa S.A. 2018; The Corner 2018; Solar Dynamics 2018; Turchi 2010). The 600-MW is made up of three separate 200-MW solar fields, and have sufficient solar field to supply the energy needed to store $11 \mathrm{~h}$ of thermal energy at each of the 200-MW sites (New Energy Update 2018). For the SAM 2018 parabolic trough solar field update, an NREL estimate is provided to effectively create an analogous parabolic trough site (e.g. 600-MW) in the U.S., by labor shifting the DEWA site from the UAE to the U.S. It is assumed that each of the three solar fields can all be considered as a single installed project.

Using the detailed SAM parabolic trough cost models (C. Turchi 2010), the labor portion of the solar field is estimated at $22 \%$ of the total installed solar field cost. Effectively the $\$ 105 / \mathrm{m}^{2}$ can be broken into: $\sim \$ 23 / \mathrm{m}^{2}$ for labor and $\sim \$ 82 / \mathrm{m}^{2}$ for non-labor (i.e., materials). To shift the UAE plant to the U.S., one must account for the difference between U.S. and UAE labor cost and productivity. It is assumed that the same level of tools and construction equipment are used. 
In Dubai, day laborers in construction can earn approximately 1,500 Emirati Dirhams (AED) per month (Dubai FAQs 2018; Guide 2 Dubai 2017), or approximately $\$ 408$. Construction supervision is more like 20,600 AED/mo (Guide 2 Dubai 2017; XE.com 2018b). As a comparison, the construction labor wage for 'Electric Power Generation' in the U.S. as of 2017 was approximately 10.4 times more than in UAE for construction labor (BLS 2017). If cheaper U.S. construction labor is used e.g. at approximately $\$ 15 / \mathrm{h}$ (PayScale 2018 ), it can be estimated the monthly labor wage could be approximately $\$ 2,800 / \mathrm{mo}$, or approximately 7 times more than UAE construction labor.

India, Pakistan and other Asian countries tend to supply low-cost manual labor in the UAE (Guide 2 Dubai 2017). Pakistan as of 2017, had an estimated labor productivity of $\$ 9 / \mathrm{h}$ (Statista 2018b). If this is used as a comparable for the construction industry, a UAE-toUSA productivity measure can be derived as $\$ 15 / h($ US $) / \$ 9 / h$ (Pakistan) $=1.67$. Taking the estimated labor requirement of $\$ 23 / \mathrm{m}^{2}$ in UAE, this can be shifted to the U.S. as $\left(\$ 23 / \mathrm{m}^{2}\right)^{\star}(7) / 1.67=\$ 96 / \mathrm{m}^{2}$. When the materials cost of $\$ 82 / \mathrm{m}^{2}$ is added, the estimated installed trough field cost is $\$ 178 / \mathrm{m}^{2}$ for the USA. The non-labor portion of the cost estimate is left unchanged, assuming globally sourced components and no tariffs.

In contrast to the above, confidential discussions with another U.S. developer suggest their large aperture trough has an estimated installed solar cost of $\$ 115 / \mathrm{m}^{2}$ in the U.S., suggesting that continued cost reduction in trough technology.

For the SAM 2018 update, it is recommended that the current value of $\$ 150 / \mathrm{m}^{2}$ remain until further data and evidence is gathered e.g. realized projects in China and UAE, international parabolic trough reviews from organizations such as NREL and DLR are undertaken, or project bids with good data are investigated.

\section{Power Block and Balance of Plant Costs}

As highlighted in prior quarterly reports, steam-turbine package bids for some of the Chinese plants are lower than the U.S. market. For example, out of the four main steam turbine bidders for the Supcon Delingha 50-MW MS power tower plant it was found that the winner, Hangzhou Turbine Co., won the steam turbine bid at an estimated $\$ 177 / \mathrm{kWe}$ (CSP Focus 2017a; CNSTE 2017). Assuming this represents the steam turbine/genset, we can estimate the cost for the full power block system using SAM's cost model. The SAM power block assumes inclusion of 17 components, of which the turbine/genset represents the largest single cost item, but only about $20 \%$ of the overall power block cost. Hangzhou Turbine Co, will provide the steam turbine, generator, auxiliary engine, regenerative system and the installation (CSP Focus 2017a; CNSTE 2017). Assuming a similar ratio of component costs, the total power block may be on the order of $\$ 177 / \mathrm{kW} \div 0.20=$ $\$ 885 / \mathrm{kWe}$. This is approximately $11 \%$ less than the current U.S. estimate for the power tower power cycle cost.

Other institutions such as the European Solar Thermal Electricity Association (ESTELA) and the German Aerospace Center (DLR) have released studies that highlight the power cycle and power block costs are potentially decreasing (Kistner 2016; ESTELA 2016; IRENA 2016). For example in an ESTELA market update, the highlighted Power Block cost in 2016 was $720-765 € /$ kWe (ESTELA 2016). This equates to approximately $\$ 809$ $\$ 860 / \mathrm{kWe}$ in $\$ 2016$ (X-Rates 2018b). Then using the CEPCI 'Equipment Index' from 2016 to 2018 (i.e. an $11.5 \%$ increase), the power block could be approximately $\$ 956 / \mathrm{kWe}$ at 
the upper end, again lower than the SAM 2018 estimates. It is not clear that the Power Block includes everything that is included in SAM. While innovation itself has not been significant for CSP turbines using steam, the increasing demand and need to increase production is likely to help decrease costs as the global installed capacity increases, and players such as the Chinese turbine manufacturers enter the market.

In 2012, when the last detailed CSP cost study was undertaken by NREL, SAM's power block values were $\$ 1,200 / \mathrm{kWe}$ (dry-cooled tower) and $\$ 1,050 / \mathrm{kWe}$ (dry-cooled trough). (Turchi 2010; Turchi \& Heath 2013). The current SAM 2017 estimate for the Power Cycle is $\$ 1,100 / \mathrm{kWe}$ and $\$ 930 / \mathrm{kWe}$ for the power tower and the parabolic trough respectively (both dry cooled). These values represent survey-based updates from the initial detailedcost studies undertaken in 2012 (tower) and 2010 (trough). For this update, NREL returns to the original 2012 values and applies CSP learning rates and process-industry cost indexes to update the values to 2017. The Chemical Engineering Plant Cost Index (CEPCI) 'Equipment Index' is used. The change in the CEPCI Equipment Index from 2012 to 2017 was $684.4 / 712.5=0.961$. That is, the index decreased during this period by $3.9 \%$.

In the last 4 to 5 years, there has been significant growth in the global installed CSP capacity. From 2012 to 2017 , the estimated reduction in CSP installed cost due to learning was approximately $20 \%$, albeit with large uncertainty (Lilliestam et al. 2017). Effectively, for the doubling of overall capacity during that period, there has been on average a $20 \%$ decrease in overall costs. The learning rate for CSP includes factors such as economies of scale, high cost pressure, industry development and beneficial policies (Lilliestam et al. 2017). The power block for CSP has not undergone significant technical change during this period but can be assumed to have benefited from greater industry maturity and project efficiency. Instead of applying the $20 \%$ learning associated with overall CSP plants - much of which is likely related to the solar components-we apply a lesser $10 \%$ learning rate to the power cycle. If the power tower and parabolic trough dry-cooled power cycle costs are decreased by $10 \%$ from their original values in 2012, the respective 2017 costs are $\$ 1,080 / \mathrm{kWe}$ and $\$ 945 / \mathrm{kWe}$ respectively. Further applying the $\mathrm{CEPCl}$ index change of a $3.9 \%$ decrease, yields the new Power Cycle estimates for 2017 of $\$ 1,040 / \mathrm{kWe}$ and $\$ 910 / \mathrm{kWe}$ for the power tower and the parabolic trough respectively. These values are consistent with those reported by ESTELA above.

The balance of plant (BOP) cost has also been updated from the 2017 value, using the $10 \%$ learning rate decrease and $\mathrm{CEPCI}$ cost index. In SAM, the BOP is made up of the steam generation system, as such the 'Heat Exchanger and Tanks' index is used. This index also decreased from 2012 to $2017: 599.9 / 661.7=0.907$, i.e., an approximate $10 \%$ reduction. The recommended SAM 2018 Power Block and BOP values are shown in Table 5. 
Table 5. Power Cycle and BOP costs for SAM 2018 (2017\$). By SAM convention, BOP costs represent the steam generation system. The benchmark values are from NREL's detailed cost study in 2012.

\begin{tabular}{|c|c|c|c|c|c|c|}
\hline Technology & $\begin{array}{c}\text { Power } \\
\text { Cycle Cost } \\
\text { in } 2012 \\
(\$ / \mathrm{kWe}) \\
\end{array}$ & $\begin{array}{c}\text { Power Cycle Cost } \\
\text { with } 10 \% \\
\text { decrease due to } \\
\text { learning (\$/kWe) }\end{array}$ & $\begin{array}{c}\text { Power Cycle } \\
\text { Cost indexed } \\
\text { to } 2017 \\
(\$ / \mathrm{kWe}) \\
\end{array}$ & $\begin{array}{c}\text { BOP Cost } \\
\text { in } 2012 \\
\text { (\$/kWe) }\end{array}$ & $\begin{array}{l}\text { BOP Cost with } \\
10 \% \text { decrease } \\
\text { due to learning } \\
(\$ / \mathrm{kWe})\end{array}$ & $\begin{array}{c}\text { BOP Cost } \\
\text { indexed to } \\
2017 \\
(\$ / \mathrm{kWe})\end{array}$ \\
\hline $\begin{array}{l}\text { Power } \\
\text { Tower }\end{array}$ & $\$ 1,200$ & $\$ 1,080$ & $\$ 1,040$ & $\$ 355$ & $\$ 320$ & $\$ 290$ \\
\hline $\begin{array}{c}\text { Parabolic } \\
\text { Trough }\end{array}$ & $\$ 1050$ & $\$ 945$ & $\$ 910$ & $\$ 110$ & $\$ 100$ & $\$ 90$ \\
\hline
\end{tabular}

Thermal Energy Storage (TES) tanks and costs

A cost estimate has been received from SQM, one of the key suppliers of solar salt in the CSP industry. The estimated cost for solar salt shipped to the U.S. (San Diego, CA) is $\$ 700-800 / \mathrm{MT}$. This is less than the current $\$ 1,000 / \mathrm{MT}$ assumed for solar salt. Abengoa suggests a salt melting cost of $\$ 50$ per ton (Kelly 2010). As such, 750 (mid value) +50 (melting) $=\$ 800 / \mathrm{MT}$ is used for installed salt.

The TES tank cost update relies on confidential information from SolarReserve. The similarity of construction for the cold and hot parabolic trough TES tanks $\left(290^{\circ} \mathrm{C}\right.$ and $390^{\circ} \mathrm{C}$ ) and the cold tank of the power tower system $\left(290^{\circ} \mathrm{C}\right)$, allow a similar cost to be used for these three carbon-steel tanks. The hot tank for the power tower $\left(565^{\circ} \mathrm{C}\right)$ requires stainless-steel construction with correspondingly higher cost. Information shared by SolarReserve provides new insight into the estimated costs for these tanks. Additional costs for controls, pumps, insulation and piping and heat exchangers (troughs only) are taken from the prior cost models (NREL 2017b).

The current SAM 2017 cost for the indirect, 2-tank parabolic trough TES is $\$ 65 / \mathrm{kWh}_{\mathrm{th}}$, while the value for direct, 2-tank system in power towers is $\$ 24 / \mathrm{kWh}$ th. As seen in Table 6 , the estimated cost for the TES is calculated at $\$ 62 / \mathrm{kWh}_{\mathrm{th}}$ for troughs $(\sim 4 \%$ drop relative to SAM 2017) and $\$ 22 / \mathrm{kWh}_{\text {th }}$ for power towers (10\% drop).

Table 6. Molten Salt Power Tower and Parabolic Trough 2018 SAM TES cost update

\begin{tabular}{|c|c|c|}
\hline Power Tower Plant & Value & Unit \\
\hline Hot Tank - Stainless Steel & $11,900^{*}$ & $\mathrm{~m}^{3}$ \\
\hline Cold Tank - Carbon Steel & $10,800^{*}$ & $\mathrm{~m}^{3}$ \\
\hline Salt inventory (includes heel) & 27,400 & $\mathrm{MT}$ \\
\hline Piping, Insulation, Valves, \& Fittings & & - \\
\hline Foundations \& Support Structures & & - \\
\hline Instrumentation \& Controls & & - \\
\hline Thermal energy for system & 2,350 & $\mathrm{MWh}_{\text {th }}$ \\
\hline Cost subtotal & & \\
\hline TES cost per unit thermal energy & $\mathbf{2 2}$ & $\mathbf{\$} / \mathbf{k W h}_{\text {th }}$ \\
\hline Parabolic Trough Plant & Value & $\mathbf{U n n i t}$ \\
\hline Hot Tank - Carbon steel & $11,90 *^{*}$ & $\mathrm{~m}^{3}$ \\
\hline
\end{tabular}




\begin{tabular}{|l|c|c|}
\hline Cold Tank - Carbon Steel & $10,800^{*}$ & $\mathrm{~m}^{3}$ \\
\hline Salt inventory (includes heel) & 27,400 & $\mathrm{MT}$ \\
\hline Pumps \& Heat Exchangers & & - \\
\hline Piping, Insulation, Valves, \& Fittings & & - \\
\hline Foundations \& Support Structures & & - \\
\hline Instrumentation \& Controls & & - \\
\hline Thermal energy for system & 943 & $\mathrm{MWh}_{\text {th }}$ \\
\hline Cost subtotal & & \\
\hline TES cost per unit thermal energy & $\mathbf{6 2}$ & $\mathbf{\$} / \mathbf{k W h}_{\text {th }}$ \\
\hline
\end{tabular}

${ }^{*}$ Active volume (a 14\% heel exists in each tank)

Compared to other reports, these TES costs are relatively conservative. For example, ESTELA estimates the parabolic trough TES cost to be $26-30 € / \mathrm{kWh}$ th (ESTELA 2016) or about 29-34 $\$ / \mathrm{kWh}_{\text {th. }}$. The NREL TES cost estimate is about $80 \%$ higher than the ESTELA estimate. DLR estimates the 2-tank indirect TES for parabolic trough using the synthetic oil-HTF as $40 € / \mathrm{kWh}_{\text {th }}$ (Pitz-Paal 2017) in September 2017. This converts to about $\$ 50 / \mathrm{kWh}$ th; the NREL estimate is about $25 \%$ higher.

In a 2016 review of CSP technology, ESTELA estimated the cost for TES in molten salt power tower systems at $13-15 € / \mathrm{kWh}$ th (ESTELA 2016). When this range is converted to $2018 \$$, the range is estimated at $17-19 \$ / \mathrm{kWh}_{\text {th }}$. The NREL value of $\$ 22 / \mathrm{kWh}_{\text {th }}$ is about $20 \%$ higher than the ESTELA range.

\section{Updated CSP Costs within SAM}

The values outlined above were included in the release of SAM 2018 on November 11, 2018. For comparison, the default cases for the MSPT and Physical Trough models are shown for SAM 2017 and SAM 2018 in Table 7. The only changes made in the default cases was setting the federal investment tax credit to zero and the selecting a uniform time of delivery schedule, i.e., each kWh of generation is valued equally. It should be noted that the default federal tax rate dropped from $35 \%$ to $21 \%$ and SAM's assumed discount rate increased from $5.5 \%$ to $6.4 \%$ between 2017 and 2018 , which also affect LCOE. These values are set by NREL's SAM financial team and not the CSP group.

Table 7. Updated performance and cost estimates for two CSP models within SAM 2018.11.11.

\begin{tabular}{|l|c|c|}
\hline Model and Parameter & SAM 2017.09.05 & SAM 2018.11.11 \\
\hline MSPT Model (115 MW gross, 10 hours TES, Solar multiple $=2.4)$ \\
\hline Annual generation (MWh) & 569,103 & 577,916 \\
\hline Total installed cost $(\$ / \mathrm{kW})$ & 6,804 & 6,507 \\
\hline LCOE, real\$, no incentives (c/kWh) & 11.2 & 11.1 \\
\hline \multicolumn{2}{|c|}{ Physical Trough Model (111 MW gross, 6 hours TES, Solar multiple = 2.0) } \\
\hline Annual generation (MWh) & 354,221 & 362,298 \\
\hline Total installed cost $(\$ / \mathrm{kW})$ & 6,066 & 5,628 \\
\hline LCOE, real\$, no incentives (c/kWh) & 15.6 & 14.9 \\
\hline
\end{tabular}

${ }^{*}$ overnight costs, i.e., does not include construction financing

\section{Potential Trough TES Improvements}

German company Wacker and DLR are working towards the use of synthetic silicone oilHTF for parabolic trough solar fields. Silicon oil increases the solar field outlet temperature 
from $393^{\circ} \mathrm{C}$ (i.e. using today's most common synthetic oil-HTF), to $425^{\circ} \mathrm{C}$, decreases the hydrogen accumulation in the HTF, and has been tested at DLR since 2016 (Pitz-Paal 2017). Analysis from DLR has found that the use of silicone oil instead of today's most used synthetic oil-HTF (Therminol VP-1 or Dowtherm A), for the same sized plant, could reduce the LCOE by $5 \%$ (Jung et al. 2015).

The use of silicone oil-HTF and the increased solar field temperature allows for increased power block efficiency and decreased size and cost for the indirect 2-tank TES system. For example with the increased solar field temperature, the gross power block efficiency using air-cooled condensers (ACCs), could increase from 37.7\% to 39.2\% (Pitz-Paal 2017). Similarly due to the increased $\Delta T$ between the hot and cold tanks for the TES, DLR have highlighted that the TES cost in 2017 could be $33 € / \mathrm{kWh}$ th or $\$ 41 / \mathrm{kWh}_{\text {th }}$ in $\$ 2018$ (ChemEng Online 2018).

A partnership between Wacker and the Chinese Royal Sun Technology is expected to develop a first commercial CSP demonstration using silicone oil in China. Silicone oil has been tested in a demonstration loop operating at $425^{\circ} \mathrm{C}$ since 2016 (Dou, Stary, and Schaffer 2017). Wacker have developed a certified and tested silicone oil called Heliosol $5 \mathrm{~A}$, which will be used at the 50-MW Royal Sun Technology parabolic trough plant (Schaffer 2016; Dou, Stary, and Schaffer 2017), which has a reported overall CAPEX of $\$ 4,180 / \mathrm{kWe}$ (Shemer 2018b). Currently there is no expectation for silicone oil-HTF parabolic trough plants in the U.S.

\section{Task 2. Supercritical $\mathrm{CO}_{2}\left(\mathrm{sCO}_{2}\right)$ Power Cycle Modeling}

Preprocessor boosts computation speed for $\mathrm{sCO}_{2}$ Power Cycle Modeling

In project year one, the primary objective for Task 2 was to develop a methodology to allow the recompression $\mathrm{sCO}_{2}$ power cycle to run within $\mathrm{SAM}$ with a simulation speed compatible with other SAM models, e.g., within a few minutes. The approach developed a "preprocessor" to develop a performance map for off-design situations that could be called instead of the slower first principles model during annual simulation runs. This preprocessor was developed to work with SAM's existing user-defined power cycle (UDPC) and later moved to a separate $\mathrm{sCO}_{2}$ Power Cycle option on SAM's Power Cycle page, thereby allowing detailed $\mathrm{SCO}_{2}$ cycle models to be integrated efficiently into an annual SAM simulation with SAM's molten-salt power tower.

In year one NREL reported success with the preprocessor concept, but implementation of the $\mathrm{sCO}_{2}$ recompression model led to poor integration between the power cycle and the other CSP components. That is, simulation speed improvements were accomplished, but the underlying $\mathrm{SCO}_{2}$ cycle behavior was found to challenge SAM's existing CSP solver routine in ways that did not occur with the steam-Rankine model. This led to a restructuring of the year two objectives to resolve the issue. Although the $\mathrm{sCO}_{2}$ model struggled to accurately represent a $\mathrm{sCO}_{2} / \mathrm{CSP}$ plant, the speed advantage of the preprocessor methodology was successfully demonstrated in year one as summarized in Table 8.

Compressor inlet pressure is a control variable that we can adjust (via $\mathrm{CO}_{2}$ inventory control) to optimize cycle performance. The off-design control algorithm first tries to achieve the design-point power output scaled by the normalized off-design HTF mass 
flow rate. If there are multiple points that achieve this power output target, then the algorithm chooses the point with the best thermal efficiency. The model discards solutions where the selected compressor inlet pressure results in a (i) main compressor outlet pressure greater than the maximum in any compressor, (ii) surge in any compressor, or a (iii) tip speed greater than the speed of sound through the $\mathrm{CO}_{2}$ in the turbomachinery.

Table 8 shows a comparison of the $1^{\text {st }}$ Principles and preprocessed-UDPC models. The $\mathrm{sCO}_{2}$ recompression model implemented in the UDPC option is roughly two orders of magnitude faster than the first principles model while achieving a root mean square (RMS) difference in the hourly data less than the 5\%-error target and a very small $(0.26 \%)$ cumulative energy difference for the annual data. These results show that the new framework is capable of quickly and accurately characterizing complex, power cycle models for an annual simulation.

Table 8: Comparison between the $1^{\text {st }}$ principles and preprocessed UDPC models for an annual simulation with the $\mathrm{SCO}_{2}$ recompression model.

\begin{tabular}{|l|c|c|}
\hline Parameter & Result & Target \\
\hline 1st principles model & Approx. 3 hours & - \\
\hline User Defined Power Cycle (UDPC) & 1.7 min & order of minutes \\
\hline UDPC vs. $1^{\text {st }}$ Principles runtime & $<1 \%$ & $<25 \%$ \\
\hline Hourly results RMS difference & $3.46 \%$ & $<5 \%$ \\
\hline Annual Total Energy difference & $-0.26 \%$ & $<5 \%$ \\
\hline
\end{tabular}

The $\mathrm{SCO}_{2}$ recompression model user interface updated within SAM

During year two NREL completed the SAM user interface section for this $\mathrm{sCO}_{2}$ cycle, and the $\mathrm{sCO}_{2}$ option is available on the Power Cycle page of the MSPT model. The first time a user selects this option in a case, a notice window appears that describes important differences between the $\mathrm{sCO}_{2}$-Brayton cycle and the default steam- Rankine cycle. The notice informs the reader that the cold HTF temperature is not an independent variable in the $\mathrm{sCO}_{2}$ model, and that the simulation will use the calculated value for this parameter. The notice box also instructs the user to review the number of panels in their receiver design, as the default value of 20 can lead to excessive pressure drops due to the smaller temperature difference across the receiver and corresponding larger HTF flowrates. Finally, the notice describes that the model will enforce partload constraints on mass flow. The $\mathrm{SCO}_{2}$ model is part of the open source SAM code that is available for download.

Figure 3 shows an example of the $\mathrm{sCO}_{2}$ user interface. When the user first selects this option, there is no saved cycle design or off-design data, and the middle and right columns will be empty. If the user runs the SAM simulation without any changes, the annual simulation will begin by designing the cycle and preprocessing the off-design performance before beginning the time-series simulation. These steps can take a few minutes, so buttons in the user interface allow one to calculate both the design and off-design performance or just calculate the design point. If the user selects the off-design option, then the user will have the option to run the annual simulation with the calculated offdesign performance. This gives the user the opportunity to review the design point before simulating the case, as well as the option to run parametrics on system values that do not affect the cycle design. If the user changes an input value that affects the cycle design, 
the stored calculations are invalid, and the option to run the simulation with the calculated performance disappears. In this scenario, the user must either change the input back to the value used for the cycle calculations or rerun the macro to develop new off-design performance parameters.

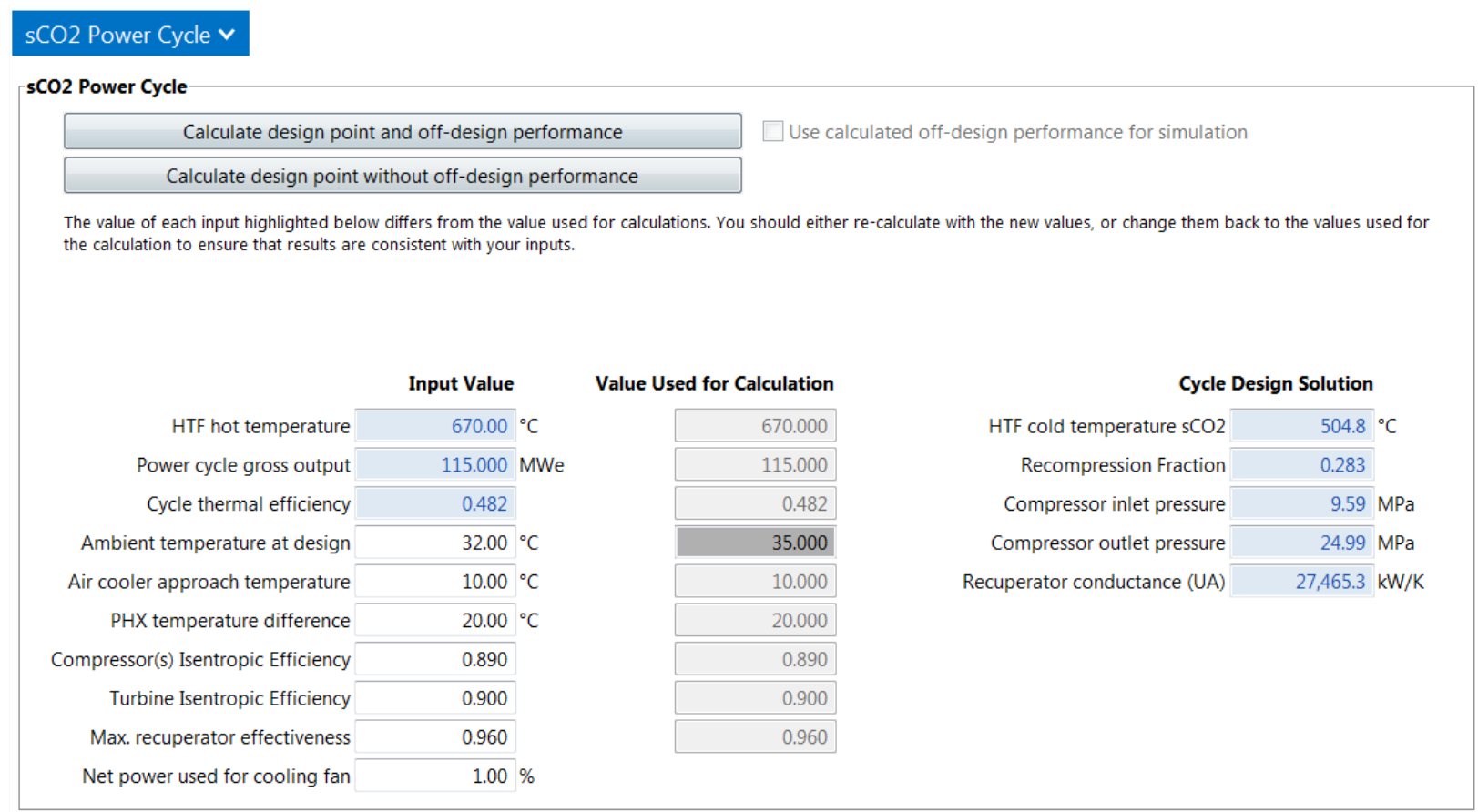

Figure 3: An example of the $\mathrm{sCO}_{2}$ user interface. Here, the top macro has already been run at a cycle design ambient temperature of $35^{\circ} \mathrm{C}$. The screen shows what happens when the Ambient temperature at design is changed to $32^{\circ} \mathrm{C}$. The grey-out cells indicate the user must either change the ambient temperature back to $35^{\circ} \mathrm{C}$ or rerun the macro.

Figure 4 and Figure 5 below show a snapshot of the system performance for a cold and hot day, respectively. The top plot in each snapshot shows the temperature and HTF mass flowrates for each component, while the bottom plot shows power cycle output and efficiency. Note that on the cold day, the $\mathrm{SCO}_{2}$ cycle can always operate at the critical point, so the cycle power output and efficiency are constant until the HTF mass flow reaches part-load. The top plot shows that mass is always conserved:

Rec._mass_flowrate $=P C \_H T F \_$mass_flowrate + TES_charge_mass_flowrate $-T E S \_$discharge_mass_flowrate

and that the HTF mass flowrate to the cycle stays within design constraints. On the hot day (Figure 5) the cycle becomes capacity limited, and the results show both power output and efficiency decreasing as the temperature increases. Note that the HTF mass flowrate to the power cycle is always decreasing as temperature increases. Mass is conserved and the HTF mass flowrate stays within design constraints on the hot day. 

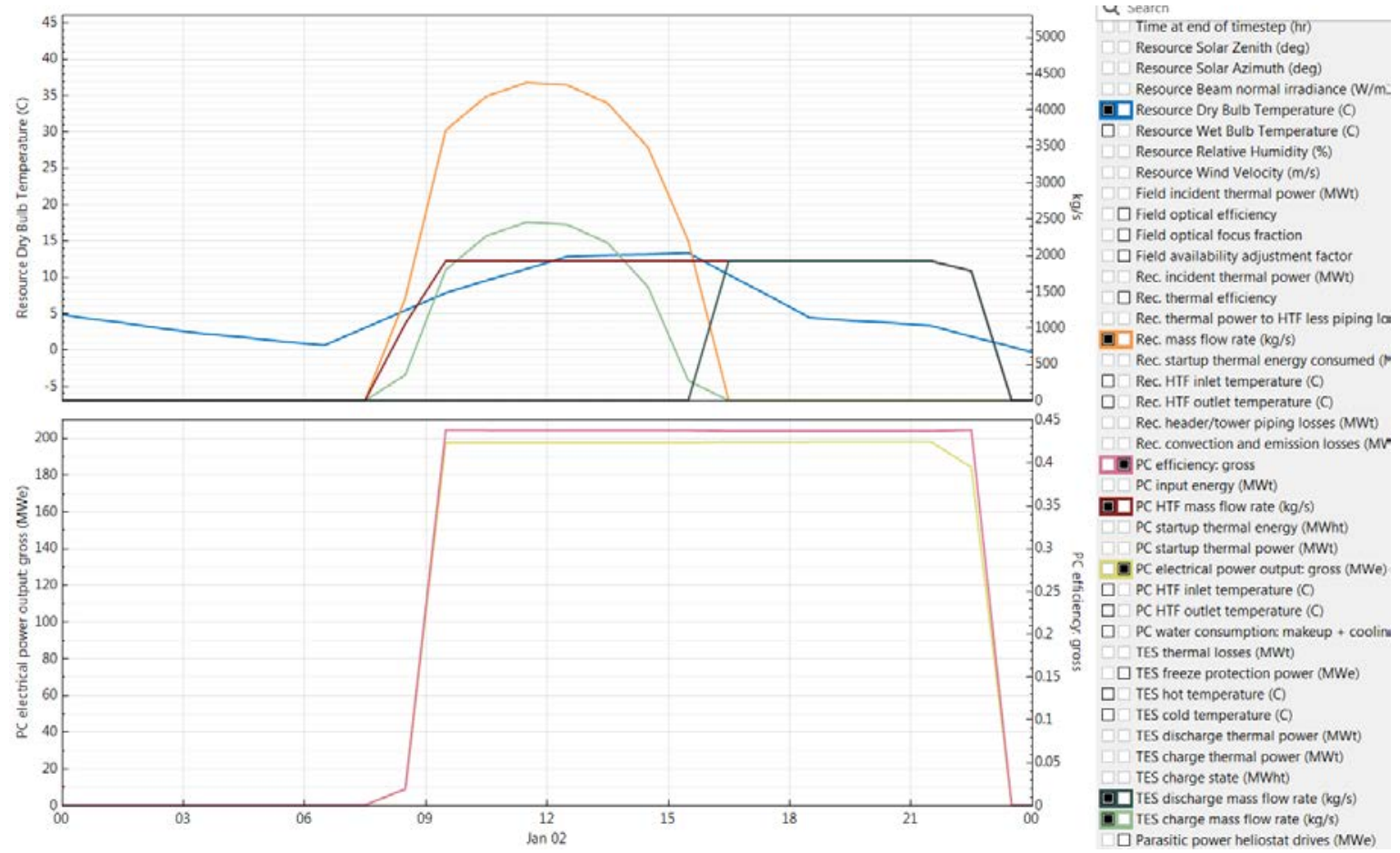

Figure 4: MSPT-sCO ${ }_{2}$ cold day behavior

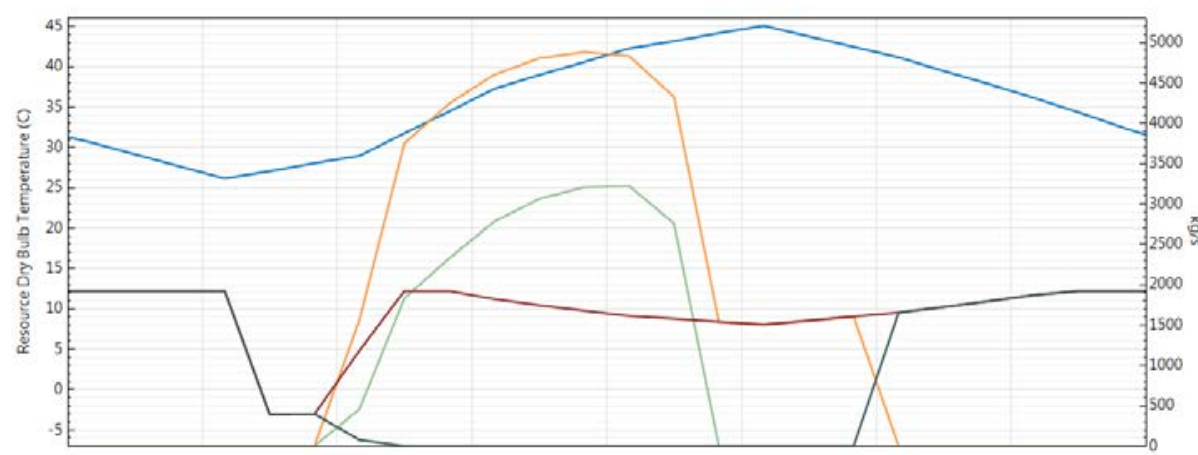

Y searth

Time at end of timestep (hi) Resource Solar Zenith (deg) Resource Solar Azimuth (deg) Resource Beam normal irradiance $(\mathrm{W} / \mathrm{m} 2$ $\square$ Resource Dry Bulb Temperature $(C)$ $\square \quad$ Resource Wet Bulb Temperature (C) Resource Relative Humidity (\%) Resource Wind Velocity $(\mathrm{m} / \mathrm{s})$ Field incident thermal power (MWt) $\square$ field optical efficiency

$\square$ Field optical focus fraction

$\square$ Field availability adjustment factor

Rec, incident thermal power (MW

$\square$ Rec, thermal efficiency

Rec, thermal power to HTF less piping los Rec. mass flow rate $(\mathrm{kg} / \mathrm{s})$ Rec, startup thermal energy consumed ( $M$. Rec. HTF inlet temperature (C)

Rec. HIF outlet temperature (C) Rec header/tower piping losses (MWt) Rec convection and emission losses (MWW - $P$ PC efficiency: gross PC input energy (MW0) PC HTF mass flow rate $(\mathrm{kg} / \mathrm{s})$ PC startup thermal energy (MWht) PC startup thermal power (MWV)

- PC electrical power output: gross (MWe)

- $P C$ HIF iniet temperature (C)

ㅁ. PC HTF outlet temperature (C)

- PC water consumption: makeup + coolinc TES thermal losses (MWt)

$\square$ TES freeze protection power (MWe)

$\square \quad$ TES hot temperature (C)

$\square$ TES cold temperature $(O)$

(1) TES discharge thermal power (MW:)

TES charge thermal power (MWt) TES charge state (MWht) TIES discharge mass flow rate $(\mathrm{kg} / \mathrm{s})$ TES charge mass flow rate $(\mathrm{kg} / \mathrm{s})$

$\square$ Parasitic power heliostat drives (MWe)

Figure 5: MSPT-s $\mathrm{CO}_{2}$ hot day behavior

Table 9 shows the results of these test cases. For each case, we analyzed the hourly model outputs and compared them to the design point values. As the three columns on the right show, the maximum normalized HTF mass flowrate (max m_dot) and maximum 
normalized cycle power output (max W_dot) are very close to their design points. The normalized cycle efficiency (max efficiency) can be slightly greater than design as the system experiences ambient temperature colder than the design point throughout the year. The calculated capacity factors and PPA prices appear realistic of expectations.

Dispatch optimization shows a small improvement in PPA price, although a reduction in capacity factor. This interesting result can be improved by modifying the dispatch model to better predict the $\mathrm{sCO}_{2}$ part load response, and we are currently working on this.

Table 9: SAM MSPT/sCO $\mathrm{CO}_{2}$ model test cases. Maximum ("max") values are shown normalized to their design point values

\begin{tabular}{|c|c|c|c|c|c|c|c|c|}
\hline $\begin{array}{c}\text { TIT } \\
\left({ }^{\circ} \mathbf{C}\right)\end{array}$ & $\begin{array}{c}\text { Capacity } \\
\text { (MWe) }\end{array}$ & $\begin{array}{c}\text { Efficiency } \\
\text { at 35C (\%) }\end{array}$ & $\begin{array}{c}\text { Dispatch } \\
\text { opt? }\end{array}$ & $\begin{array}{c}\text { Capacity } \\
\text { Factor (\%) }\end{array}$ & $\begin{array}{c}\text { PPA } \\
\mathbf{C} / \mathbf{k W h}\end{array}$ & $\begin{array}{c}\text { max } \\
\mathbf{m} \text { _dot }\end{array}$ & $\begin{array}{c}\text { max } \\
\mathbf{W} \text { dot }\end{array}$ & $\begin{array}{c}\text { max } \\
\text { efficiency }\end{array}$ \\
\hline 554 & 200 & 42 & no & 58.4 & 10.29 & 0.995 & 0.99 & 1.05 \\
\hline 554 & 200 & 42 & yes & 57.8 & 10.25 & 0.996 & 0.99 & 1.04 \\
\hline 600 & 200 & 46 & no & 57 & 9.94 & 0.996 & 0.993 & 1.03 \\
\hline 650 & 200 & 48.25 & no & 56.6 & 9.72 & 0.996 & 0.993 & 1.03 \\
\hline 700 & 200 & 50.5 & no & 56.1 & 9.54 & 0.996 & 0.993 & 1.02 \\
\hline 750 & 200 & 51.5 & no & 55.5 & 9.51 & 0.996 & 0.993 & 1.02 \\
\hline 554 & 115 & 42 & no & 59 & 10.26 & 0.995 & 0.99 & 1.05 \\
\hline 650 & 115 & 48.25 & no & 57.3 & 9.66 & 0.996 & 0.993 & 1.03 \\
\hline 750 & 115 & 51.5 & no & 55.6 & 9.54 & 0.996 & 0.993 & 1.02 \\
\hline 554 & 10 & 42 & no & 55.7 & 13.09 & 0.996 & 0.99 & 1.04 \\
\hline 750 & 10 & 51.5 & no & 47.1 & 13.53 & 0.996 & 0.993 & 1.02 \\
\hline 750 & 10 & $48.8 *$ & No & 47.8 & 13.78 & 0.996 & 0.993 & 1.02 \\
\hline
\end{tabular}

* This case was generated with the same total recuperator conductance as the $51.5 \%$ case the row above it, but the isentropic efficiencies of the turbomachinery were adjusted to more capacityrealistic values of $80 \%$ for the compressors and $88.5 \%$ for the turbine [Turchi 2014].

\section{Development of the Partial-cooling $\mathrm{SCO}_{2}$ Cycle within SAM}

In year three NREL developed the design and off-design performance models for the partial-cooling $\mathrm{sCO}_{2}$ cycle (Figure 6). Initial assumptions are made about how the cycle is configured and operated. The model assumes that the inventory of $\mathrm{CO}_{2}$ in the system is regulated such that the low pressure (i.e., the pre-compressor (inlet) in the system is an independent off-design control variable. "Inventory control" has been suggested for cycle control by multiple developers and researcher teams. The model also assumes that the main compressor $(C)$ and pre-compressor (P-C) coolers adjust their fan speeds to reach the main and pre-compressor inlet temperatures, respectively. Finally, the model assumes that the shaft speed of each turbomachinery component is fixed at its design speed (i.e. an "integrally geared" configuration). These assumptions mirror those in the recompression off-design model. 


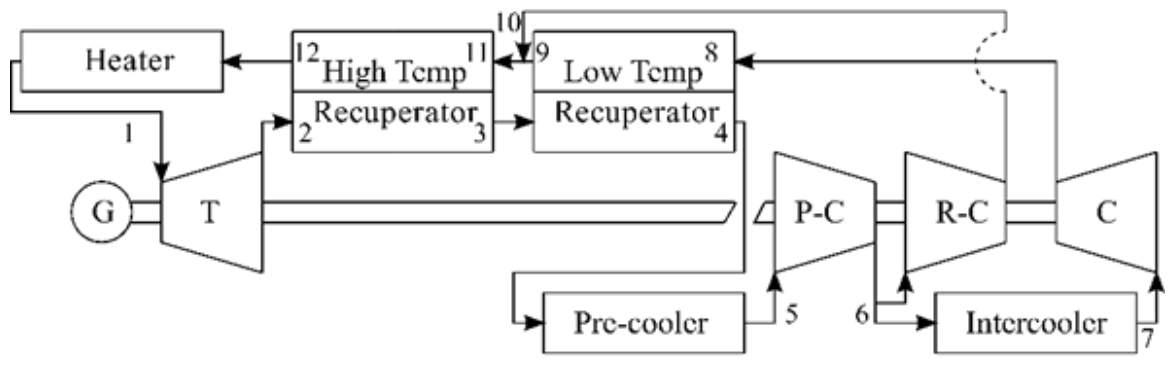

Figure 6. Equipment schematic of the partial-cooling cycle.

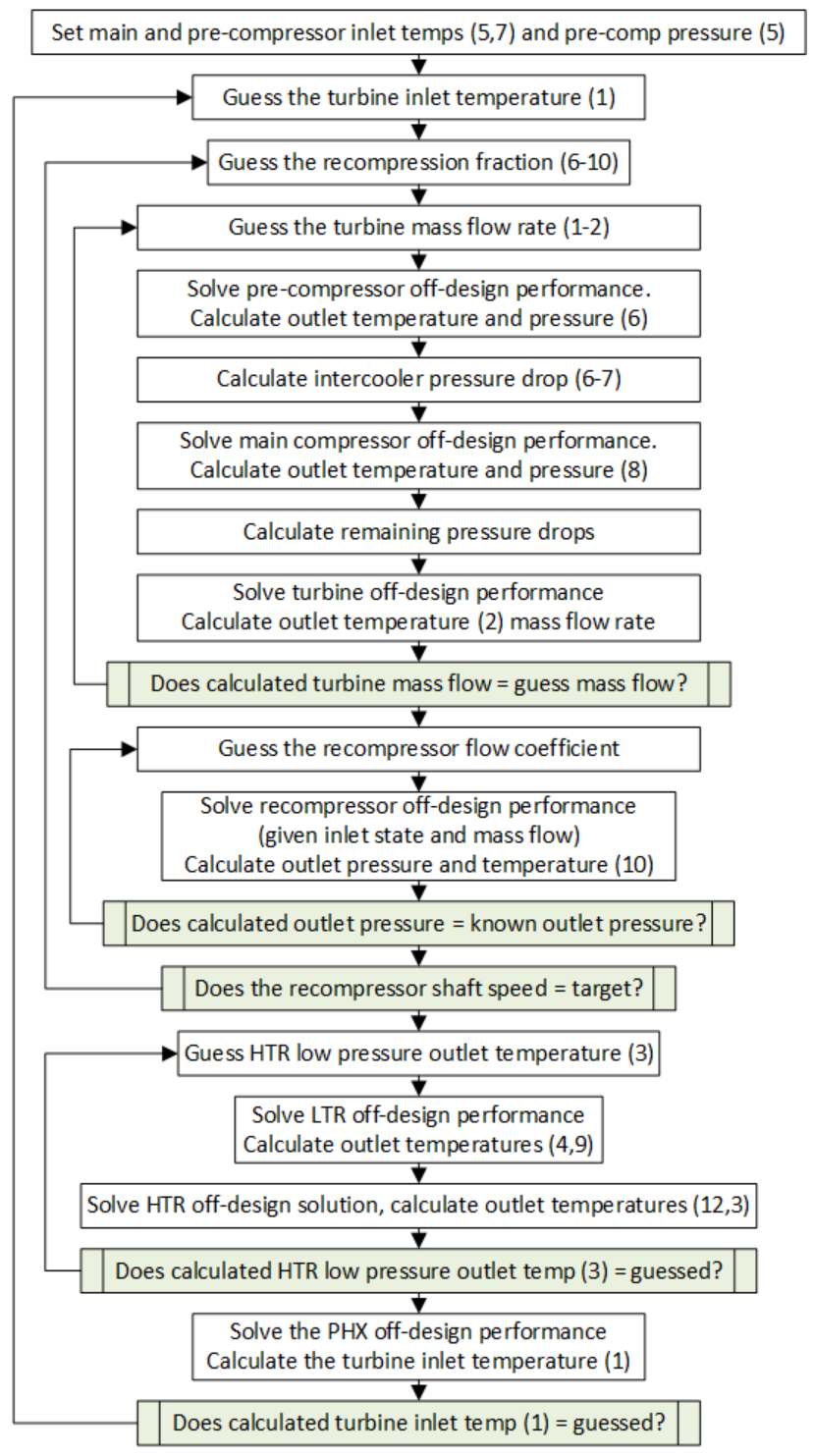

Figure 7: Logic diagram of the off-design partial-cooling cycle model. Numbers in parentheses refer to Figure 6.

Figure 7 shows the logic-flow diagram for the off-design model, which assumes that the pre-compressor inlet pressure and temperature and main compressor inlet temperature 
are known. The model first guesses the turbine inlet temperature. Then it guesses the recompression fraction and turbine mass flow rate. With this information the model calculates the pre-compressor, main compressor, and turbine performance. If, given pressures provided by the compressor, the turbine calculates a different turbine mass flow rate than the guess, the model continues to iterate. After the turbine mass flow rate converges, the model solves for the re-compressor shaft speed required to achieve the mass flow rate and pressures that are constrained by the other turbomachinery components. If that shaft speed is not equal to the design shaft speed, then the model repeats the recompression fraction iteration (and the nested turbine mass flow rate iteration). Interestingly, although the partial-cooling cycle adds a compressor relative to the recompression cycle, its iteration is less complex because it can converge the turbomachinery performance without solving recuperator performance.

Next, the off-design model guesses the high-temperature recuperator (HTR) lowpressure outlet temperature. Then, the model can solve the low-temperature recuperator (LTR) performance that achieves its off-design conductance. With the LTR outputs, the model can solve the HTR performance that achieves its off-design conductance. If the calculated HTR low-pressure outlet temperature is not equal to the guess value, the recuperator iteration repeats. Finally, after the recuperator performance is solved, the model solves the primary heat exchanger performance that achieves its off-design conductance and calculates the turbine inlet temperature. If the calculated turbine inlet temperature is not equal to the value guessed at the beginning of the entire off-design iteration, then the entire iteration sequence repeats. The off-design model uses inventory control-the same algorithm as the recompression cycle-to find the pre-compressor inlet pressure that achieves the target power output.

Figure 8 illustrates the behavior of system parameters as a function of pre-compressor inlet pressure. Areas shaded red denote regions the control algorithm flags as infeasible. For example, when pre-compressor inlet pressure exceeds its design value, the cycle power is greater than design and the main compressor outlet pressure is greater than design. As the pre-compressor inlet pressure decreases, the power output and efficiency decrease until both the main and pre-compressors approach surge. Similarly, low precompressor inlet pressures are shaded red when surge occurs. 

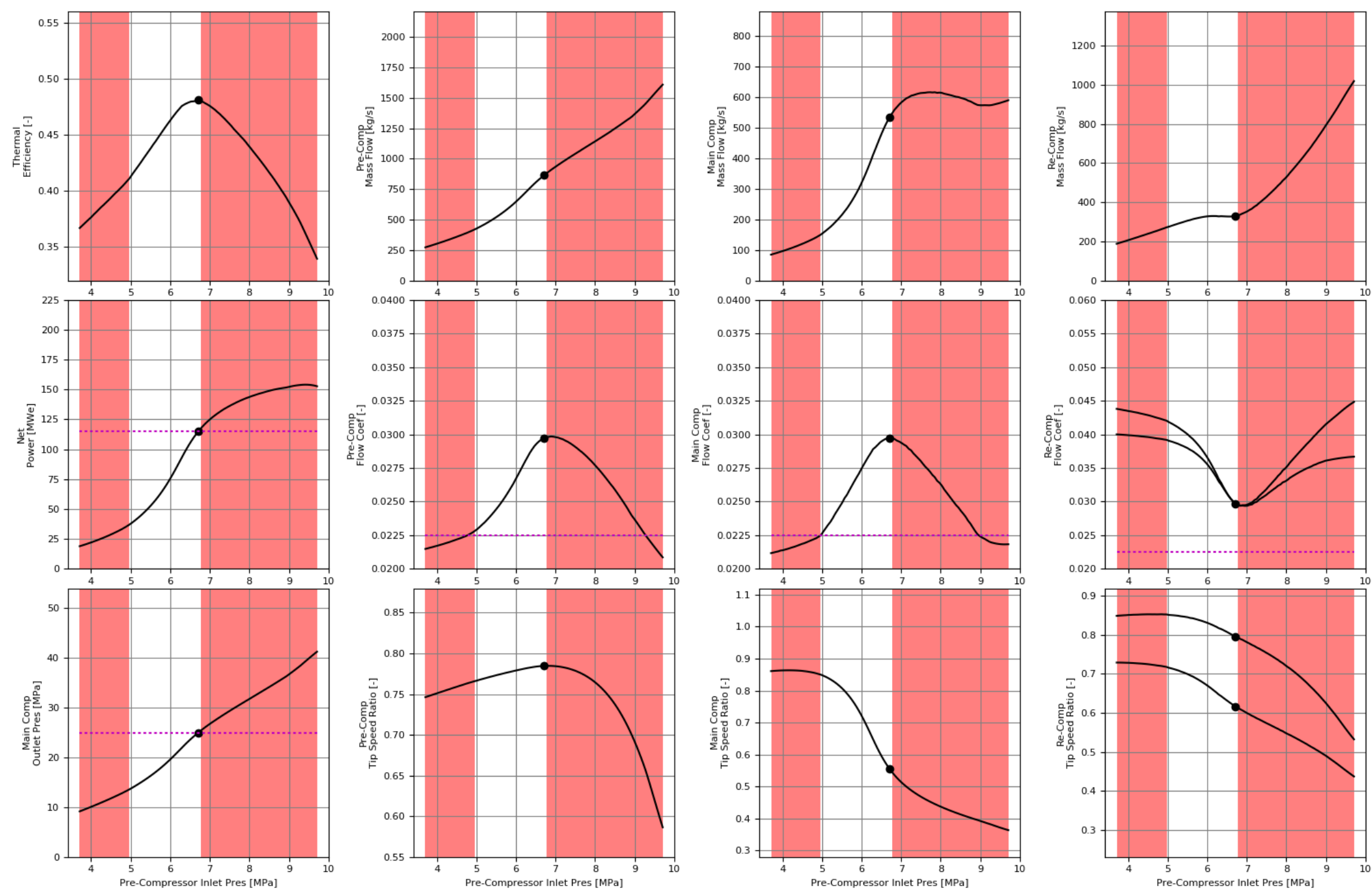

Figure 8. Pre-compressor inlet pressure sweep at the design ambient temperature $\left(35^{\circ} \mathrm{C}\right)$. Dots represent the design-point condition; dotted lines show constraints; shaded zones are prohibited by the simulation model. 
Figure 9 shows the optimized off-design performance of the partial-cooling cycle for varying off-design ambient temperatures. At the design ambient temperature $\left(T_{a m b}=\right.$ $35^{\circ} \mathrm{C}$ ) the off-design model achieves the design point efficiency and power-as required. At warmer ambient temperatures, the power output decreases because the fluid is less dense at the design pressure and the compressors cannot move enough mass flow rate without exceeding cycle maximum pressure limits. At temperatures between $35^{\circ} \mathrm{C}$ (design) and $30^{\circ} \mathrm{C}$, the cycle maintains the target power output and efficiency increases. However, at temperatures colder than $30^{\circ} \mathrm{C}$, the recompressor is limited by surge constraints at the pre-compressor inlet pressures that would achieve the cycle target power output. To allow feasible recompressor behavior, the cycle power output decreases (In actual operation, one would reduce cooling by idling fans to maintain the target performance).
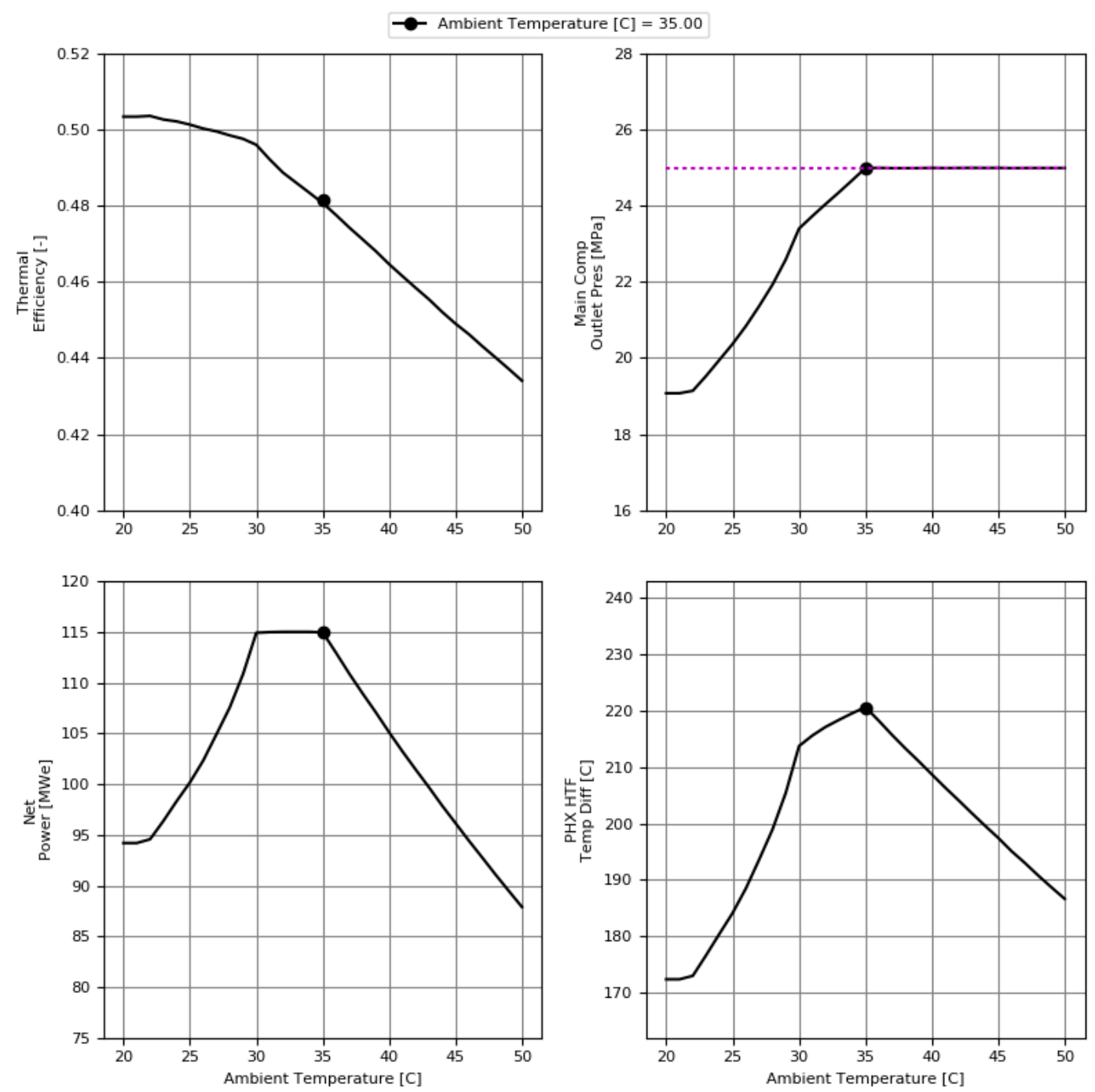

Figure 9: Optimized off-design performance of the partial-cooling cycle for varying off-design ambient temperatures. 
The trends in these results match those witnessed with the recompression off-design model. At ambient temperatures colder than design, where the power output declines, one simple solution is to turn down or shut off cooling fans to increase the difference between the ambient temperature and compressor inlet temperature so that the cycle can achieve its target power. The diminished cycle output at hotter temperatures is a more challenging problem, and possible solutions require more detailed cost-performance analysis.

\section{Comparing Annual System Performance with SAM's sCO $\mathrm{CO}_{2}$ Power Cycle Models}

In project year three, NREL developed an optimized design and off-design partial-cooling cycle model that captured the attributes of the partial-cooling cycle on the solar field and thermal storage design and performance. A system model that addresses the interplay between the solar components and the power cycle will allow for informed analysis of the benefits and tradeoffs between the simple $\mathrm{sCO}_{2}$ cycle, recompression cycle, partialcooling cycle, and typical steam Rankine cycle to determine the potential of these cycles to achieve the SunShot performance targets.

The process of designing a $\mathrm{sCO}_{2}$ cycle for MSPT systems requires detailed understanding of how the cycle efficiency, temperature range for heat input, and cost affect the MSPT design, cost, and performance. MSPT electricity generation is proportional to cycle efficiency, but cycle designs with higher efficiencies are often more expensive and have a smaller temperature range for heat input. This smaller temperature range results in higher HTF mass flow rates through the tower and receiver as well as a fixed storage volume providing less storage capacity. It also causes the receiver to operate at a hotter average temperature, which increases thermal losses to the environment. In project year three NREL calculated efficiency, cost, and heat input temperature range as a function of heat exchanger conductance for three different $\mathrm{SCO}_{2}$ cycle configurations (simple, recompression, partial cooling), and then used these relationships to design the MSPT, simulate MSPT performance, and finally optimize each cycle configuration to minimize the MSPT levelized cost of energy (LCOE).

The results indicated the partial-cooling cycle minimum LCOE is about $6 \%$ less than either the simple or recompression cycle minimum LCOEs, and the partial-cooling cycle advantage is driven by two main factors. One factor is that the cycle has a larger PHX temperature difference. This results in less expensive thermal energy storage, which leads to lower total installed cost for the MSPT system. The second factor is that the larger temperature difference leads to a smaller HTF mass flow rate, which results in less HTF pump electricity consumption. The magnitude of this difference causes the partial-cooling MSPT system to generate more net electricity than the recompression cycle although it has a lower cycle efficiency. Finally, the simple cycle temperature difference is only slightly smaller than the partialcooling cycle temperature difference, but the simple cycle efficiency is lower. Consequently, the simple

The analysis and results of the $\mathrm{SCO}_{2}$ power cycle comparison with SAM's power tower system model are documented in a manuscript submitted to Solar Energy in November 2018. cycle results in a less expensive MSPT system that generates less net electricity than the recompression cycle, and the simple and recompression cycles have similar minimum LCOEs (Neises and Turchi 2018). 


\section{Task 3. Optical Modeling of Power Tower Systems}

During project year 1, NREL implemented improvements to NREL's publicly available optical modeling tools to improve performance for power tower technologies. Binary-tree mapping methods were applied to NREL's SolTrace ray-tracing code to greatly reduce computational expense for power tower systems. Geometry and statistical components were improved to expand the type and behavior set of systems that can be modeled, and finally, improvements to the SolTrace modeling interface and memory management protocols were provided for compatibility with SAM and SolarPILOT and for better utilization of previously simulated data.

The SolTrace speed improvements averaged greater than 1000x in eight example cases. This exceeded the metric target of 20x speed enhancement as seen in Table 10.

Table 10. Summary of test cases for SolTrace speed improvement. The "Base" gives the simulation time in original form, while "New Time" gives the new simulation time. All speed enhancements exceed the target metric of 20x.

\begin{tabular}{|c|c|l|c|c|c|}
\hline Case & \# Elements & Description & Base (s) & $\begin{array}{c}\text { New } \\
\text { Time (s) }\end{array}$ & $\begin{array}{c}\text { Improve. } \\
\text { Factor }\end{array}$ \\
\hline 1 & 100,512 & Default SolarPILOT case, $500 \mathrm{MW}_{\mathrm{t}}$ & 11,672 & 6.7 & $1742 \mathrm{x}$ \\
\hline 2 & 100,512 & $\begin{array}{l}\text { Same as Case 1, afternoon sun } \\
\text { position, } \theta=23^{\circ}, \alpha=253^{\circ}\end{array}$ & 8,325 & 6.4 & $1300 \mathrm{x}$ \\
\hline 3 & 6,282 & $\begin{array}{l}\text { Default SolarPILOT case with single- } \\
\text { facet heliostats }\end{array}$ & 927 & 2.5 & $370 \mathrm{x}$ \\
\hline 4 & 95,174 & Ivanpah-like solar field & 6,531 & 9.6 & $680 \mathrm{x}$ \\
\hline 5 & 34,188 & eSolar-like hexagonal field & 5,447 & 6.1 & $893 \mathrm{x}$ \\
\hline 6 & 79,812 & $\begin{array}{l}\text { North field, mixed heliostats (small } \\
\text { near tower, large outer ring) }\end{array}$ & 6,683 & 6.2 & $1078 \mathrm{x}$ \\
\hline 7 & 60,127 & $\begin{array}{l}\text { Ivanpah Unit 2 solar field with random } \\
\text { vertical heliostat displacement }\end{array}$ & 4,042 & 3.7 & $1092 \mathrm{x}$ \\
\hline 8 & 60,127 & $\begin{array}{l}\text { Ivanpah Unit 2 solar field with high } \\
\text { optical slope error ( 10 mrads) }\end{array}$ & 3,830 & 3.7 & $1035 \mathrm{x}$ \\
\hline
\end{tabular}

\section{Accuracy of Updated SolTrace Code}

To demonstrate the accuracy of the revised code, SolTrace was used to indirectly calculate view factors for eight different surface geometries whose analytical and numerical solutions are provided in the Engineering Equation Solver (EES) library [EES, v.10]. The target accuracy was $\pm 2 \%$. An additional goal was to show that view factors could be calculated numerically using SolTrace.

SolTrace is often used to predict flux on receiver surfaces. These data are then used in post-run analysis to calculate surface temperatures and thermal losses, including radiative losses. For purposes of efficient radiative transfer analysis, it would be extremely helpful if SolTrace could calculate and report surface-to-surface view factors in addition to surface flux for all surfaces. Theoretically SolTrace can be used used to calculate view factors numerically by taking advantage of the SolTrace Monte Carlo ray tracing engine. 
SolTrace does not currently model radiating surfaces (only reflecting surfaces) and consequently does not directly calculate and report view factors. In order to use SolTrace to do these calculations it was necessary to mimic a radiative surface using reflection. SolTrace was temporarily modified to model a diffuse reflecting surface characterized by the diffuse gray radiative distribution [Siegel \& Howell, 1992]. This distribution function includes $\theta$, the angle between the outgoing ray and the reflecting surface normal vector, and $\varphi$, the azimuthal angle of the outgoing ray about the surface normal vector axis:

$$
\theta=\sin ^{-1}(\sqrt{\text { random number }\{0 . .1\}}), \quad \varphi=2 \pi \text { (random number }\{0 . .1\}
$$

As shown in Figure 10, a diffuse surface $A_{1}$ reflects energy, part of which is intercepted by surface $A_{2}$. The ratio of reflected energy intercepted by $A_{2}$ to the energy incident on $A_{1}$ is effectively the view factor. Reflecting incident rays normal to surface $A_{1}$ using the above reflection distribution effectively mimics a gray diffuse radiating surface. The outoing reflected ray vector can be calculated from these two angular parameters.

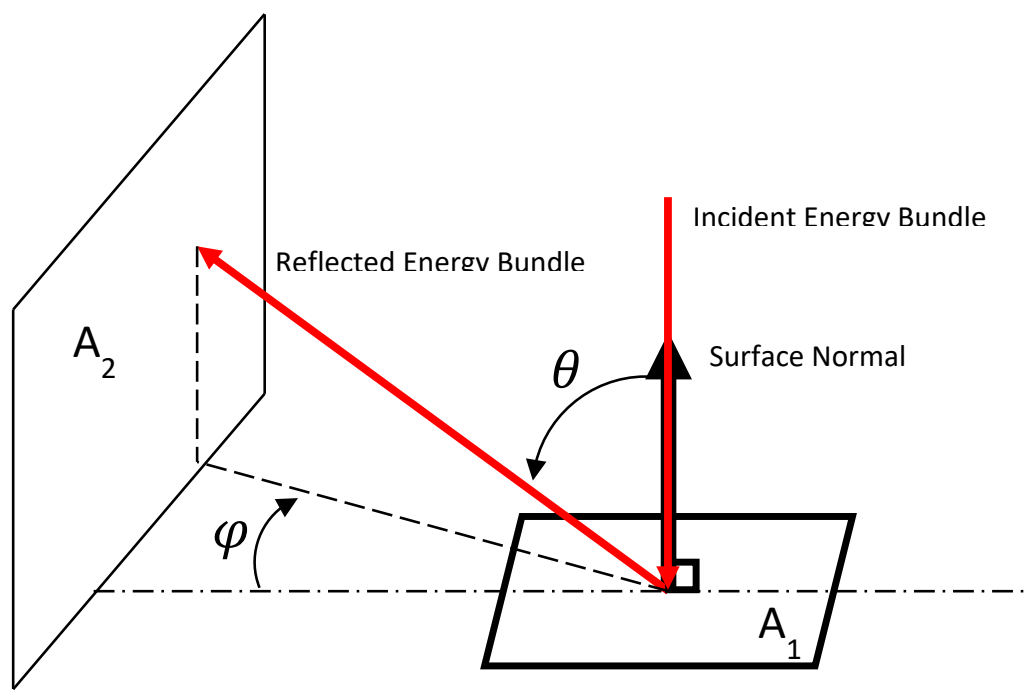

Figure 10. Simulation of a radiating surface $A_{1}$ for view-factor analysis in SolTrace.

SolTrace currently offers two options for both surface normal vector distributions (used in calculating the reflected-ray specular direction vector) and specular reflection distributions (further perturbation of the reflected-ray direction vector about the specular reflected direction). These are 1-D gaussian and 1-D uniform (pillbox) distributions neither of which can be used to adequately approximate the above diffuse distribution. In addition to reflection distributions, SolTrace also allows users to define a sunshape distribution which is applied in the same way as the specular reflection distribution. In SolTrace, when a ray is traced from the sun to the first stage of a SolTrace geometry, its initial vector direction is depicted as if the sun were an infinite distance away (i.e. parallel wavefront). Once the ray intersection on a surface normal to the sun direction is found then the sunshape distribution is applied and the ray direction is perturbed according to the applied distribution. As noted above, to mimic a diffuse radiative surface, SolTrace was temporarily modified such that the sunshape distribution was hardcoded to that of the diffuse equation above. Because of code structure, it was more expedient to modify the sunshape rather than the optical error distribution for purposes of this analysis. In FY17, SolTrace could include an option to calculate view factors between any set of surfaces 
and output these view factors in the form of a table. This table will be useful in postSolTrace thermal radiation exchange analysis. Optical error distributions, both surface normal and specular, were subsquently turned off in the analysis. A bundle of rays, $(\mathrm{N}=$ 100 million) was then traced from the sun to the primary (or radiative) surface and reflected from this surface without losses according to the diffuse distribution. Some of these reflected rays intercept the secondary (receiving) surface. For a sufficiently large number of rays, the ratio of the number of rays intercepted by the secondary receiving surface to the number of rays incident upon the primary radiative surface should numerically approach the analytical view factor solution between these surfaces assuming diffuse gray characteristics.

The resulting calculations for eight different geometries were compared to analytical solutions for view factors available within EES. The geometries are shown in Figure 11, and the analysis was performed using the default parameters specified within EES.

Finite parallel plates

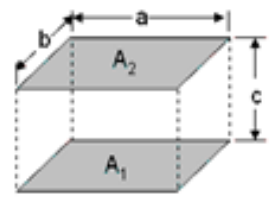

\section{Disk to disk (same center)}

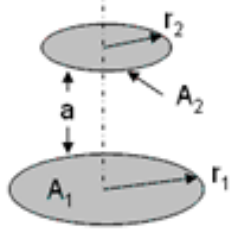

\section{Perpendicular Offset Rectangles}

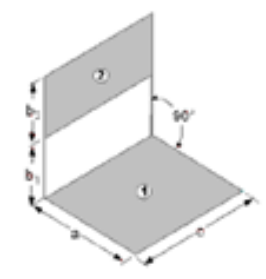

Perpendicular Rectangles with no Common Points

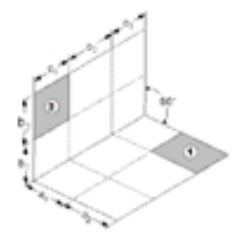

Finite perpendicular plates

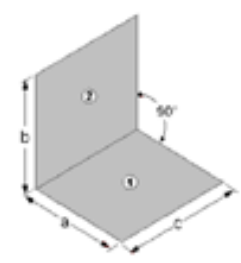

Rectangle to circular disk in a parallel plane

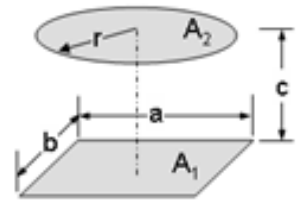

Perpendicular Rectangles with a Common Point

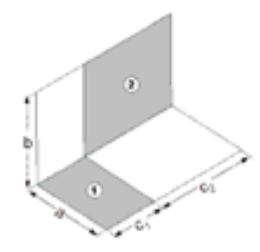

Finite adjacent plates

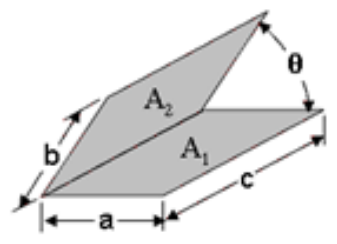

Figure 11. Eight cases for view-factor analysis taken from EES. 
The SolTrace results are shown in Table 11 compared to the EES analytical solutions. In all cases except one (rectangle to circular disk in a parallel plane), the SolTrace result agreed exactly with the EES solution. Upon further inspection, the EES solution for this case was not analytical but also a Monte Carlo solution; therefore, one would expect some variation between this and the SolTrace Monte Carlo solution. This variation was on the order of $1 \%$ which satisfies the metric goal of less than $2 \%$.

Table 11. Comparison of view factors calculated by SolTrace versus analytical solutions in EES.

\begin{tabular}{|lccc|}
\hline Geometry & $\begin{array}{c}\text { EES View } \\
\text { Factor }\end{array}$ & $\begin{array}{c}\text { SolTrace View } \\
\text { Factor }\end{array}$ & Difference \\
\hline Finite parallel plates & 0.4756 & 0.4756 & $0.00 \%$ \\
\hline Finite perpendicular plates & 0.1493 & 0.1493 & $0.00 \%$ \\
\hline Disk to disk (same center) & 0.1339 & 0.1339 & $0.00 \%$ \\
\hline Rectangle to circular disk in a parallel plane & 0.174 & 0.176 & $1.14 \%$ \\
\hline Perpendicular offset rectangles & 0.07235 & 0.07235 & $0.00 \%$ \\
\hline Perpendicular rectangles with a common point & 0.0605 & 0.0605 & $0.00 \%$ \\
\hline Perpendicular rectangles with no common points & 0.01626 & 0.01626 & $0.00 \%$ \\
\hline Finite adjacent plates & 0.4833 & 0.4833 & $0.00 \%$ \\
\hline
\end{tabular}

\section{SolTrace Cross-Platform Agreement}

SolTrace results were checked for consistency when run on Linux, Windows, and iOS operating systems. A set of eight test cases (Table 10) was run on each operating system. MS Windows is the reference operating system, and Mac OSX and Linux results were compared with the Windows results. The SolTrace input parameters used for this comparison included tracing one million rays, using two processor cores, and employing the same random number generator seed of 123 . While the metric definition technically compares differences in peak flux, average flux and number of rays intercepted, one can start by comparing the traced ray information in the same way that Task 1.3.2 used these data. That is, identical ray-trace results will lead to identical flux and ray-intercept results. SolTrace outputs intersection and direction-cosine data for each ray. If this table of data is identical down to the last ray traced for each case, then one can be assured that the flux parameters are identical as well. The metric value would be exactly zero (0).

This, in fact, was accomplished for five of the eight cases run comparing Mac OSX with MS Windows and five of the eight cases run comparing Linux with MS Windows. While one may expect exact agreement across platforms, it is often the case that variable initialization and memory management differences can lead to discrepancies, and these issues can be very difficult to diagnose because they arise from differences within the system architecture. Still, from a practical standpoint, the information generated by the same software running on different platforms should be equivalent in the context of the engineering requirements under consideration, e.g., within $0.1 \%$.

Table 12 summarizes the case-by-case differences between simulations executed on the three different operating systems. Flux intensity is characterized over a $30 \times 30$ grid on the receiver surface. The results show exact agreement for five of eight cases, with small discrepancies in cases 5,6 , and 8 . 
For the cases that were not identical, NREL examined the peak flux difference for Linuxto-Windows case 6 as an example. To determine whether this is due to a systematic error, Case 6 was re-evaluated with double the number (i.e., 2 million) rays. This result is also shown in Table 12. The values reported are substantially lower than the threshold requirement, and this implies that the peak flux error was not due to an underlying platform-based inconsistency. The original Case 6 error is caused by the relatively small number of rays run over a relatively large number of flux bins such that the peak flux uncertainty is $3.3 \%$, which is greater than the observed error. Given this, NREL believes that the Linux-Windows platform comparison shows excellent agreement and can be considered equivalent. Similar results are seen for the OSX comparison, although cases 5 and 6 were not rerun in those systems.

Table 12: Comparison of cross-platform error between Linux (Slackware 64 bit) and Windows (Windows 7 x64) and OSX and Windows. Values shown indicate relative metric error between corresponding cases on each platform.

\begin{tabular}{l|ccc|ccc}
\hline & \multicolumn{3}{|c|}{ Linux to Windows } & \multicolumn{3}{c}{ OSX to Windows } \\
\hline & \multicolumn{3}{|c}{ Average } & Number of & \multicolumn{3}{c}{ Average } & $\begin{array}{c}\text { Number of } \\
\text { ray hits }\end{array}$ \\
\hline Case 1 & Peak Flux & Flux & ray hits & Peak Flux & Flux & 0.000001 \\
Case 2 & 0 & 0 & 0 & 0 & 0.000002 & 0 \\
Case 3 & 0 & 0 & 0 & 0 & 0 & 0 \\
Case 4 & 0 & 0 & 0 & 0 & 0 & 0 \\
Case 5 & 0 & 0 & 0 & 0 & 0 & -0.000018 \\
Case 6 & 0.000797 & 0.000013 & 0.000017 & 0.00159 & -0.000011 & -0.000022 \\
w/ 2e6 rays & 0.001098 & 0.000009 & 0.000015 & -0.00111 & -0.000028 & \\
Case 7 & 0.000009 & 0.000004 & 0.000011 & & & 0 \\
Case 8 & 0 & 0 & 0 & 0 & 0 & 0.000011 \\
\hline
\end{tabular}

\section{SolTrace View Factor Validation}

Receivers used in CSP applications are often comprised of a number of surfaces in either an external or cavity configuration. NREL's SolTrace software is routinely used to model incident flux on these surfaces from heliostats in a power tower field. These receiver surface flux maps are used in subsequent thermal analysis to calculate surface temperatures that account for radiative energy exchange between all surfaces. A necessary input to such thermal analyses is the view factor for each surface relative to all other surfaces in the receiver. View factor calculations can be extremely complex for multi-surface geometries, such as may be necessary for SunShot receiver designs.

Often the solutions for these view factors end up as infinite series expansions and approximations are made by limiting number of expansion terms to a practical value. Many such analytical approximations can be found in the open literature for a variety of simple surface configurations, but these published solutions often differ in accuracy and so can provide slightly different results. A numerical approach can also be used to calculate view factors. In Subtask 1.3.2, it was demonstrated that SolTrace can be used to accurately calculate view factors for a single pair of surfaces using its Monte Carlo numerical engine. This was done indirectly using SolTrace in a way in which it was not originally designed. Given this success, the goal of Subtask 2.3.2 was to develop the 
capability within SolTrace to calculate not only receiver surface flux maps for which it was originally designed, but also calculate and output view factors for those same surfaces using the same SolTrace geometry input file. This capability will provide highly accurate numerical solutions and eliminate the need to calculate these view factors via approximations external to SolTrace.

In project year two, SolTrace was first modified by adding a new "diffuse" optical error distribution option to the optical properties table. During year one this optical error distribution was temporarily hardwired into the code; now this capability is a userselectable option. A SolTrace script was then written which operates on existing SolTrace project files containing receiver geometries that are to be analyzed. The script requires that the receiver geometry to be analyzed for view factor data be defined inside one stage (which is almost always the case). The script prompts the user for the SolTrace project file, the stage number containing the receiver geometry and the number of rays to be traced. It then copies the geometry data for all receiver surfaces into memory and creates a temporary project in memory with two stages: a "radiative" first stage and a "target" second stage. It should be noted that in SolTrace, the first stage is where rays are generated from the source (e.g., sun) for subsequent tracing through the $1^{\text {st }}$ stage to the remaining stages. The process then proceeds as follows:

One of the receiver surfaces is copied into the $1^{\text {st }}$ (radiative) stage while the rest are copied to the $2^{\text {nd }}$ (target) stage. Relative position and orientation are preserved between all surfaces. A SolTrace-defined sun position is then calculated for the temporary project such that the sun vector is normal to the single surface in the $1^{\text {st }}$ (radiative) stage. Rays are traced from the sun and reflected off the surface in the radiative stage using the diffuse distribution option and a surface hemispherical reflectivity $=1.0$ (no absorption). These reflected rays then continue to the $2^{\text {nd }}$ (target) stage. The surfaces in the target stage are defined with a reflectivity $=0.0$ (perfectly absorbing). Whatever rays from the radiative surface in the $1^{\text {st }}$ stage that the target stage "sees", i.e., intersects, are absorbed by that surface and tallied so that they cannot reflect to other surfaces. The ratio of the number of rays absorbed by any one surface to the number of rays reflected by the single surface in the $1^{\text {st }}$ (radiative) stage is equivalent to the view factor between the that radiative surface and that particular absorbing surface. This value is calculated for each of the surfaces in the $2^{\text {nd }}$ (target) stage and stored in memory. The project is cleared, and the process then repeats for each of the remaining surfaces in the receiver geometry until all view factors have been calculated. The script reports these values to the user in a file.

The PEC 2.3.2 evaluation criterion requires that surface view factors be calculated for two different cavity geometries each composed of at least five surfaces. Using the new version of SolTrace, view factors between any two surfaces were required to be within $2 \%$ of analytic view factor solutions reported in the literature for those same surface geometries. As stated earlier, it should be noted here that many closed-form solutions in the literature are approximations to infinite series solutions and some discrepancy (on the order of 2-3\%) has been found between solutions from different published sources. To provide a comparison with another numerical approach, Fluent, a computational fluid dynamics package based on a finite element numerical method, was used to calculate numbers for additional comparison. In some cases, published analytic solutions were not found for certain geometries and the comparison was limited to that between the two numerical approaches, SolTrace and Fluent. 
The two receiver geometries analyzed are shown in Figure 12. Figure 12 (left) is a rectangular box cavity comprised of five planar surfaces. The surface numbers are indicated in red. Similarly, a hexagonal box cavity is illustrated in Figure 12 (right). This cavity consists of seven planar surfaces. In both cases, the cavity aperture is shown as the relative sun direction.
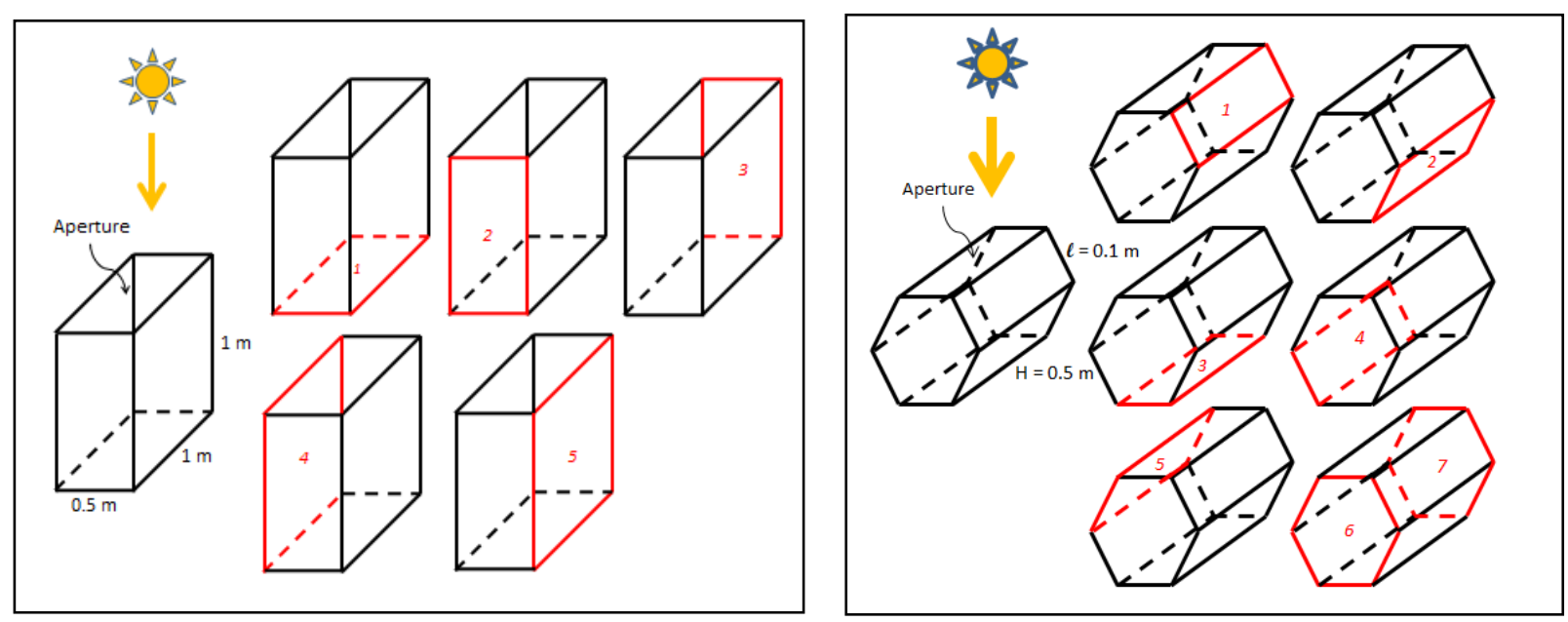

Figure 12. Rectangular box cavity (left) and hexagonal box cavity (right)

The view factor $F_{i, j}$ between any two surfaces is defined as the ratio of radiation absorbed by surface $j$ (column index) to the diffuse radiation reflected from surface $i$ (row index). View factors calculated using SolTrace, EES analytical solutions and the Fluent CFD code are presented together with relative error between SolTrace and each of the other solutions, EES and Fluent.

Table 13 shows results for the rectangular box cavity geometry shown in Figure 12 . For the rectangular box geometry, the difference in results for all cases is insignificant. All agree to less than $\pm 1 \%$ (achieving the target of $<2 \%$ relative error) with most surface view factors agreeing to within $\pm 0.5 \%$. Rectangular surfaces in parallel and orthogonal orientations to one another have simple analytical solutions and so one would expect that the analytical solution to compare well with the numerical solutions provided by both SolTrace and Fluent. 
Table 13. Surface view factor comparison for rectangular box receiver (Figure 12, left)

\begin{tabular}{|c|c|c|c|c|c|c|c|c|c|c|c|}
\hline $\begin{array}{c}\text { SolTrace } \\
F_{i, j} \\
\end{array}$ & & & & & & & & & & & \\
\hline & 1 & 2 & 3 & 4 & 5 & & & & & & \\
\hline 1 & 0 & 0.1493 & 0.1493 & 0.2924 & 0.2923 & & & & & & \\
\hline 2 & 0.1493 & 0 & 0.1167 & 0.2924 & 0.2923 & & & & & & \\
\hline 3 & 0.1493 & 0.1167 & 0 & 0.2924 & 0.2923 & & & & & & \\
\hline 4 & 0.1462 & 0.1462 & 0.1462 & 0 & 0.4153 & & & & & & \\
\hline 5 & 0.1462 & 0.1462 & 0.1462 & 0.4153 & 0 & & & & & & \\
\hline EES $F_{i, j}$ & & & & & & Fluent $\mathrm{F}_{\mathrm{i}}$ & & & & & \\
\hline & 1 & 2 & 3 & 4 & 5 & & 1 & 2 & 3 & 4 & 5 \\
\hline 1 & 0 & 0.1493 & 0.1493 & 0.2924 & 0.2924 & 1 & 0 & 0.1496 & 0.1494 & 0.2927 & 0.2926 \\
\hline 2 & 0.1493 & 0 & 0.1167 & 0.2924 & 0.2924 & 2 & 0.1496 & 0 & 0.1156 & 0.2928 & 0.2927 \\
\hline 3 & 0.1493 & 0.1167 & 0 & 0.2924 & 0.2924 & 3 & 0.1495 & 0.1157 & 0 & 0.2926 & 0.2927 \\
\hline 4 & 0.1462 & 0.1462 & 0.1462 & 0 & 0.4153 & 4 & 0.1466 & 0.1468 & 0.1467 & 0 & 0.4134 \\
\hline 5 & 0.1462 & 0.1462 & 0.1462 & 0.4153 & 0 & 5 & 0.1466 & 0.1466 & 0.1466 & 0.4135 & 0 \\
\hline$\%$ Error & & & & & & $\%$ Error & & & & & \\
\hline & 1 & 2 & 3 & 4 & 5 & & 1 & 2 & 3 & 4 & 5 \\
\hline 1 & $0.0 \%$ & $0.0 \%$ & $0.0 \%$ & $0.0 \%$ & $0.0 \%$ & 1 & $0.0 \%$ & $-0.2 \%$ & $-0.1 \%$ & $-0.1 \%$ & $-0.1 \%$ \\
\hline 2 & $0.0 \%$ & $0.0 \%$ & $0.0 \%$ & $0.0 \%$ & $0.0 \%$ & 2 & $-0.2 \%$ & $0.0 \%$ & $0.9 \%$ & $-0.1 \%$ & $-0.1 \%$ \\
\hline 3 & $0.0 \%$ & $0.0 \%$ & $0.0 \%$ & $0.0 \%$ & $0.0 \%$ & 3 & $-0.1 \%$ & $0.8 \%$ & $0.0 \%$ & $-0.1 \%$ & $-0.1 \%$ \\
\hline 4 & $0.0 \%$ & $0.0 \%$ & $0.0 \%$ & $0.0 \%$ & $0.0 \%$ & 4 & $-0.3 \%$ & $-0.4 \%$ & $-0.3 \%$ & $0.0 \%$ & $0.5 \%$ \\
\hline 5 & $0.0 \%$ & $0.0 \%$ & $0.0 \%$ & $0.0 \%$ & $0.0 \%$ & 5 & $-0.3 \%$ & $-0.3 \%$ & $-0.3 \%$ & $0.4 \%$ & $0.0 \%$ \\
\hline
\end{tabular}

In summary, SolTrace was modified and a script was created to seamlessly calculate surface-to-surface view factors using existing SolTrace project files with single-stagedefined receiver geometry. Two cavity geometries were analyzed, view factors calculated and compared with both published analytical solutions and with the Fluent CFD code. Agreement was found to be excellent. This new SolTrace capability will allow more efficient thermal analysis using the expanded SolTrace output. 
Table 14. Surface view factor comparison for hexagonal box cavity (Figure 12, right).

\begin{tabular}{|c|c|c|c|c|c|c|c|c|c|c|c|c|c|c|c|}
\hline \multicolumn{16}{|c|}{ SolTrace $F_{\mathrm{ij}}$} \\
\hline & 1 & 2 & 3 & 4 & 5 & 6 & 7 & & & & & & & & \\
\hline 1 & 0.0000 & 0.1223 & 0.1889 & 0.2098 & 0.1889 & 0.0839 & 0.0839 & & & & & & & & \\
\hline 2 & 0.1223 & 0.0000 & 0.1223 & 0.1889 & 0.2098 & 0.0839 & 0.0839 & & & & & & & & \\
\hline 3 & 0.1889 & 0.1223 & 0.0000 & 0.1223 & 0.1889 & 0.0839 & 0.0839 & & & & & & & & \\
\hline 4 & 0.2098 & 0.1889 & 0.1223 & 0.0000 & 0.1223 & 0.0839 & 0.0839 & & & & & & & & \\
\hline 5 & 0.1889 & 0.2098 & 0.1889 & 0.1223 & 0.0000 & 0.0839 & 0.0839 & & & & & & & & \\
\hline 6 & 0.1615 & 0.1615 & 0.1614 & 0.1615 & 0.1615 & 0.0000 & 0.0311 & & & & & & & & \\
\hline 7 & 0.1615 & 0.1615 & 0.1615 & 0.1615 & 0.1615 & 0.0311 & 0.0000 & & & & & & & & \\
\hline \multirow[t]{9}{*}{ EES $F_{i, j}$} & & & & & & & & Fluent $\mathrm{F}_{\mathrm{i}}$ & & & & & & & \\
\hline & 1 & 2 & 3 & 4 & 5 & 6 & 7 & & 1 & 2 & 3 & 4 & 5 & 6 & 7 \\
\hline & 0 & 0.122 & 0.189 & 0.21 & 0.189 & NA & NA & 1 & 0 & 0.1230 & 0.1887 & 0.2088 & 0.1886 & 0.0840 & 0.0840 \\
\hline & 0.122 & 0 & 0.122 & 0.189 & 0.21 & NA & NA & 2 & 0.1230 & 0 & 0.1230 & 0.1885 & 0.2088 & 0.0840 & 0.0840 \\
\hline & 0.189 & 0.122 & 0 & 0.122 & 0.189 & NA & NA & 3 & 0.1885 & 0.1231 & 0 & 0.1231 & 0.1885 & 0.0841 & 0.0840 \\
\hline & 0.21 & 0.189 & 0.122 & 0 & 0.122 & NA & NA & 4 & 0.2086 & 0.1886 & 0.1232 & 0 & 0.123 & 0.0839 & 0.0839 \\
\hline & 0.189 & 0.21 & 0.189 & 0.122 & 0 & NA & NA & 5 & 0.1888 & 0.2086 & 0.1885 & 0.1231 & 0 & 0.0840 & 0.0839 \\
\hline & NA & NA & NA & NA & NA & 0 & 0.032 & 6 & 0.1619 & 0.1617 & 0.1615 & 0.1616 & 0.1620 & 0 & 0.0300 \\
\hline & NA & NA & NA & NA & NA & 0.032 & 0 & 7 & 0.1613 & 0.1619 & 0.1617 & 0.1615 & 0.1620 & 0.0301 & 0 \\
\hline \multirow[t]{2}{*}{$\%$ Error } & & & & & & & & $\%$ Error & & & & & & & \\
\hline & 1 & 2 & 3 & 4 & 5 & 6 & 7 & & 1 & 2 & 3 & 4 & 5 & 6 & 7 \\
\hline 1 & $0.0 \%$ & $0.0 \%$ & $0.0 \%$ & $0.0 \%$ & $0.0 \%$ & NA & NA & 1 & $0.0 \%$ & $-0.6 \%$ & $0.1 \%$ & $0.5 \%$ & $0.2 \%$ & $-0.1 \%$ & $-0.1 \%$ \\
\hline 2 & $0.0 \%$ & $0.0 \%$ & $0.0 \%$ & $0.0 \%$ & $0.0 \%$ & NA & NA & 2 & $-0.5 \%$ & $0.0 \%$ & $-0.6 \%$ & $0.3 \%$ & $0.5 \%$ & $-0.1 \%$ & $-0.1 \%$ \\
\hline 3 & $0.0 \%$ & $0.0 \%$ & $0.0 \%$ & $0.0 \%$ & $0.0 \%$ & NA & NA & 3 & $0.2 \%$ & $-0.6 \%$ & $0.0 \%$ & $-0.6 \%$ & $0.2 \%$ & $-0.2 \%$ & $-0.1 \%$ \\
\hline 4 & $0.0 \%$ & $0.0 \%$ & $0.0 \%$ & $0.0 \%$ & $0.0 \%$ & NA & NA & 4 & $0.6 \%$ & $0.1 \%$ & $-0.7 \%$ & $0.0 \%$ & $-0.6 \%$ & $0.0 \%$ & $0.0 \%$ \\
\hline 5 & $0.0 \%$ & $0.0 \%$ & $0.1 \%$ & $0.0 \%$ & $0.0 \%$ & NA & NA & 5 & $0.0 \%$ & $0.5 \%$ & $0.2 \%$ & $-0.6 \%$ & $0.0 \%$ & $-0.1 \%$ & $-0.1 \%$ \\
\hline 6 & NA & NA & NA & NA & NA & $0.0 \%$ & $-2.3 \%$ & 6 & $-0.2 \%$ & $-0.1 \%$ & $-0.1 \%$ & $-0.1 \%$ & $-0.3 \%$ & $0.0 \%$ & $3.4 \%$ \\
\hline 7 & NA & NA & NA & NA & NA & $-2.3 \%$ & $0.0 \%$ & 7 & $0.1 \%$ & $-0.3 \%$ & $-0.2 \%$ & $0.0 \%$ & $-0.3 \%$ & $3.1 \%$ & $0.0 \%$ \\
\hline
\end{tabular}

\section{Scripting Tools in SolarPILOT}

NREL has developed a scripting language called "LK" that allows users to write and execute programs that directly interact with CSP-relevant modeling tools such as SAM, SDK, and SolTrace. Using a relatively small set of scripting functions, a user can perform a wide variety of tasks and interact more directly with the modeling tool. Using LK, a user might write a script that reads data from a file, performs trigonometric manipulations, executes a SAM or SolTrace simulation, generates plots and charts, and saves output data, for example.

In previous work, NREL has supported access to SolarPILOT functionality by two separate means: a stand-alone graphical user interface (GUI) and integration of portions of the model into SAM via an application programming interface (API) that is not exposed to the user. Each option offers advantages, with the SAM implementation providing a simplified means of interaction while supporting SAM scripting, and the GUI providing a fuller set of options but without any scripting support. In this task, NREL augmented the standalone SolarPILOT GUI with an implementation of the LK scripting language that includes functions customized for this application. The primary goal of this work was to allow scripting to provide at least $80 \%$ of the actions that could be undertaken by a user within the GUI. To determine whether the scripting activity meets the $80 \%$ task milestone, NREL identified 21 functions that are provided by the SolarPILOT user interface. LK scripting was developed for 20 of these functions (95\%) plus an additional five functions not available via the GUI, as summarized in Table 15. 
Table 15: Comparison of interface and scripting functionality

\begin{tabular}{r|lcc}
\hline & Feature & GUI & Scripting \\
\hline 1 & Set numeric variable values & $\mathrm{X}$ & $\mathrm{X}$ \\
\hline 2 & Set fixed-choice variable values & $\mathrm{X}$ & $\mathrm{X}$ \\
\hline 3 & Specify location and weather file & $\mathrm{X}$ & $\mathrm{X}$ \\
\hline 4 & Specify market payment allocation factor table & $\mathrm{X}$ & $\mathrm{X}$ \\
\hline 5 & Display/retrieve calculated interface values & $\mathrm{X}$ & $\mathrm{X}$ \\
\hline 6 & Specify land boundaries & $\mathrm{X}$ & $\mathrm{X}$ \\
\hline 7 & Open case & $\mathrm{X}$ & $\mathrm{X}$ \\
\hline 8 & Save case & $\mathrm{X}$ & $\mathrm{X}$ \\
\hline 9 & New/reset case & $\mathrm{X}$ & $\mathrm{X}$ \\
\hline 10 & Add and delete heliostat templates & $\mathrm{X}$ & $\mathrm{X}$ \\
\hline 11 & Add and delete receiver templates & $\mathrm{X}$ & $\mathrm{X}$ \\
\hline 12 & Run performance simulation using analytical engine & $\mathrm{X}$ & $\mathrm{X}$ \\
\hline 13 & Run performance simulation using ray trace engine & $\mathrm{X}$ & $\mathrm{X}$ \\
\hline 14 & Run parametric simulation & $\mathrm{X}$ & $\mathrm{X}$ \\
\hline 15 & Generate layout & $\mathrm{X}$ & $\mathrm{X}$ \\
\hline 16 & Specify optimization parameters & $\mathrm{X}$ & $\mathrm{X}$ \\
\hline 17 & Run optimization & & $\mathrm{X}$ \\
\hline 18 & Modify individual heliostat positions & & $\mathrm{X}$ \\
\hline 19 & Modify individual heliostat performance characteristics & & $\mathrm{X}$ \\
\hline 20 & Select heliostats by geometrical region & & $\mathrm{X}$ \\
\hline 21 & Select heliostats by scalable vector graphics region & $\mathrm{X}$ & $\mathrm{X}$ \\
\hline 22 & Defocus heliostats & $\mathrm{X}$ & $\mathrm{X}$ \\
\hline 23 & Create field performance plot & $\mathrm{X}$ & $\mathrm{X}$ \\
\hline 24 & Create receiver flux plot & & \\
\hline 25 & Retrieve individual heliostat performance characteristics & $\mathrm{X}$ \\
\hline 26 & Retrieve summary performance statistics & & \\
\hline
\end{tabular}

The ability to programmatically save heliostat field performance plots was not provided via a script. However, it is possible to execute a script and subsequently view the resulting field performance in the GUI, which is updated after completing the simulation. The scripting environment provides significant functionality beyond what is available via the GUI. Most notably, scripting allows users to programmatically modify heliostat locations, performance, and operational status, and it provides tools for selecting groups of heliostats. Additional description of these capabilities is provided below.

\section{Setting and retrieving input values [Features 1-6, Table 15]}

SolarPILOT includes approximately 375 settings, input variables, and parameters that can be manipulated by the user. These items are assigned one of several available data types, such as string, double, and integer. Several more complex data structures are also utilized, including point vector (a list of point structures with positional attributes), matrix (a multidimensional list of data), and weather data (a structure that defines time-series weather information). A primary goal of the scripting interface is to provide a mechanism for assignment and retrieval of input and output parameters, and this is implemented via

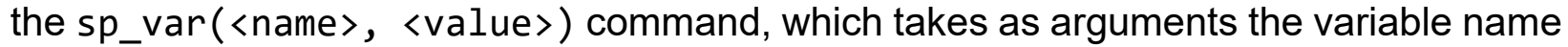
and, optionally, the assignment value. If no value is provided, the function returns the 
current value for the variable. The data type passed to this argument is flexible and corresponds to the data type of the variable to be assigned.

\section{Case management [7-9]}

Scripting provides functionality to create, open, and save cases in accordance with the GUI. These actions are useful when operating a script that may pull information from various case files.

\section{Template management [10-11]}

SolarPILOT employs "templates" for managing heliostat and receiver geometries so that multiple configurations can be used in the same plant. For example, a heliostat field may consist of a finite set of heliostat focal lengths such that the system should be modeled using several heliostats with different focal length properties. In the GUI, this is accomplished by manually creating the necessary number of templates and adjusting the properties of each individually. The placement of templates within the field can be assigned in one of several ways, but the procedures are relatively restrictive or require multiple steps to achieve the desired outcome. We have added scripting functions to add and drop receiver and heliostat templates. Once added, the template is assigned a unique identifier that allows the user to

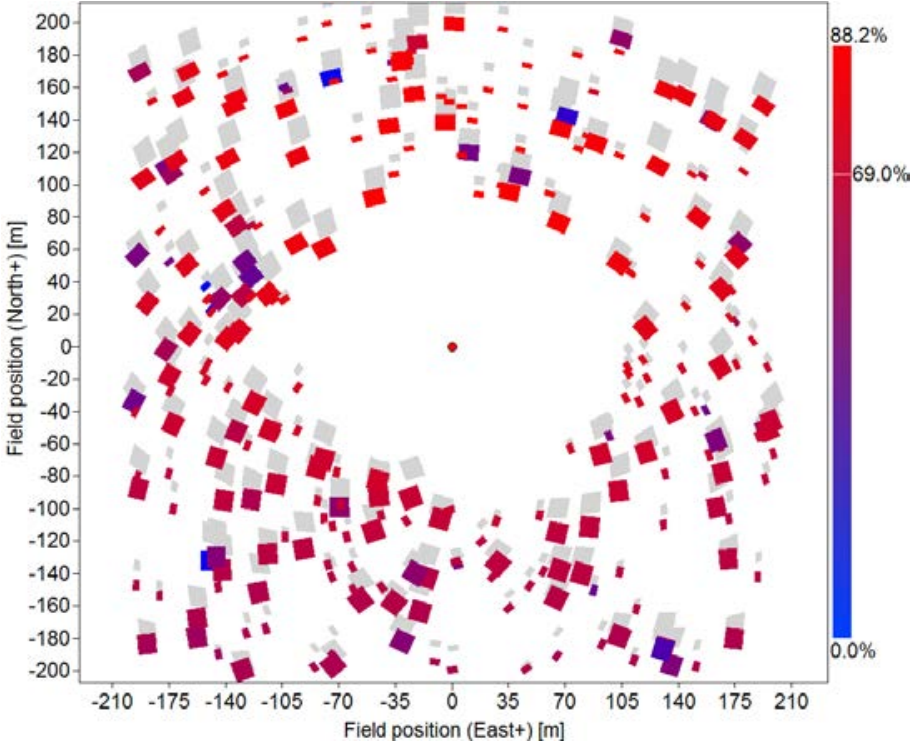

Figure 13: Demonstration of script-based assignment of heliostat templates for random heliostat positions. manipulate the template characteristics. Individual heliostats may be assigned to one of the available templates upon layout of the field. Figure 13 illustrates the result of a random layout using two templates - one large and one small. Scripting provides the ability to construct any layout of interest with any number of associated heliostat geometries. Likewise, multiple receivers may also be programmatically constructed and configured.

\section{Executing tasks [12-17]}

The core functionality of SolarPILOT includes the generation of heliostat field layouts, characterization of their optical performance, optimization of design variables, and analysis of performance and design over a range of parameter values. It is therefore important to provide the following scripting functions that achieve these outcomes:

\footnotetext{
run_layout()

Generate a heliostat field layout. Optionally, the user may provide heliostat positions to use in the layout.

run_performance( ) Calculate the optical performance of the solar field. This algorithm updates the overall performance metrics information and information specific to each heliostat.
} 

to specify the variable name, optional upper and lower bounds, optional initial step size, and an optional initial guess value for each variable.

The combination of these functions in a scripting environment allows a wide range of actions to be taken. In combination with the variable setting and retrieval functions described above, the script user may execute any parametric analysis or calculation procedure that can be programmed.

\section{Manipulating heliostat characteristics [18-22]}

The SolarPILOT GUI lacks the tools to allow users to select and modify individual heliostats based on their location in the field and developing a case in which heliostat performance differs across the field is somewhat intractable. Scripting provides an opportunity for this capability, both in programmatically modifying heliostat performance, but also in providing methods for selecting groups of heliostats. The following options are now available to select heliostats by region within the solar field using the get_heliostats() method:

$\begin{array}{ll}\begin{array}{ll}\text { all } \\ \text { cylindrical }\end{array} & \begin{array}{l}\text { Returns a list of all heliostats in the field } \\ \text { User provides radial and azimuthal angular bounds, and the function returns a } \\ \text { list of heliostats within the region }\end{array} \\ \text { cartesian } & \begin{array}{l}\text { User provides minimum and maximum Cartesian coordinates, and the function } \\ \text { returns a list of heliostats within the region }\end{array} \\ \text { polygon } & \begin{array}{l}\text { User provides a set of points defining a polygon... } \\ \text { SVG }\end{array} \\ \text { SVG file } & \text { User provides geometry in scalable vector format... } \\ & \text { User provides the file name of a drawing in scalable vector format... }\end{array}$

The options "polygon," "SVG," and "SVG file" provide sophisticated means of selecting precise regions of heliostats. A user may adopt external software to generate polygons or vector graphics, and then impose those paths on the heliostat field to select heliostats. These options may be valuable for users seeking to model specific plants with geological features, fields with spatially varying soiling patterns, or other scenarios. A case study below illustrates the flexibility of the heliostat selection methods.

\section{Generating data [23-26]}

The scripting tool provides several functions that access and export data. These include plotting for receiver flux, export functions for variable definitions and simulation or layout results, and a function that provides summary information after a simulation.

\section{Case study: Heliostat field soiling due to road proximity}

We demonstrate the scripting functionality using two case studies. In the first, consider a surround heliostat field with an access road that crosses the field towards the southwest. The road is assumed to cause local soiling due to dust from vehicle traffic, and the soiling pattern follows the wind path, which blows predominantly from the west. Soiling is nonuniform, and decays quickly as the distance between a given heliostat and the road increases. Figure 14 shows the LK script used to implement this scenario: (i) a function "soil" is defined to calculate the position-dependent soiling, (ii) the access road is defined as an exclusion region with a long, narrow rectangle, (iii) the layout is generated, (iv) the 
heliostats in the layout are retrieved and the reflectivity of each is modified depending on its position in the field, (v) a performance simulation is executed, and (vi) the results are updated in the SolarPILOT GUI. Figure 15 shows the layout and results of the performance simulation with a plot of heliostat reflectivity.

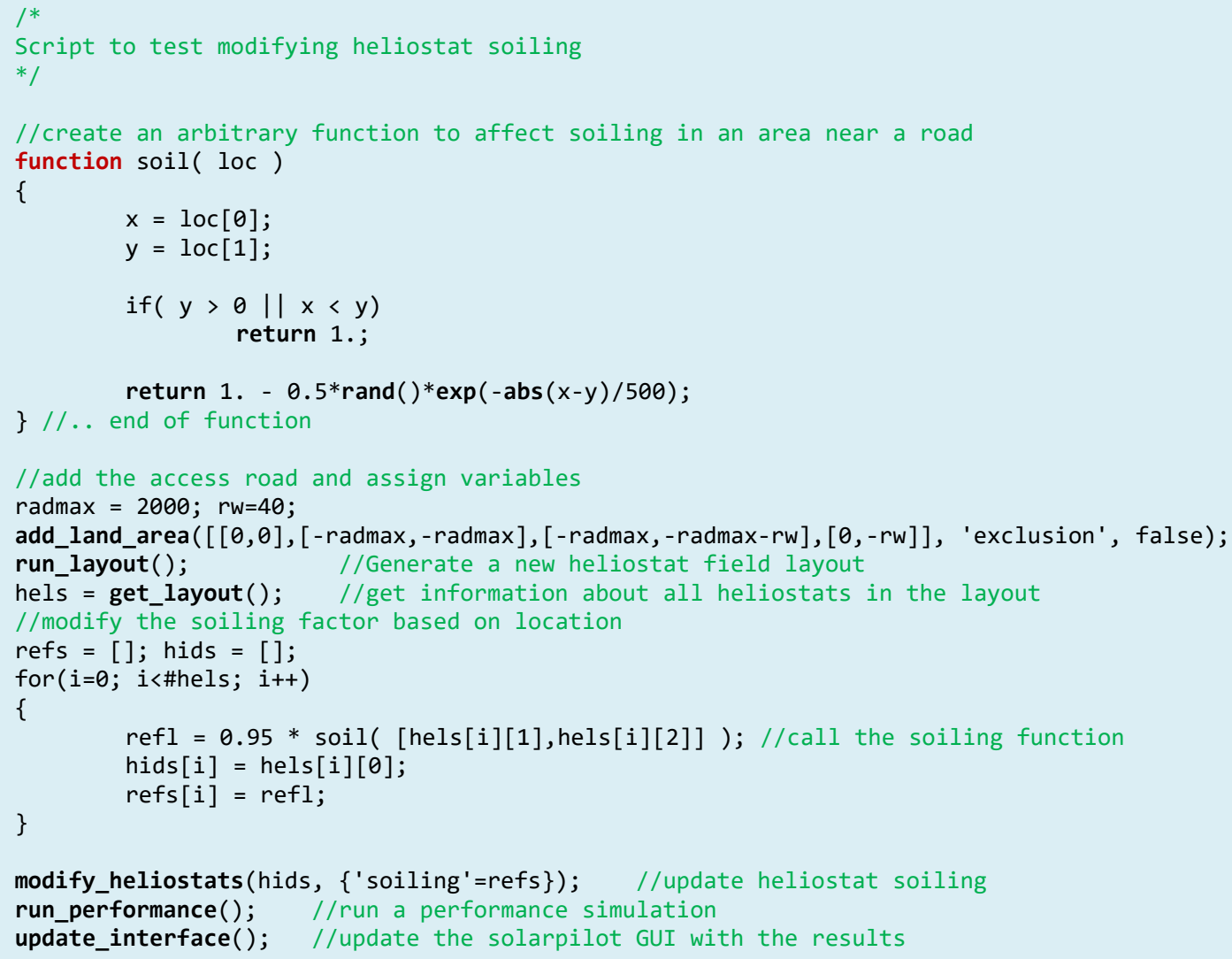

Figure 14: Sample LK script used to calculate and assign soiling near an access road.

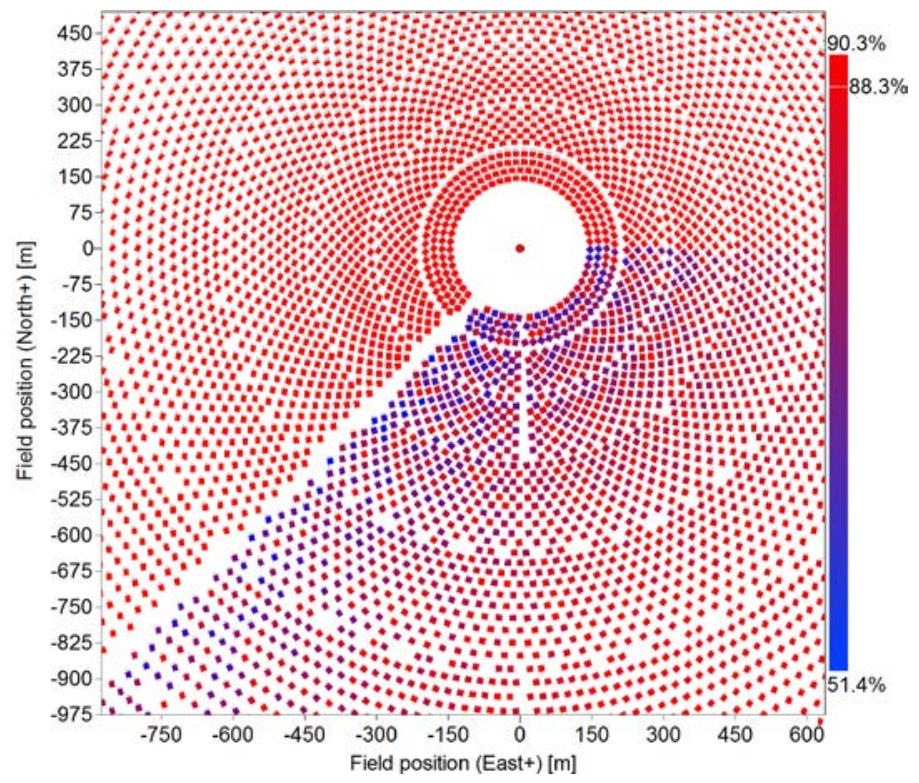

Figure 15: Reflectivity plot for heliostats with soiling applied by LK script. 


\section{Case study: selecting and modifying heliostats using scalable graphics}

Scalable vector graphics (SVG) files provide a systematic means of defining paths using lines, arcs, 2- and 3-point Bezier curves, and other path structures. Various external software packages are capable of generating SVG files, most prominently Adobe Photoshop ${ }^{\circledR}$ and InkScape. In this example, consider a heliostat field subject to passing clouds. The outline of the cloud can be measured and represented as a path in SVG format, and the cloud's shadow has an opacity of $80 \%$. We seek to determine the performance impact of the passing cloud on the solar field using LK scripting. Figure 16 and Figure 17 illustrates the implementation of this exercise.

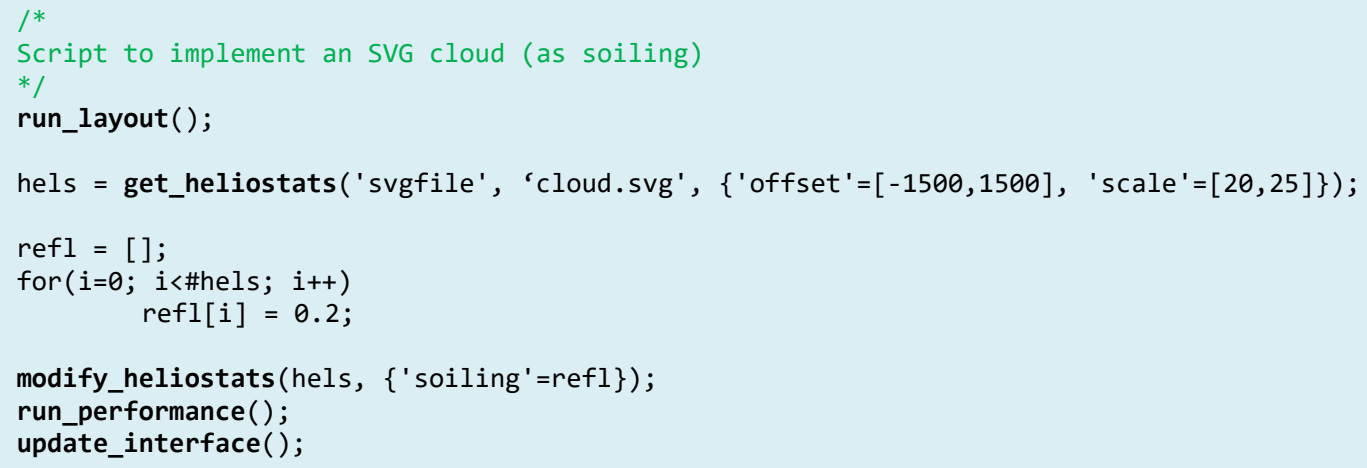

Figure 16: LK script implementing the SVG cloud case study.
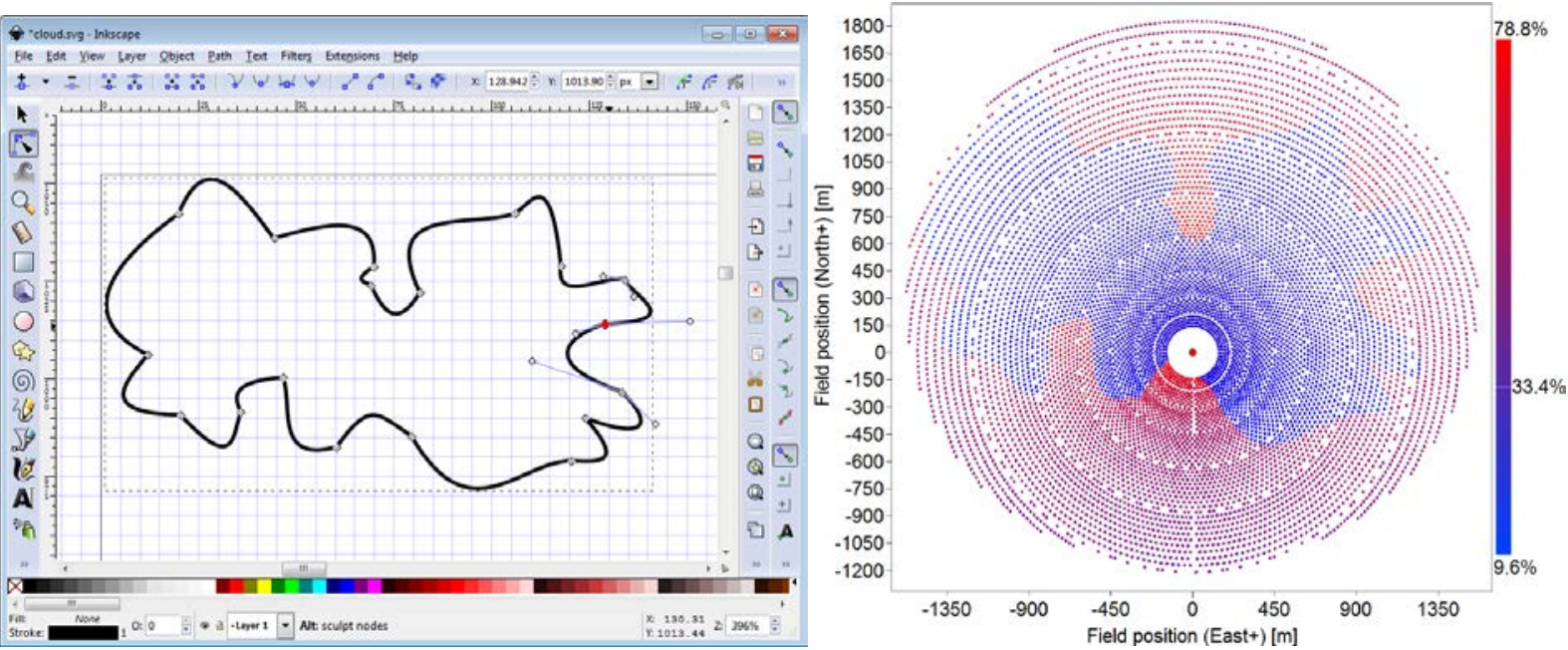

Figure 17: SVG path drawn in InkScape and imposed as a cloud in SolarPILOT.

\section{Open-Source Code Release of SolarPILOT and SolTrace}

In project year three, NREL transitioned SolarPILOT ${ }^{\mathrm{TM}}$ and SolTrace optical modeling tools from their current package-release format into open source software (OSS). This approach offers several benefits, namely, OSS (i) increases interest by engaging users in the creation and improvement in the project, (ii) provides substantial transparency by exposing underlying algorithms and capabilities, (iii) relieves the software maintenance burden placed on NREL and DOE, (iv) takes advantage of CSP community knowledge in constructing new features or fixing bugs, ( $v$ ) ensures that the software can live on beyond the loss of key staff or through reprioritization of funding, and (vi) preserves a detailed, 
public record of the software development process. One aspiration of OSS is to provide a hub for development of CSP optical models, whereas prior model development has been scattered and duplicative.

\section{Open-source platform}

The selection of OSS platform is an important choice that will dictate much about the workflow and community involvement for the project. One key aspect of OSS is revision control - which defines a formal system that records and annotates the state of the code and documentation over time. Revision control systems can operate in different ways, but the most prevalent ones provide common functionality such as management of a central "master" repository, procedures for modifying the code, tools for conflict resolution should users introduce incompatible code, logs of changes made over time, and the ability to "checkout" historical versions of the code. The two most common version control systems are Apache ${ }^{\mathrm{TM}}$ Subversion ${ }^{\circledR}$ and Git, with Git-based platforms in use by nearly 9 in 10 developers. Git was selected as the deployment version control system.

Git provides a system for developing code, but it does not serve as a platform (i.e., a web service). Several software development platforms are available, including Github.com, Bitbucket.org, Gitlab.com, or enterprise-hosted services. In addition to hosting the code and Git software, these sites provide tools for team communication, identifying and describing issues or sub-projects, downloading code, creating project wikis, etc. NREL maintains a repository library with a paid subscription at github.com/NREL, which provides various projects with the ability to develop code in public or private mode, control membership groups, track usage and contribution statistics, and take advantage of other features. Hence, the natural choice for this project is to also host the code on Github alongside other related projects, including SAM, SSC, WEX, and LK.

The SolTrace and SolarPILOT codes were originally developed using Subversion repositories (repos) hosted on an NREL server. In year three, the code for both projects was transitioned to Github at url's https://github.com/NREL/SolTrace and https://github.com/NREL/SolarPILOT, respectively. These were created as private repos with access only granted internally to NREL developers. The goal of the work was to fully transition the code to OSS, provide detailed instructions on building for different operating systems, document the project structure, and clean up vestigial code and extraneous comments.

\section{Github implementation: Organization}

Both SolTrace and SolarPILOT are dependent on other projects, which means that users must first download and compile those dependencies. These are summarized in Table 16. SolarPILOT is organized such that the code for the user interface, scripting, and help documentation is contained within the main SolarPILOT repository, while the underlying computation and layout algorithms are contained within the SAM simulation core (SSC). This convention is most convenient for use of the layout algorithms within SAM and prevents duplication of the code bases for the two projects. Other SSC functionality is required for SolarPILOT (e.g., weather file processing). 
Table 16: Project dependencies for SoITrace and SolarPILOT. Checkmarks indicate dependence on the project. Note that SolarPILOT is also dependent on SolTrace.

\begin{tabular}{|c|c|c|c|c|}
\hline Library & Description & Subdependencies & SolTrace & SolarPILOT \\
\hline WXWIDGETS & $\begin{array}{l}\text { Graphical interface development } \\
\text { toolkit }\end{array}$ & & $\checkmark$ & $\checkmark$ \\
\hline LK & Scripting library & wxWidgets & $\checkmark$ & $\checkmark$ \\
\hline WEX & Extensions to wxWidgets & wxWidgets, LK & $\checkmark$ & $\checkmark$ \\
\hline $\begin{array}{l}\text { GOOGLE } \\
\text { TEST }\end{array}$ & Automated code testing & & & $\checkmark$ \\
\hline SSC & SAM simulation core & $\begin{array}{l}\text { wxWidgets, WEX, } \\
\text { LK, Google Test }\end{array}$ & & $\checkmark$ \\
\hline SOLTRACE & Raytrace simulation engine & (noted) & & $\checkmark$ \\
\hline
\end{tabular}

Documentation and Wiki

While the organization of the project is intended to be intuitive, some documentation is required to instruct users on how to quickly compile the code, prepare dependencies, and contribute their material. Each project contains a "readme.md" ('md' for markdown) file that serves as a starting point for new users or a quick reference for those already familiar with the project. The readme provides a quick overview of build steps and dependencies, provides links to more detailed documentation, and gives a high-level description of the project.

Other files include the "contributing.md" and "license.md." The former states the procedure and requirements for contributing new code or fixing bugs, and the latter describes conditions of use for the code. Both topics are discussed in more detail below. Github also provides a wiki service for each project that can be used to provide more extensive documentation. Both SolTrace and SolarPILOT have wikis that contain detailed build instructions for all platforms, additional information on contributing, and usage of related projects. The wiki's can be maintained or expanded by users in the future in accordance with changes to the code.

\section{Tracking Use and Contributions}

Github provides several handy tools for tracking the projects. Code downloads, "clones" (downloading the repository via the Git client), "forks" (copies made with the intention of spawning a new derivative project), number of contributors, contribution statistics (lines of code created/deleted, frequency and timing of commits), and other interesting information is readily available through the Github project website. These data give insight into who is using the code and which aspects of it are particularly productive or ripe for future research.

\section{Parallel development}

Collaborative code development allows contributors to work separately and merge changes or additions. The general process entails (i) cloning the code from the server onto the user's local machine, where a full copy of the code exists independently of the server, (ii) making changes to the local code over some period of time, (iii) committing the code, in which changes are logged by Git on the local machine, and (iv) pushing the commits back to the server, effectively publishing them such that others can access them. Once commits have been pushed and are available, other users can pull from the server and incorporate those changes into their local copies of the code. 
This process works well for continuous development, but commits are intentionally incremental, providing incomplete functionality or inadvertently introducing bugs into the software. To handle human error and the piece-wise development process, we adopt a common procedure that maintains a stable code version, an in-flux but functional development version, historical version placemarks, and in-progress feature development versions. Git enables these permutations without duplicating the code base with branching, which takes its name from the analogy of tree branches. A contributor creates a branch when developing new code or undertaking bug fixes. As the development progresses, changes are committed to the branch. Other branches are not affected by the commits. Once the new feature or bug fix has been fully developed and tested, the branch is merged back into the main code and the changes are available to all users who wish to begin their own branches.

Two special branches are maintained, namely the "master" and "develop" branches. The "master" branch represents the stable version of the software and is only updated to include new commits at the time of a release. The "develop" branch is the main area for

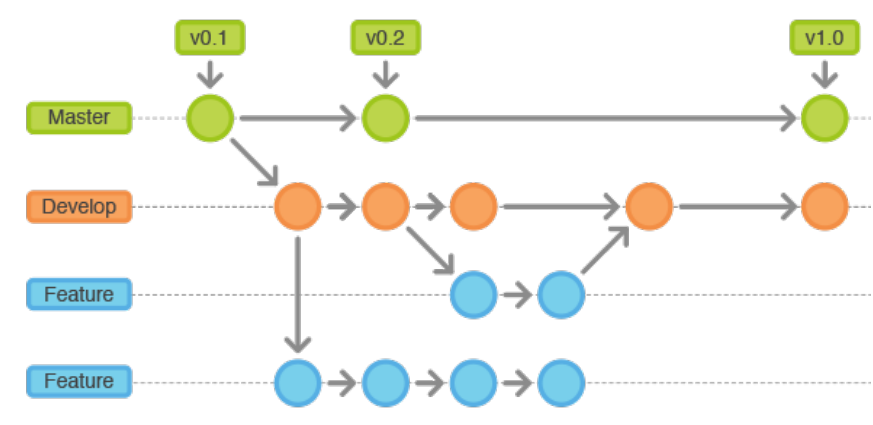

Figure 18: Example of the branching scheme. Each dot represents a commit. new development; users wishing to add features create a branch that is an offshoot of "develop," and merge completed code back into it. Figure 18 shows an example of this scheme with two active feature branches. Furthermore, major versions are tagged, allowing any user to go back and access the code as it existed in the past. This is particularly useful for providing patches to existing versions or investigating changes in software output between versions.

\section{Contributing}

Contributors to the code follow a process that is designed to facilitate high-quality software and rigorous tracking. Contributors are also required to agree to NREL's terms, relinquishing certain intellectual property (IP) rights and submitting to the licensing agreement. The agreement states:

I agree to contribute to SolarPILOT. I agree to the following terms and conditions for my contributions: First, I agree that I am licensing my contributions under the terms of the current SolarPILOT license. Second, I agree that, in order to conform to any future open source software license(s) under which SolarPILOT may be provided, the terms of my license may be modified without any notice to me and without my consent. Third, I represent and warrant that I am authorized to make the contributions and grant the license. If my employer has rights to IP that includes my contributions, I represent and warrant that I have received permission to make contributions and grant the required license on behalf of my employer.

Contributors need to prepare their machine to use Git and obtain the code as follows:

- Install the Git client on the local machine 
- Clone SolarPILOT or SolTrace and all dependencies to create local copies of the code on the machine

- Build each project. This requires a C++ compiler like GCC or Visual Studio.

The process for contributing is as follows:

- Use the Git client to move to the branch or revision that is the starting point for the contribution

- Create a new branch

- Create a new issue on the Github site, describing the feature or bug fix to be added, the timeline for the changes, and any other notes that might help others assist on the project. The notes serve as documentation.

- Make changes and commit them

- Once changes are tested, create a pull request on the Github webpage. This notifies the NREL reviewers that code is available to merge back into the project. NREL will undertake a review to determine whether the contribution is suitable and meets the software standards. If so, the change is merged. Otherwise, the pull request is closed, or revisions are suggested.

- A successful merged pull request also closes the associated issue that was created on Github. The branch that was created is deleted.

This process ensures multi-party review and allows NREL to maintain control over the software, even with contributions coming from various external sources.

\section{Debugs and Other Code Improvements}

In addition to the OSS transition, several noteworthy improvements were made to SolarPILOT during year three. The first improvement resolves a longstanding issue present on Linux-based systems that caused the interface to occasionally freeze. The issue was pervasive enough to prevent Linux users from adopting the software. In part due to the OSS transition, we were able to identify the problem and resolve it, and Linux systems now have a comparable tool to Windows users.

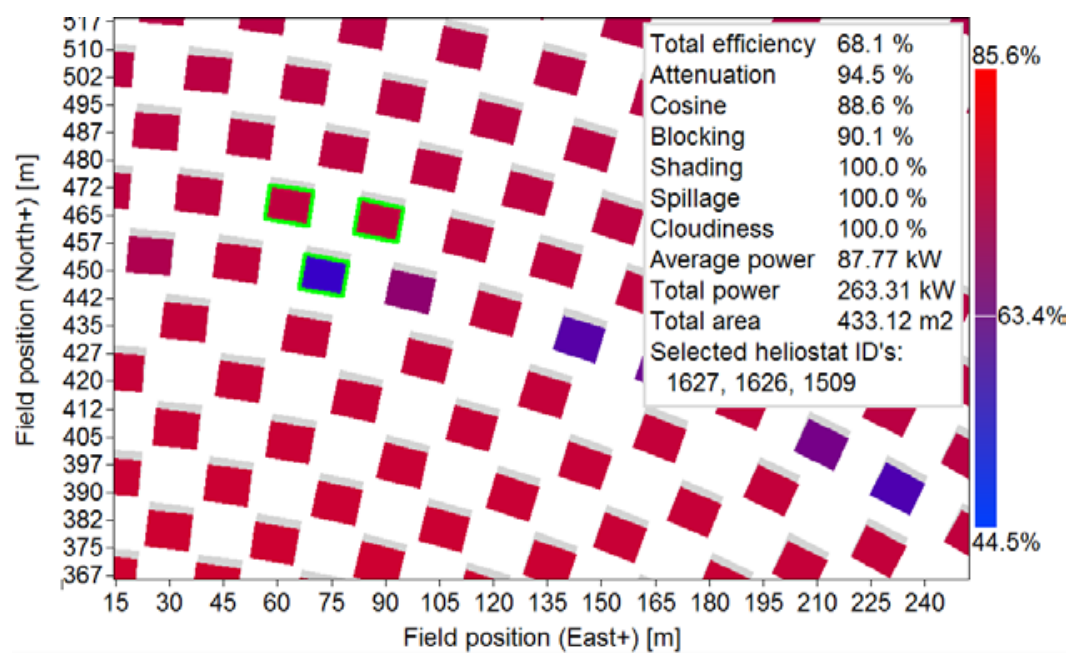

Figure 19: Demonstration of heliostat selection functionality in SolarPILOT.
The second improvement is the development of individual heliostat information reporting dialog on the heliostat field plot. Previously, users who sought information on individual heliostats were required to export data to a text file and search to find the heliostat of interest. In the latest version, we have added the ability to right-click any number of heliostats to display statistics that may be useful to designers, as shown in Figure 19. Selected heliostats can furthermore be removed from the layout using controls on 
the plot page. If desired, removed heliostats can later be restored. This provides improved control and important information using mouse and keyboard functionality.

Lastly, an information webinar was given on July 18, 2018 to document the use and utility of the OSS versions of SolTrace and SolarPILOT. That video can be accessed at the NREL's SAM website at https://sam.nrel.gov/webinars.

\section{Task 4. Thermal-Application Modeling Tools for SAM}

\section{Validation of New Solar Industrial Process Heat (IPH) Models in SAM - Trough Model}

The new thermal-application (i.e., solar IPH) models developed for SAM were validated against existing models and field data during project years one and two. The trough model was first checked by comparing the old $\mathrm{C}++$ code with the new thermal-application code. The new thermal-application code was successfully debugged and the simulation results in the new code agreed with those in the old code within $0.001 \%$, indicating that the only difference between models is due to numerical precision.

Confirmation that the new thermal-application code agrees with the former code is significant because the former code has been validated against data from FLABEG's Ultimate Trough loop at SEGS VIII (Zhu and Neises 2015). Zhu \& Neises compared NREL's SAM model to FLABEG's theoretical model and found the maximum difference between the NREL model and the FLABEG model to be less than $1.2 \%$. The thermal efficiency predicted by FLABEG's theoretical model agreed with the measured thermal efficiency within the $95 \%$ confidence level. Thus, it may be inferred that SAM's trough model matched the experimental data with less than $10 \%$ error as required for PEC 1.4.

This analysis demonstrated that the new thermal-application trough code matched the previously validated output from the solar field predictions made in Zhu \& Neises 2015. A comparison of the new and previous model results is shown in Figure 20, which indicates excellent agreement between the two codes. Occasionally, subtle differences in a decision variable can fall on a different side of a controller decision, which can result in the model solving for a different plant operating mode (e.g., shut down rather than operate in the next hour). This is the cause of the few larger deviations in the temporal data seen in Figure 20. These variations balance over the annual simulation; the difference in the annual cumulative data was $0.04 \%$. 


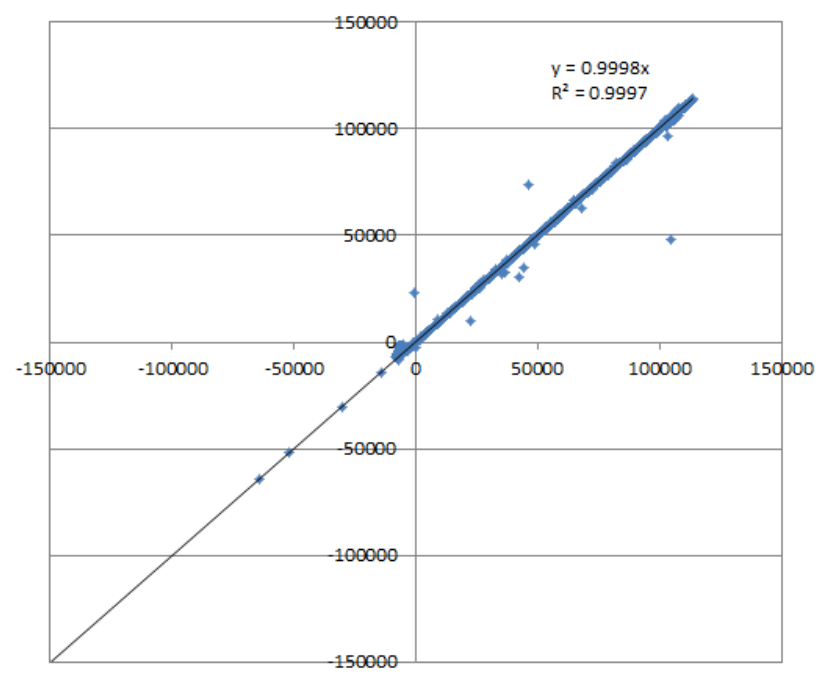

Figure 20. Hourly thermal-energy generation comparison of existing SAM trough model versus new thermal-application model code for an annual simulation. Perfect agreement would plot a $45^{\circ}$ line.

Field data for model validation was obtained for Enel Green Power's Stillwater, Nevada Solar/Geothermal hybrid plant. This plant has $24,780 \mathrm{~m}^{2}$ of SkyFuel SkyTroughs used to preheat geothermal brine. Data from the Stillwater solar field allows one to examine the model's match to daily, transient energy outputs. NREL generated a SAM case file to match the physical conditions (trough, receiver and loop dimensions, HTF properties, design operating temperatures, etc.) of the Stillwater solar field. The thermal-energy output from this model was compared to data from the operating plant using local DNI values and operating conditions from the plant (mass flows, temperatures, and pressures) on 30-minute intervals for 58 consecutive days in 2015. The analysis used a satellite weather file for Stillwater, but substituted ground-measured DNI, temperature and wind speed data for the days in question. Comparison of model to data was then made for the 58 -day period. The summary results are shown in Table 17, which indicates good agreement with the data and achievement of the PEC 1.4 metric. The amount and quality of data for this site allowed the team to avoid resorting to stochastic estimates for system parameters.

Table 17. Validation comparison of HTF-Trough model and Stillwater data based on $\mathbf{5 8}$ days of data.

\begin{tabular}{|c|c|c|c|}
\hline $\begin{array}{c}\text { Stillwater thermal energy } \\
\text { output }\left(\mathbf{M W h} \mathbf{h}_{\mathrm{t}}\right)\end{array}$ & $\begin{array}{c}\text { SAM thermal energy } \\
\text { output }\left(\mathbf{M W h} \mathbf{h}_{\mathrm{t}}\right)\end{array}$ & Difference & Comments \\
\hline 4,832 & 4,919 & $+1.8 \%$ & $\begin{array}{c}\text { Meets PEC } 1.4 \text { target of } \\
<10 \% \text { deviation }\end{array}$ \\
\hline
\end{tabular}

While the cumulative data for the 58-day period showed good agreement, there were discrepancies in the 30-minute temporal data. Figure 21 depicts the simulation results for a week in late March. SAM generally follows the trends well, but one can note periods where SAM's prediction deviates from plant operations. Plant startup/shutdown behavior on March 30 and 31 appear to be due to operating decisions outside of weather considerations. 


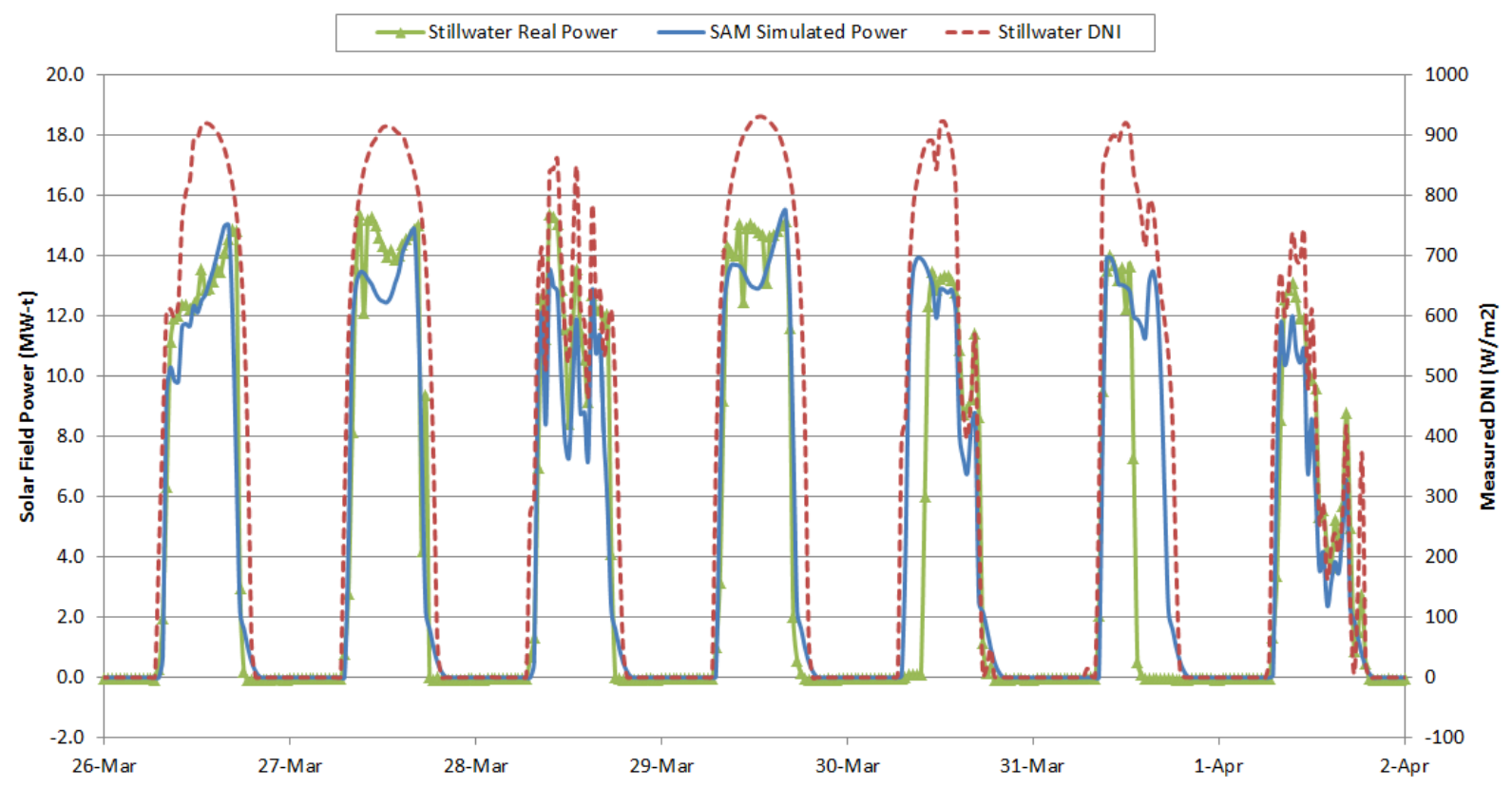

Figure 21. Comparison of Stillwater plant data and SAM simulation for one week in late March.

Of greater interest is SAM's ability to track startup and shutdown behavior based on energy considerations alone. Figure 22 highlights two cloudy days in March. SAM follows the overall trends well, but the match for individual time steps is not always accurate. This manifests itself in a large error when one examines the RMS error for the temporal data. The RMS value for the 58-day period was $2.2 \mathrm{MW}_{\mathrm{t}}$, which represents $14 \%$ of the design point power rating while the cumulative error was less than $2 \%$, as noted in Table 17 .

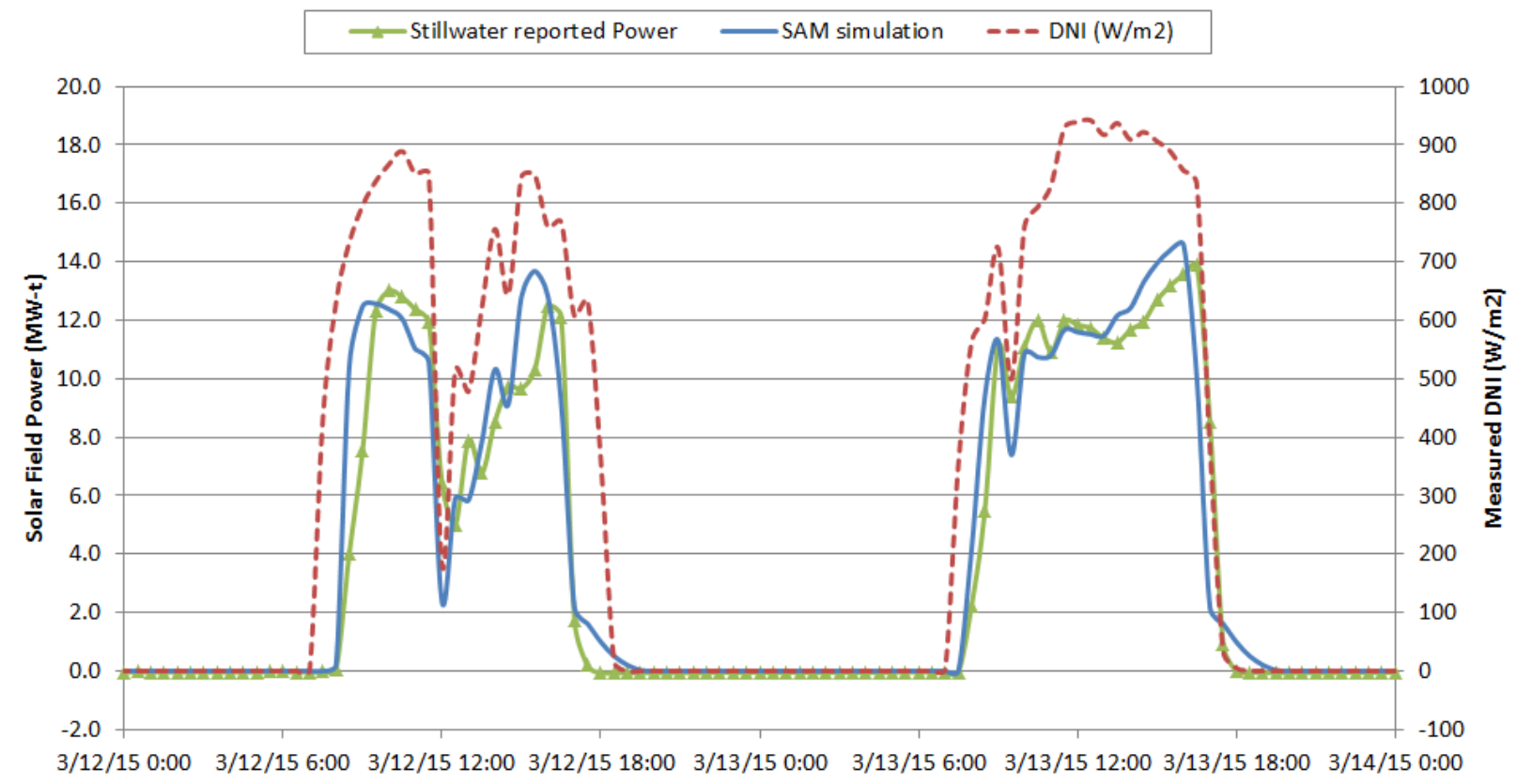

Figure 22. Comparison of Stillwater plant data and SAM simulation on two partly cloudy days. 


\section{Validation of New Solar IPH Models in SAM - Direct Steam Generation (DSG) Model}

Working with Tubosol, who are the plant operators of the Puerto Errado 2 (PE-2) plant in Calasparra, Spain, NREL received and processed operational data of the entire $150 \mathrm{MW}$ solar field (Novatec Solar 2011), for the month of June 2015. The data for the solar field (made up of 28 rows in total), is at 1-second intervals, and is split into two equal segments (PE-2.1 and PE-2.2), each segment being approximately $75 \mathrm{MW}$. This resolution of data allowed for in-depth observation of the behavior of the solar field, both in normal and transient operation. The parallel solar field segments allow PE-2 to divert steam from both solar fields to one $15 \mathrm{MW}$ turbine in winter, rather than generating electricity from both $15 \mathrm{MW}_{\mathrm{e}}$ turbines at part load due to a lack of solar radiation. This leads to greater overall efficiency.

Each independent solar field segment has the specifications shown in Table 18 (Novatec Solar 2011), which have been used for the SAM DSG model validation. It was decided because each segment can be operated independently that the validation would be done only on one solar field segment. A weather file which uses data from the site for DNI and ambient temperature was created for the validation.

Table 18. Data used for the SAM DSG validation of the PE-2 solar field segment

\begin{tabular}{|l|c|l|}
\hline Parameter & Value & Unit \\
\hline Product name & Nova-1 & NA \\
\hline Number of rows in solar field & 14 & $\mathrm{NA}$ \\
\hline Solar field length & 940 & $\mathrm{~m}$ \\
\hline Aperture area & 151,000 & $\mathrm{~m}^{2}$ \\
\hline Operating Temperature & 270 & ${ }^{\circ} \mathrm{C}$ \\
\hline Operating Pressure & 55 & bar \\
\hline Peak Thermal Output $\left(\mathrm{MW}_{\mathrm{t}}\right)$ & 75 & $\mathrm{MW}_{\mathrm{t}}$ \\
\hline
\end{tabular}

The validation of the DSG process heat model was done by comparing the predicted thermal energy from the SAM model with the plant data from the PE-2 solar field segment. PE-2 is an electric power plant, and the data did not provide a direct measurement of the solar-thermal power output from the solar field. Outlet temperature and mass flow rate are known, but steam quality cannot be easily measured, thus the exiting enthalpy is not directly measured. Steam quality is the ratio of steam mass to total mass in a two-phase, water/steam system. Unlike the validation of the SAM liquid-HTF trough model, where the solar field thermal output was directly measured and compared to the SAM solar field thermal output, this was not possible for the DSG model validation. While SAM can undertake sub-hourly simulations, an annual dataset is required. As such, 1-s data are computationally burdensome, and the PE-2 solar field data were averaged to 10-min intervals.

The solar field segment output data from PE-2 consists of pressure, temperature and mass flow rate of the combined water/steam fluid. As noted above, the steam quality and enthalpy are unknown at each timestep. To calculate the solar field thermal power output each 10-min timestep, the steam quality is estimated in two ways (identified as Case 1 and Case 2). 
Case 1: A constant steam quality of 0.748 was determined from the design-point conditions obtained from PE-2 (Novatec Biosol 2011) and used to calculate the enthalpy at each 10-min step.

Case 2: The varying steam quality is estimated from the steam drum level given in the operations data at every timestep. The steam drum level, as confirmed with Tubosol, is a measure of the steam and water mix in the steam drum, where the steam drum separates the remaining water in the fluid from the steam produced by the solar field. The calculated enthalpy is multiplied by the mass flowrate to obtain an approximate value of thermal power delivered by the solar field. This estimated thermal power is then compared with the one predicted by the SAM simulation. This is potentially a more accurate depiction of time-dependent steam quality.

There are differences between the way the SAM DSG model predicts the solar field operation compared to the way the real PE-2 solar field operates. Therefore, in order to make a more realistic comparison, a couple of constraints are added for Case 2:

i. The solar field has hot fluid in the field during the night periods (as well as the day), and the thermal energy can theoretically be calculated during this time. However, as no thermal power from the field is delivered during the night to generate steam for the steam turbine, the solar field thermal power output from $9 \mathrm{pm}$ to 6 am is ignored.

ii. Time periods when sunlight is available, but PE-2 is not running for other reasons, are excluded from the SAM comparison. Figure 23 shows a plot of such a situation, where the thermal power predicted by the SAM model is shown against the real estimated solar field thermal power output. It can be seen the estimated solar field thermal output was barely present during the day (e.g. the green line), even though there was sufficient DNI for SAM to predict some thermal power generation. The thin blue line represents the SAM simulated power. As can be seen in Figure 23, due to the DNI variations (e.g. perhaps due to several clouds that day), the model responded to the spikes in DNI with a considerable power production, whereas the estimated real output was nearly zero through the day. Hence, the simulated thermal power for days like these were ignored, as operational decisions made at site cannot be simulated or accounted for in the DSG model. The startup constraints used in the DSG model are being explored as a means to address some of this issue. 


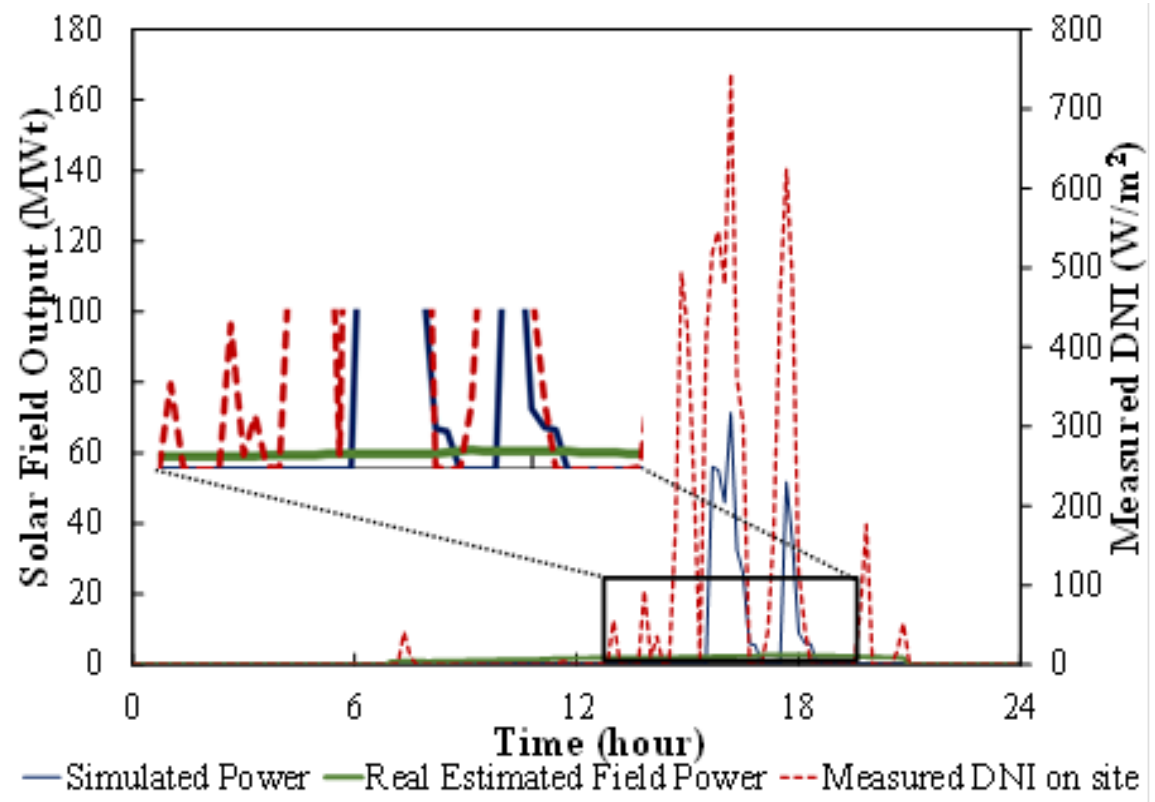

Figure 23. Comparison of the SAM-estimated output and the PE-2 solar field output on a day with transients, and showing the need for a constraint to exclude the SAM output when the estimated real output was minimal

Table 19 shows the comparison between thermal energy generation predicted by the SAM DSG model and that estimated using real field data (for both the constant and variable steam quality cases).

Table 19. Comparison of the thermal energy generated between the real PE-2 solar field section and the SAM-simulated solar field, for the cases of constant and varaible steam quality (Case 1 and Case 2 respectively). Analysis covers the month of June 2015.

\begin{tabular}{|c|l|c|c|c|c|}
\hline Case & \multicolumn{1}{|c|}{ Condition } & $\begin{array}{c}\text { PE-2 estimated } \\
\text { thermal energy of } \\
\text { solar field (MWh) }\end{array}$ & $\begin{array}{c}\text { SAM thermal } \\
\text { energy of solar } \\
\text { field (MWh) }\end{array}$ & $\begin{array}{c}\text { Difference } \\
\text { (MWh) }\end{array}$ & $\begin{array}{c}\text { Diff. } \\
\text { (\%) }\end{array}$ \\
\hline $\mathbf{1}$ & $\begin{array}{l}\text { Constant steam quality at } \\
\text { design conditions }\end{array}$ & 141,105 & 126,534 & 14,571 & -10.3 \\
\hline $\mathbf{2}$ & $\begin{array}{l}\text { 2.1: Estimated variable steam } \\
\text { quality }\end{array}$ & 130,864 & 126,534 & 4,330 & -3.3 \\
\hline & $\begin{array}{l}\text { 2:2: Estimated variable steam } \\
\text { quality with constraints }\end{array}$ & 127,082 & 126,128 & 954 & -0.8 \\
\hline
\end{tabular}

As can be seen in Table 19, with constant steam quality (Case 1), the PE-2 estimated thermal energy generated for June 2015, was approximately $141,100 \mathrm{MWh}$, compared to approximately $126,500 \mathrm{MWh}$ from the SAM simulation. In other words, the SAM thermal output was approximately $10.3 \%$ less than the real estimated value. Case 1 can be considered an oversimplification, as there will be a varying steam quality produced by the real PE-2 solar field segment. Discussions with Tubosol confirmed that the steam quality can vary from $70-80 \%$ dependent on the DNI conditions. In Case 2 from Table 19, when variable steam quality is calculated for the PE-2 solar field, the estimated solar thermal energy generated was $130,800 \mathrm{MWh}$ compared to the simulated output of $126,500 \mathrm{MWh}$ 
(Case 2.1). The difference in the energy generated between the SAM-simulated solar field and PE-2 is approximately $-3.3 \%$. When the constraints are added, the difference between the PE-2 thermal energy and the SAM output drops to $0.8 \%$. Both scenarios meet the success metric of being within $10 \%$ of real DSG solar thermal field output. Further work might explore the settings of SAM's startup constraints to better match with the behavior seen at PE-2 rather than apply a constraint on SAM output purely to match PE-2 behavior.

Figure 24 shows the comparison between the SAM simulation (blue) and the estimated PE-2 thermal power output, on days that had significant DNI variation (left), and a single transient in an otherwise very sunny day (right). The validation of the DSG SAM model was also presented in a conference in 2017 (Kurup et al. 2018).
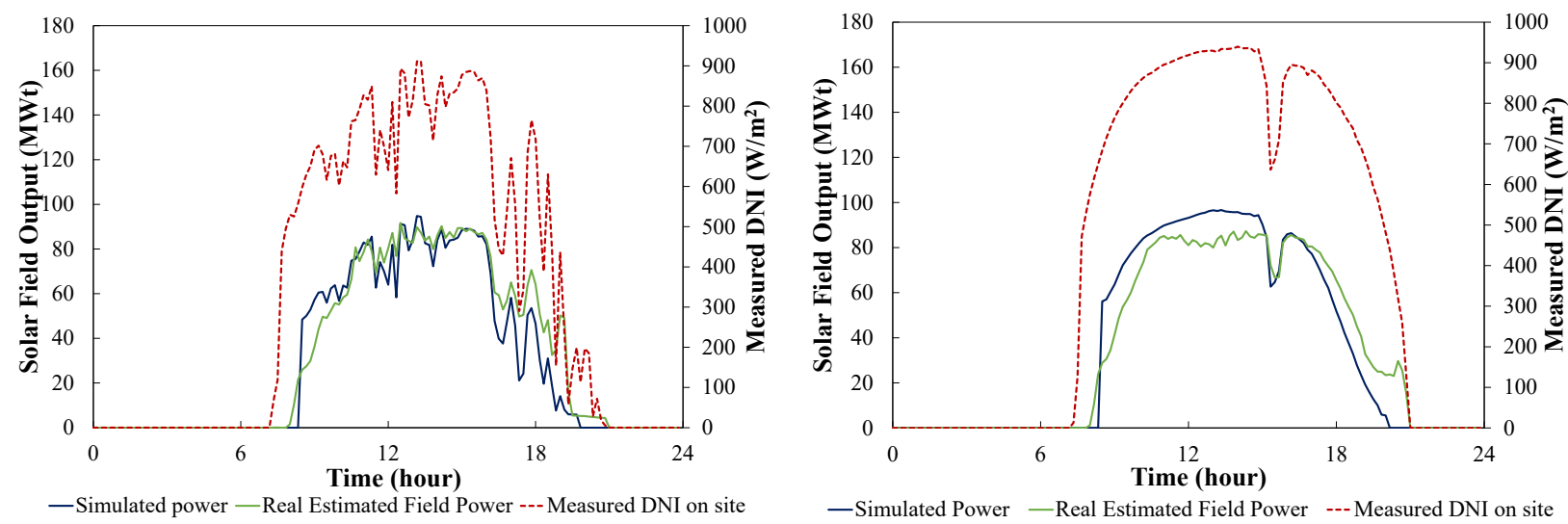

Figure 24. Comparison of SAM-simulated solar field power output and real estimated output on days with significant variation in DNI (e.g. a cloudy day, left image), and a clear sunny day with one fast transient (right image)

\section{Process Heat Collectors Review}

Direct use of solar thermal energy (e.g. through non-concentrating and concentrating technologies) for IPH is a simpler application than for electric power production (C. Turchi, Kurup, and Zhu 2016). The heat can be used with little conversion loss, avoiding the heatto-electricity losses associated with using CSP for electricity production. For industrial and commercial sites, renewable heat for IPH has been rare in the United States.

The obvious competition for solar IPH within the United States is natural gas, and prior analysis indicates that solar collector cost reduction is required to provide solar heat at a competitive price for industrial processes such as sterilization, material drying, or thermal desalination (Kurup and Turchi 2015a; C. Turchi, Kurup, and Zhu 2016). In most of these IPH applications heat delivery via saturated steam is desired. Steam generated from solar collectors can either be made in the solar field itself, i.e. direct steam generation (DSG), or the more traditional approach where an HTF from the solar field (e.g. synthetic oil or pressurized water) transfers heat to a boiler through a heat exchanger. For solar IPH, the delivery of steam through DSG decreases complexity to the end-user and removes potentially high-cost capital items such as an organic HTF and boiler.

Solar IPH with the concentrating collectors designed for power generation applications can supply heat at temperatures exceeding $400^{\circ} \mathrm{C}$, which is significantly in excess of typical process heat requirements (Kurup and Turchi 2015a). Large collectors such as the 
SkyTrough, EuroTrough, and Ultimate Trough (Adrian Farr 2009; Kurup and Turchi 2015b), have been optimized for power production at $400^{\circ} \mathrm{C}$ and higher; however, deploying these large-aperture designs for smaller scale IPH applications can be problematic. Consequently, several companies have developed and are marketing small concentrating collectors designs for solar IPH applications.

Specific solar IPH collectors are reviewed that exhibit the ability to install on roofs or small ground areas near an end-user, instead of the larger scale power generation CSP collectors common with CSP electricity generation projects. Typically, the size of the solar field will be constrained for solar IPH applications, and it is unnecessary to deploy such large collectors for typical IPH steam conditions. This review of concentrating solar IPH collectors is not exhaustive but represents known and active solar technology developers. The first section will look at liquid-HTF troughs and linear-Fresnel, followed by DSG troughs and linear Fresnel. Table 20 shows a summary of the solar IPH collectors and companies highlighted in this review.

Table 20. Summary table of the solar IPH collectors and companies as of Jan. 2019.

\begin{tabular}{|c|c|c|c|c|c|}
\hline Technology & $\begin{array}{l}\text { Name of } \\
\text { Company }\end{array}$ & $\begin{array}{l}\text { Founding } \\
\text { Country of } \\
\text { Company }\end{array}$ & $\begin{array}{l}\text { Main markets } \\
\text { technology is } \\
\text { deployed or } \\
\text { planned in }\end{array}$ & $\begin{array}{l}\text { Applications/inte } \\
\text { grations for the } \\
\text { technology }\end{array}$ & $\begin{array}{l}\text { Number of installations or } \\
\text { capacity installed if known }\end{array}$ \\
\hline \multirow{9}{*}{$\begin{array}{l}\text { Liquid-HTF } \\
\text { Trough }\end{array}$} & Rackam & Canada & $\begin{array}{l}\text { Canada, Brazil, } \\
\text { Spain, USA }\end{array}$ & $\begin{array}{l}\text { Solar IPH e.g. for } \\
\text { paper and pulp, } \\
\text { sludge drying }\end{array}$ & $\begin{array}{c}\text { Approximately } 7 \\
\text { installations in Canada, } \\
\text { Brazil, Spain and USA ( } 6 \\
\mathrm{MW}_{\text {th }} \text { in total) }\end{array}$ \\
\hline & Heliovis & Austria & Spain, MENA & $\begin{array}{l}\text { Solar IPH e.g. } \\
\text { food processing }\end{array}$ & $\begin{array}{c}1 \mathrm{MW}_{\text {th }} \text { installed in Spain, } \\
\text { similar project planned in } \\
\text { MENA }\end{array}$ \\
\hline & Sunvapor & USA & USA & $\begin{array}{l}\text { Solar IPH e.g. } \\
\text { food processing }\end{array}$ & $\begin{array}{c}\text { Planned 1-MW } \mathrm{MW}_{\text {th }} \text { for } \\
\text { California food processor }\end{array}$ \\
\hline & NEP Solar & Australia & $\begin{array}{l}\text { Switzerland, } \\
\text { Australia }\end{array}$ & $\begin{array}{l}\text { Solar IPH e.g. } \\
\text { food processing }\end{array}$ & $\begin{array}{c}\text { Approximately } 3 \text { sites in } \\
\text { Switzerland } \\
\end{array}$ \\
\hline & Lucida & Turkey & $\begin{array}{l}\text { Jordan as first } \\
\text { for first } \\
\text { commercial } \\
\text { plant }\end{array}$ & Solar IPH & $\begin{array}{l}\text { Only demos installed, first } \\
\text { commercial project in } \\
\text { Jordan of } 990 \mathrm{~kW}_{\text {th }}\end{array}$ \\
\hline & $\begin{array}{l}\text { Inventive } \\
\text { Power }\end{array}$ & Mexico & Mexico & $\begin{array}{c}\text { Solar IPH e.g. for } \\
\text { food processing, } \\
\text { hotel }\end{array}$ & $\begin{array}{l}\text { Estimated } 40 \text { installations } \\
\text { in Mexico }\end{array}$ \\
\hline & Absolicon & Sweden & $\begin{array}{c}\text { Sweden, } \\
\text { Austria, China } \\
\text { and Greece }\end{array}$ & Solar IPH & $\begin{array}{l}\text { Approximately } 7 \\
\text { installations }\end{array}$ \\
\hline & Artic Solar & USA & USA & $\begin{array}{l}\text { Solar IPH e.g. } \\
\text { food processing }\end{array}$ & Approximately 3 sites \\
\hline & Ultra Lite Solar & Canada & $\begin{array}{l}\text { USA, Canada, } \\
\text { MENA }\end{array}$ & $\begin{array}{l}\text { Solar IPH e.g. } \\
\text { desalination }\end{array}$ & Only demos installed. \\
\hline \multirow{3}{*}{$\begin{array}{l}\text { Liquid-HTF } \\
\text { Linear } \\
\text { Fresnel }\end{array}$} & $\begin{array}{c}\text { Skyven } \\
\text { Technologies }\end{array}$ & USA & USA & Solar IPH & No installation yet \\
\hline & Hyperlight & USA & USA & $\begin{array}{l}\text { Solar IPH and } \\
\text { geothermal } \\
\text { hybrids }\end{array}$ & 0.5 acre demonstration \\
\hline & Heliac & Denmark & Denmark & $\begin{array}{l}\text { Solar IPH e.g. for } \\
\text { district heating }\end{array}$ & $2-\mathrm{MW}_{\text {th }}$ demonstration \\
\hline
\end{tabular}




\begin{tabular}{|c|c|c|c|c|c|}
\hline \multirow[t]{2}{*}{ DSG Trough } & GlassPoint & USA & $\begin{array}{l}\text { Oman, Kuwait, } \\
\text { California }\end{array}$ & $\begin{array}{l}\text { Solar enhanced } \\
\text { oil recovery (solar } \\
\text { EOR) }\end{array}$ & $\begin{array}{c}1,021 \mathrm{MW}_{\text {th }} \text { in construction } \\
\text { in Oman, } \\
850 \mathrm{MW}_{\text {th }} \text { planned in } \\
\text { California }\end{array}$ \\
\hline & Solarlite & Germany & $\begin{array}{l}\text { Thailand, } \\
\text { Germany and } \\
\text { India }\end{array}$ & $\begin{array}{c}\text { Solar IPH, } \\
\text { electricity, solar } \\
\text { EOR } \\
\end{array}$ & $\begin{array}{l}5 \mathrm{MWe}\left(\sim 20 \mathrm{MW}_{\text {th }}\right) \text { for the } \\
\text { biggest site in Thailand }\end{array}$ \\
\hline \multirow{2}{*}{$\begin{array}{l}\text { DSG Linear } \\
\text { Fresnel }\end{array}$} & Industrial Solar & Germany & Jordan & $\begin{array}{c}\text { Solar IPH e.g. for } \\
\text { pharmaceutical } \\
\text { processing }\end{array}$ & $222 \mathrm{~kW}_{\text {th }}$ for site in Jordan \\
\hline & SunCNIM & France & France & Electricity & $\begin{array}{c}9 \mathrm{MWe}\left(\sim 27 \mathrm{MW}_{\text {th }}\right) \text { site in } \\
\text { construction }\end{array}$ \\
\hline
\end{tabular}

\section{Liquid-HTF Trough}

Parabolic trough collectors typically use a liquid-HTF in the solar field and there are several companies that produce troughs for solar IPH application.

1. Rackam

Rackam is a Canadian solar IPH developer and manufacturer. The main innovations include the use of micro-sun aluminum sheets from Alanod Solar for each collector module (Alanod Solar 2014), and the wheel tracking mechanism. Currently there are two models Rackam delivers, the S20 (2.34-m aperture) for ground mount and the S10 (1.16$\mathrm{m}$ aperture) for roof-mount cases (Rackam 2016). Rackam has deployed their system in Brazil, Canada, Spain, and the U.S. (Rackam 2018; CSP Plaza 2018a), and as of 2017 has installed six fields with a total collector area of approximately 2,092 $\mathrm{m}^{2}$ (CSP Plaza 2018a). The newest site under construction in Brazil is a 5.16-MW th solar field, which will include nearly $12,000 \mathrm{~m}^{2}$ of installed collector area once completed (CSP Plaza 2018a; Rackam 2017b).

IPH project developer Heat2Hydro Inc. has partnered with Rackam to deploy the Rackam trough systems. In 2017 Heat2Hydro setup a 100-kW th test loop using S20 parabolic troughs (Figure 25). The operational test loop in Surprise, Arizona provides heat for sludge drying, a byproduct of the wastewater treatment (Rackam 2017a). Heat2Hydro estimates a 5-MWth plant could be built to treat all of the City of Surprise's wastewater sludge (Rackam 2017a). The S20 trough from Rackam is currently being certified by the U.S. Solar Ratings and Certification Corporation (SRCC).
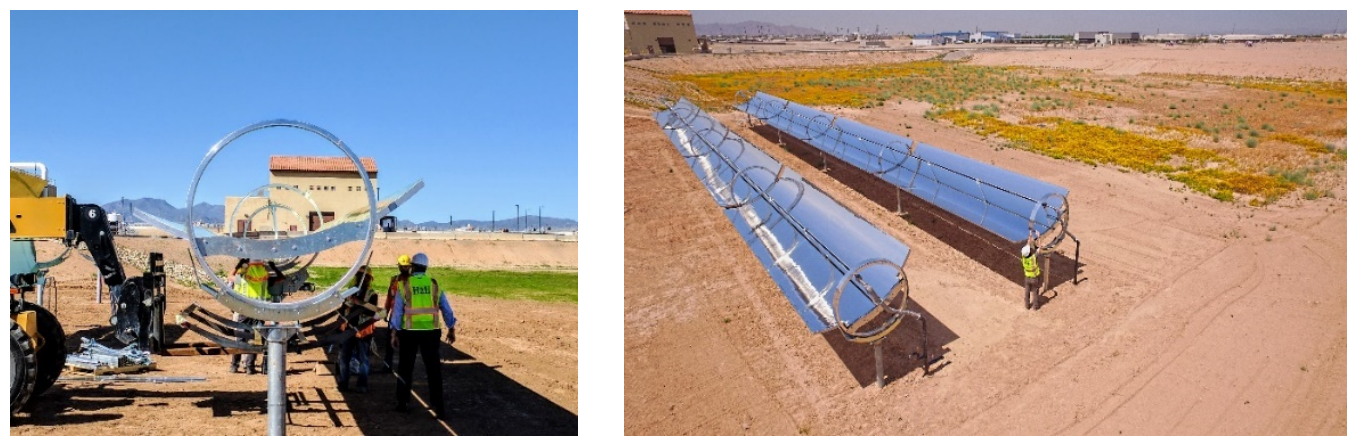

Figure 25. Rackam S20 100-kWth loop being tested at the Heat2Hydro test site in Surprise, Arizona for sludge drying. Photos from Heat2Hydro, credit: Heat2Hydro.

2. Heliovis 
Heliovis, an Austrian company, has developed an innovative inflated tube structure for solar IPH. The 7.8-m aperture collector is made of three plastic films; the first a robust and durable transparent film, the second the mirror film, and the third is the surrounding base film (Kazkaz 2018; Heliovis 2017). The schematic of the HelioTube can be seen in Figure 26, where an air pressure difference in the tube allows for the mirror film to be curved as needed. The overall length for one module is $220 \mathrm{~m}$ (Kazkaz 2018).

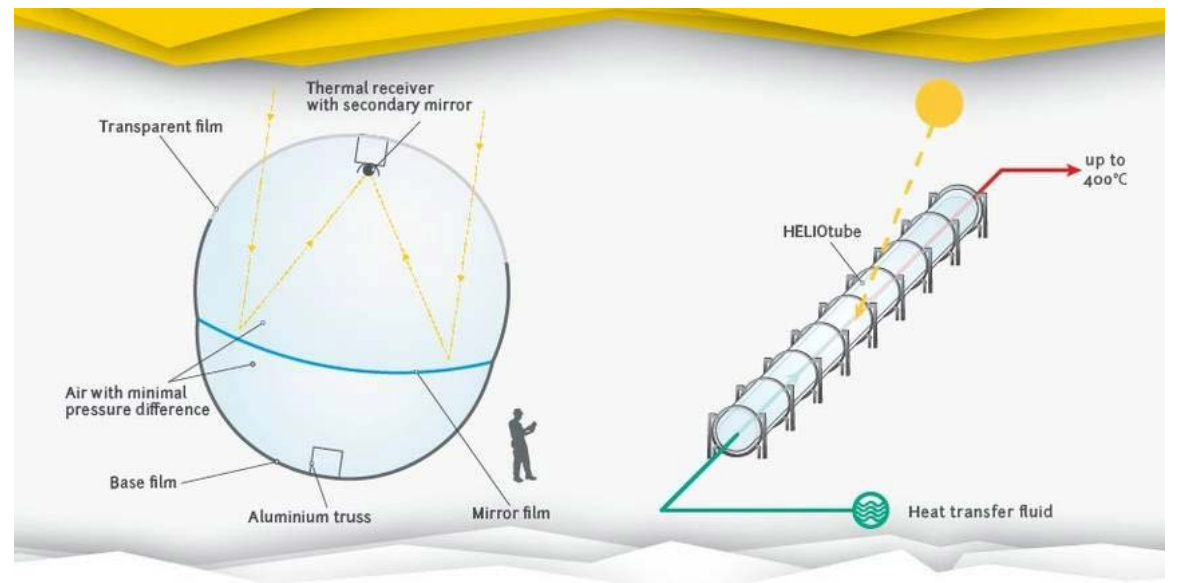

Figure 26. HelioTube inflated tube schematic. (Markham 2017)

Small system size and low project-development budgets mean it is important for the U.S. solar IPH market to have easy-to-install collectors with short payback periods. Discussions with Heliovis indicate that their inflated tube collector, which uses roll-to-roll manufacturing, could have low solar field installed costs. The design leverages inexpensive, easily available architectural plastics and has significantly less steel than other collector structures. The potentially low installed solar field costs will need to be understood better.

The HelioTube benefits from ease of manufacture, speed of installation and cheaper materials than current metal and glass/mirror film troughs. The 1-MWth module at the Heliovis test site in Spain (Figure 27) is connected to a mushroom producer and was constructed in eight weeks (Kazkaz 2018). Currently the test site uses a liquid-HTF, though future HelioTube developments could employ DSG.

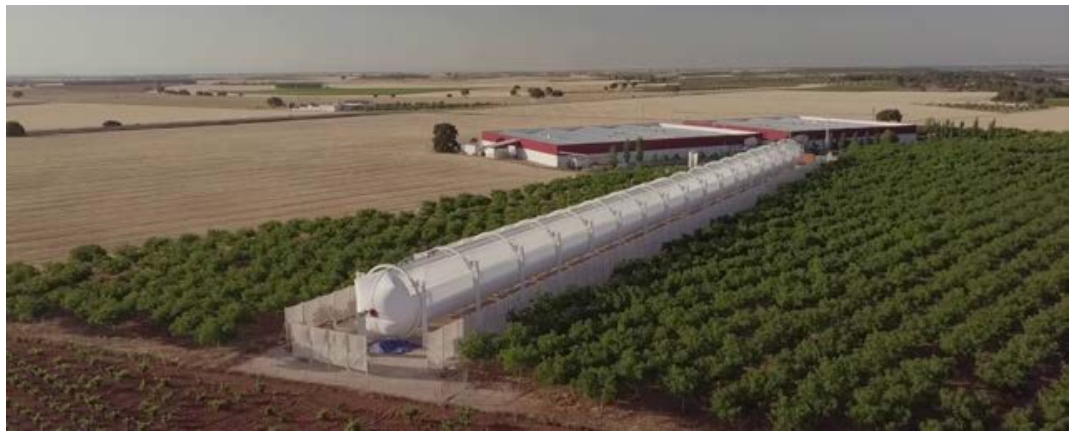

Figure 27. Heliovis inflated HelioTube demonstration in Spain for mushroom drying (Kazkaz 2018). Credit: Heliovis. 


\section{Sunvapor}

Sunvapor, a California-based solar IPH project and technology developer, has developed the Green Trough through a $\$ 1.7$ million DOE-funded project (DOE 2016). Sunvapor is aiming to reduce the installed collector cost to less than $\$ 100 / \mathrm{m}^{2}$ and cut manufacturing and material costs by nearly $50 \%$, through the use of wood for the collector structure (DOE EERE 2017). The Green Trough, and other low-cost collectors in this report, could be vital in making CSP for solar IPH competitive in California. The demonstration of the Green Trough in California is shown in Figure 28.

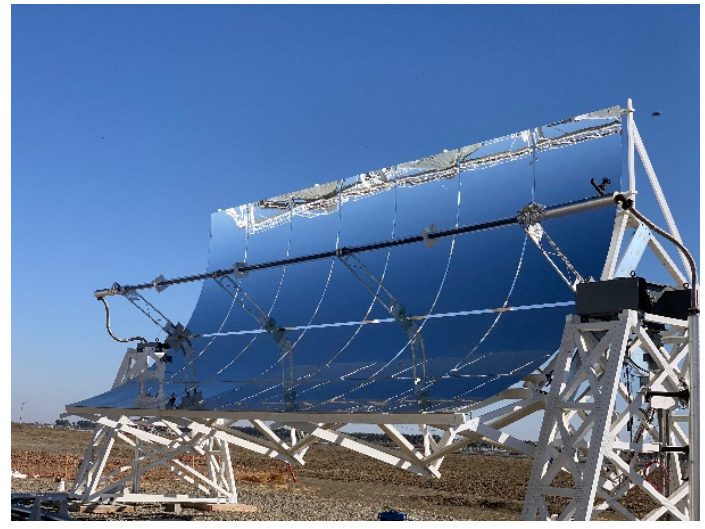

Figure 28. Sunvapor Green Trough demonstration at a site in California. Photo provided by Sunvapor, credit: Sunvapor.

Sunvapor recently were awarded a $\$ 1.5$ million DOE project that combined the Green Trough with a TES system based on phase change materials (PCMs) (DOE EERE 2018). The aim of the project is to provide steam at $\sim 180^{\circ} \mathrm{C}$ with a target $\mathrm{LCOH}$ of less than 1.5 $/ \mathrm{kWh}$ th (DOE EERE 2018; PR Newswire 2018b). The NREL PCM model described later is being leveraged for use with the Sunvapor award.

\section{NEP Solar}

NEP Solar, an Australian company, is offering the PolyTrough 1800 (NEP Solar 2013; Minder 2013) that uses either an oil or water-glycol HTF. The 1.85-m aperture trough uses weather-resistant aluminum reflectors, is designed to produce a maximum solar field outlet temperature of $250^{\circ} \mathrm{C}$, and is both roof and ground mountable (NEP Solar 2013).

A previous paper in conjunction with the Bavarian Center for Applied Science (ZAE Bayern) and the Swiss Institute for Solar Technology (SPF), looked at the validation of operational data from a NEP Solar PolyTrough 1800 site in Saignelégier, Northwest Switzerland (Kurup et al. 2018). The $627 \mathrm{~m}^{2}$ solar field uses a pressurized water-glycol mix as the HTF (Frank et al. 2014), with solar field exit temperatures between 110 and $130^{\circ} \mathrm{C}$ (Minder 2013). The solar IPH site has a 360-kWth peak power, and the heat from the solar field is utilized as part of the milk processing. SAM was used to model the Swiss site, and found that the annual predicted thermal yield compared to the experimentally measured thermal output of the solar field to be within $5 \%$ of each other (Kurup et al. 2018). An image of the roof-mounted solar field in snowy conditions, at the Saignelégier dairy processing plant is shown in Figure 29. 


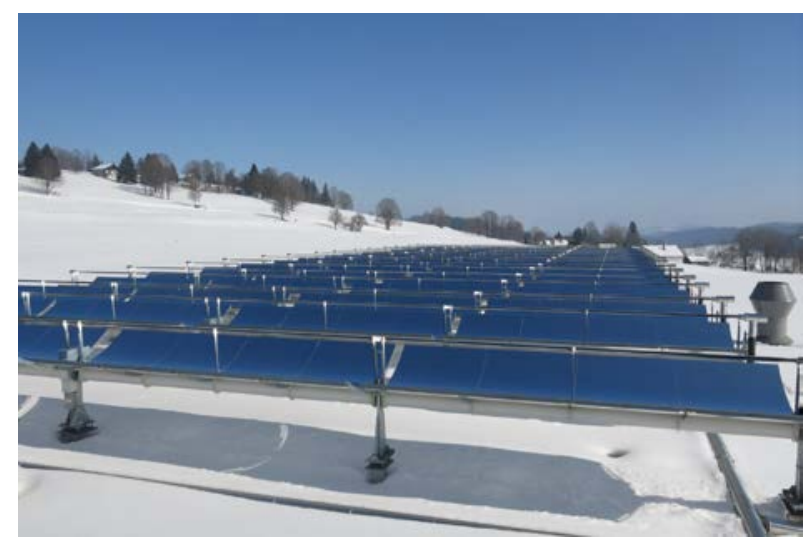

Figure 29. PolyTrough 1800 roof mounted solar field at the Saignelégier dairy processing plant in Switzerland (Minder 2013)

5. Lucida Solar

Turkish company Lucida Solar has developed a dual-axis tracking, modularized system (Figure 30). Each modular hexagonal section is made up of 30 parabolic trough units with an aperture area of $81.2 \mathrm{~m}^{2}$ (Valenzuela and López-Martín 2017). The main innovation is the dual-axis tracker which allows each trough string unit to track elevation while the unit rotates in the azimuth direction to increase the efficiency of the thermal capture (Valenzuela and López-Martín 2017). A non-evacuated receiver is fixed, i.e., it does not rotate with the collector, which simplifies HTF handling.
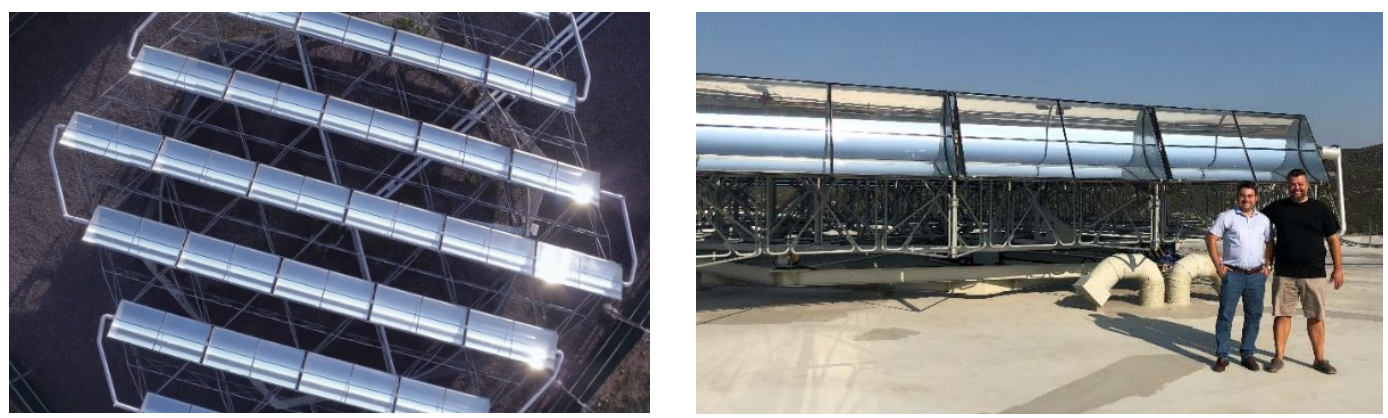

Figure 30. Lucida Solar dual-axis tracking installation in Izmir, Turkey. Photos provided by Lucida Solar, credit: Lucida Solar.

Tests and modeling undertaken by the Spanish organization Ciemat-Plataforma Solar de Almería (PSA), have indicated that compared to a NEP Solar PolyTrough 1800 solar field of approximately the same aperture area, the thermal energy delivered from the Lucida field could be approximately $30 \%$ greater, mainly due to the dual-axis tracking (Valenzuela and López-Martín 2017). Discussions with Lucida Solar highlight that their first commercial solar IPH plant is in Jordan, where expensive diesel oil is burned for heat. This first project is estimated at $990-\mathrm{kW}$ th.

6. Inventive Power

Inventive Power, a Mexican trough developer, has deployed some 40 systems across Mexico as of September 2018 (Inventive Power 2018). Inventive Power has installed parabolic troughs which utilize water/glycol or oil-HTF, mainly for food processing plants (e.g. dairy and animal feed processing), hotels, and agricultural plants such as fruit drying 
(AEE INTEC 2018; Muang 2018). Mexico has high onsite-fuel costs and excellent DNI, as such the solar IPH is very suitable for industrial sites.

Inventive Power's main collectors are the Power Trough 110 and the Power Trough 250, with 1.2-m and 2.5-m aperture widths respectively (Inventive Power 2016, 2017c). Both collectors use anodized aluminum for the reflector, can be either roof or ground mounted, and are designed to have solar field output temperatures of 50 to $200^{\circ} \mathrm{C}$ for the Power Trough 110, and up to $260^{\circ} \mathrm{C}$ for the Power Trough 250 (Inventive Power 2016, 2017c). Figure 31 shows both the roof mounted (left) and ground mounted (right) Power Trough 110 solar fields for two sites.
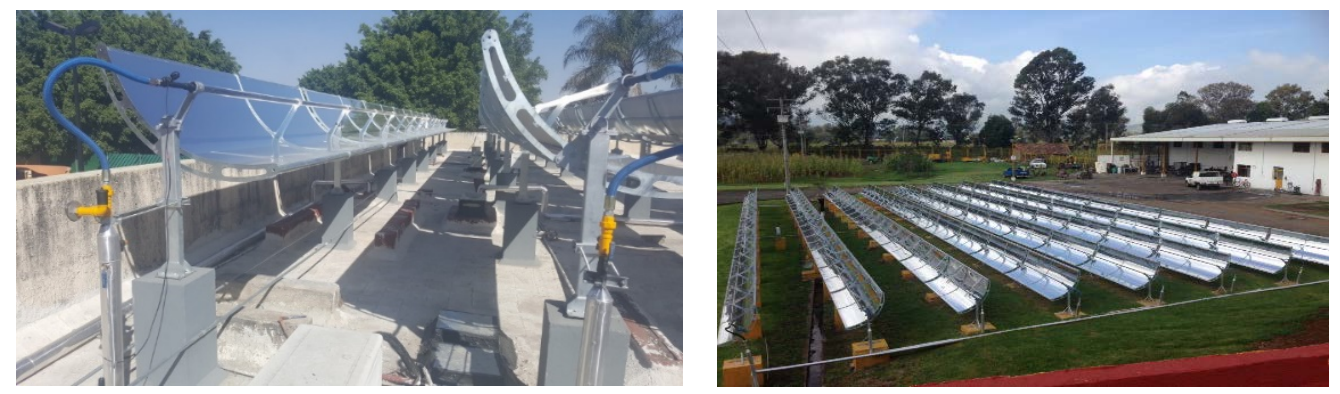

Figure 31. Roof-mounted Power Trough 110 solar field (left), and ground-mounted solar field (right). Photos from Inventive Power, credit: Inventive Power

Figure 31 left, highlights a 32-collector solar field (approximately $99 \mathrm{~m}^{2}$ aperture area) for domestic water heating at the Howard Johnson hotel in Guadalajara, Mexico (Inventive Power 2017b). Figure 31 right shows 80 collectors (approximately $247 \mathrm{~m}^{2}$ ) used for boiler preheating for an animal food manufacturer in Morelia, Mexico (Inventive Power 2017a; AEE INTEC 2017).

\section{Absolicon}

Swedish trough developer and manufacturer Absolicon has created iterations of an enclosed trough for solar IPH, which can be ground or roof mounted. The main offering is the T160, which is designed to heat a synthetic oil to $160^{\circ} \mathrm{C}$ (Absolicon 2017) and has been tested by SPF with a reported thermal efficiency of $76.6 \%$ (Absolicon 2018c). Absolicon has a 200- $\mathrm{m}^{2}$ installation of 10 collectors at the Hemab Energy Park in Sweden (Absolicon 2011), and is branching out to Austria, China and Greece (Absolicon 2018b). For example, in Athens, Greece, Absolicon and Solar ++ AB, are installing a $100 \mathrm{~m}^{2}$ T160 solar field to provide heat for a Colgate Palmolive production plant (Absolicon 2018b). Figure 32 shows the $200 \mathrm{~m}^{2}$ solar field for the Smedjebacken site in Sweden (Absolicon 2012), where approximately $80-\mathrm{kW}$ th peak of heat can be provided in summer, to decrease the oil and fuel usage in the industrial area. 


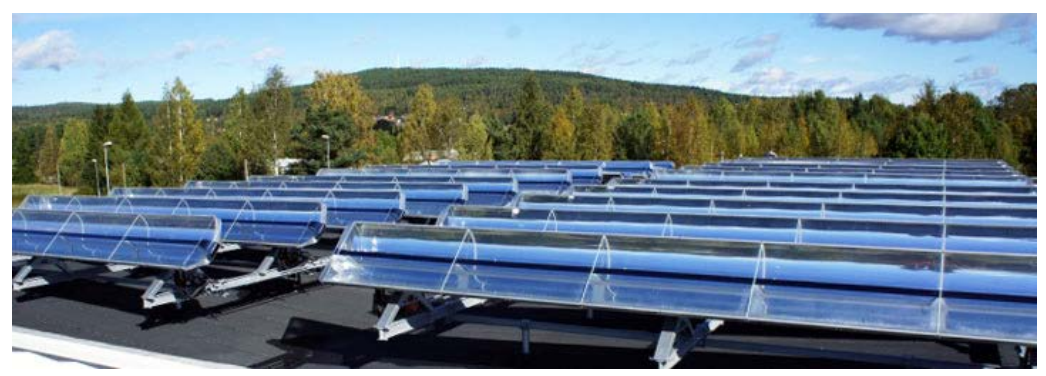

Figure 32. Absolicon T160 roof mounted solar field at the Smedjebacken Industrial park in Sweden (Absolicon 2012). Credit: Absolicon.

Absolicon seeks to increase its manufacturing capacity and scale of production via mass manufacturing, automation and increased control of the supply chain (e.g. for parts and materials) to gain cost reductions of the collector. Figure 33 shows the robotic inspection ongoing at the first manufacturing plant in Sweden.

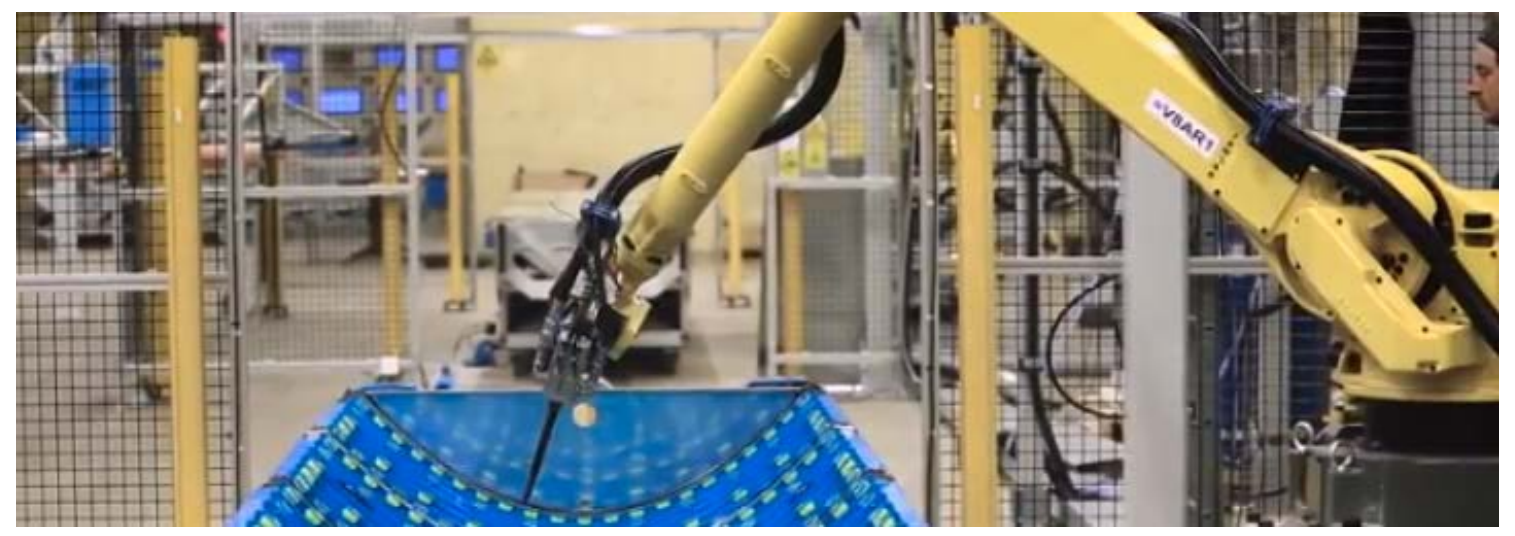

Figure 33. Robotic inspection of Absolicon T160 trough in Swedish manufacturing line (Absolicon 2018a). Credit: Absolicon.

Figure 34 shows Absolicon's reported effect of increased manufacturing volume for the rear bulkhead that holds the reflector plates in the trough. By increasing the manufacturing volume from 100 units to 100,000 units per year, where rolls of aluminum sheet metal are pressed and formed, the cost reduction potential for that component is on the order of $90 \%$ (Absolicon 2018c). The cost is shown in Swedish Krona (SEK), with an exchange rate of approximately 9 SEK to 1 USD. Other components have also been identified for cost reduction through increased manufacturing investment and volume production, for example the use of dies for the plastic components, which could reduce the cost to one sixth of small volume production (Absolicon 2018c). These claims have not been verified through NREL analysis, but the premise is sound and similar has been found in other NREL manufacturing analysis (Akar et al. 2018). Using easy-to-manufacture rolls of material, cost reduction of this order is possible as volume increases. 


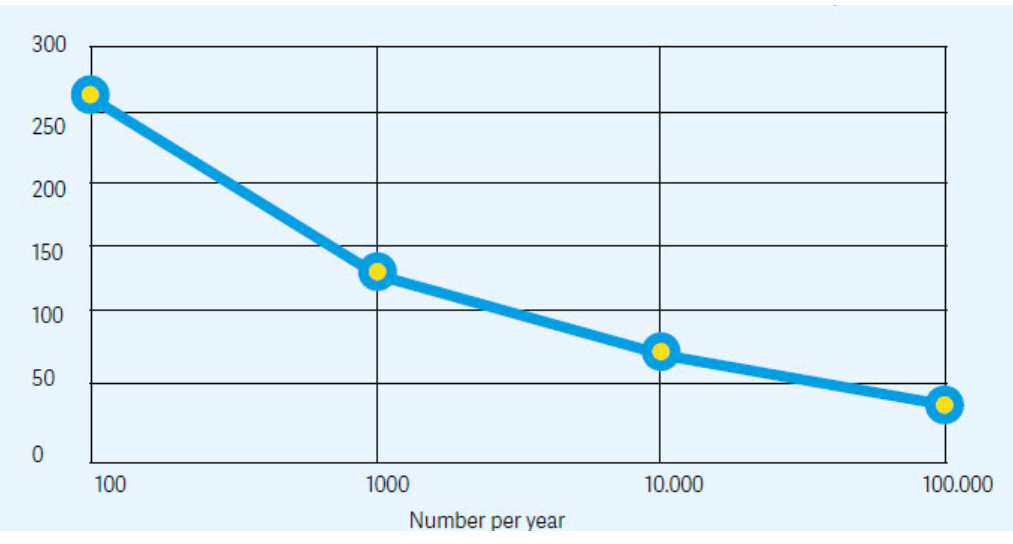

Figure 34. Cost reduction potential (given in SEK) for the Absolicon rear bulkhead through mass manufacturing investments (Absolicon 2018c).

Absolicon have partnered with Heli New Energy Technology to ship their first robotic manufacturing line to China, and have plans to sell fully automated manufacturing lines in other countries and license the T160 (Epp 2018). The line in China has a yearly manufacturing capacity of $100,000 \mathrm{~m}^{2}$ of the T160 and a sales contract of approximately $€ 2.5$ million or $\$ 2.9$ million USD. With the sales revenue, upgrades to the existing manufacturing plant in Sweden could allow for one collector to be manufactured every 6 minutes (Epp 2018; Absolicon 2018a). This is an important step, where the design and mass manufacture of the collector, could allow cost decreases.

8. Artic Solar

Artic Solar is a Florida-based, Veteran Owned solar thermal manufacturer, targeting the $100-200^{\circ} \mathrm{C}$ range for a variety of industrial processes (Artic Solar 2019), as shown in Figure 35 left. Artic Solar are developing and deploying the patented External Concentration Parabolic Collector (XCPC), where 3 mirrored elements make up a XCPC unit. Figure 35 right shows two XCPC units coupled together.
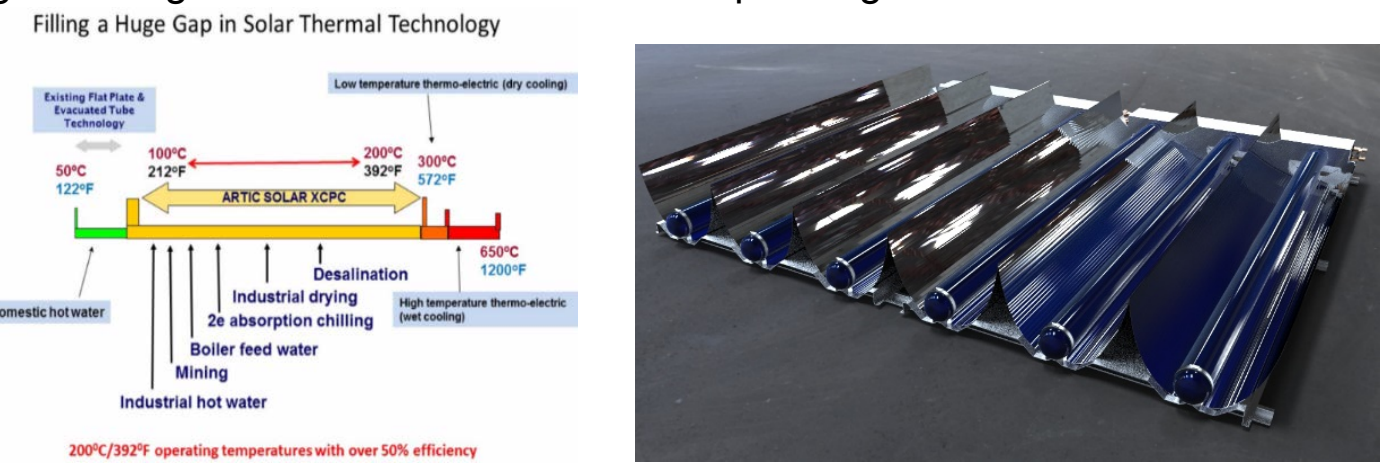

Figure 35. Artic Solar target operating range for industrial applications (left), and two XCPC units coupled together (right). Credit: Artic Solar.

The XCPC is a patented (U.S. Patent \#9,383,120 B1) technology (Winston 2016), where a non-tracking, non-imaging concentrating collector allows the system to produce heated fluids up to $\sim 400^{\circ} \mathrm{F} / 200^{\circ} \mathrm{C}$ (Artic Solar 2019). The XCPC is also certified with the SRCC (SRCC 2018), and Artic Solar is the exclusive licensee of the XCPC in the U.S. In the majority of cases the technology uses a liquid-HTF like pressurized water, and depending 
on the temperature required, the fluid can be changed to a higher temperature HTF. For industrial applications, Artic Solar decrease O\&M by removing the need for tracking of the collector, and there is additional benefit that the collector can provide heated fluid in direct and indirect radiation conditions.

While the technology has been patented, there is significant development and research still possible and needed for the optimization and improvement of the technology. For example, for the use of the technology and integration into areas such as desalination systems.

The latest deployed system from Artic Solar in December 2018, is for integration into a distillery in Jacksonville, Florida. Here 12 XCPC units provide heat for the solar steam boiler at the Four Father's Distillery (Digital Journal 2018), and are designed to decrease the natural gas use (Dixon 2019). The Four Father's Distillery is currently the only U.S. distillery to use a solar steam boiler, and uses a water-glycol mix to allow the water to be heated to steam conditions (Dixon 2019). The solar boiler integration is expected to save thousands of dollars annually from the avoided costs of burning natural gas (Dixon 2019).

\section{CSP Ultra Lite Solar}

CSP Ultra Lite Solar (referred to as Ultra Lite), is a Canadian company which was originally developing high temperature technologies for hydrogen production and fueling vehicles. The company has re-engineered its technology from hydrogen production to process heating and CSP applications (Ultra Lite Solar 2018a). Ultra Lite are targeting the use of the their collector technology towards medium and high temperature industrial applications of solar fuels, solar EOR, desalination and district heating (Ultra Lite Solar 2018a).

Ultra Lite have developed three variations of the Ultra Lite (UL) trough. The UL1 trough is a developing technology that uses pressurized air to hold the primary mirror film reflector in place (Ultra Lite Solar 2018b). The UL3 is a more conventional design, though production ready, where a film is bonded to an aluminum sheet, and the trough structure is held by a support structure (Ultra Lite Solar 2018b). A rendering of the UL3 suitable for $\mathrm{IPH}$ can be seen in Figure 36, and can reportedly reach $200^{\circ} \mathrm{C}$ (Ultra Lite Solar 2018b). In terms of IP, it has been found that the company has 13 patents filed or pending.

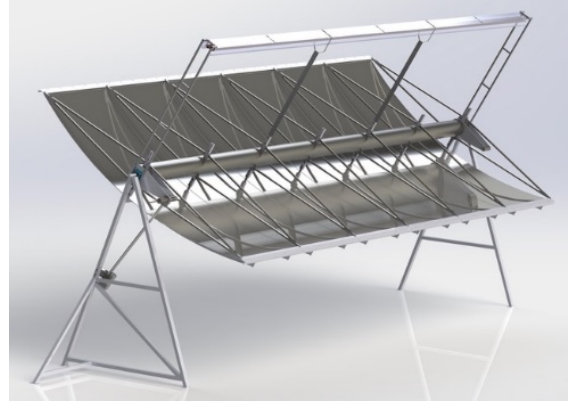

Figure 36. Ultra Lite UL3 trough rendering, designed for solar IPH applications. Photo from Ultra Lite, credit: Ultra Lite. 
Benefits of the Ultra Lite troughs could include: lower-cost manufacturing and assembly if less support structure is needed (due to the air pressure assisted structure), thin film materials and local content (Ultra Lite Solar 2018c).

\section{Liquid-HTF Linear Fresnel}

1. Skyven Technologies

Skyven Technologies (based in Texas) is a recent company entering the solar IPH space. Founded in 2013, with private backing and grants from the National Science Foundation (Pitchbook 2018; Skyven Technologies 2018b), Skyven Technologies is looking to heat liquids up to $250^{\circ} \mathrm{C}$ for process heating (Skyven Technologies 2018a). Figure 37 (left) shows the modular design, which contains rows of mirror facets controlled to track the sun, concentrating the light onto a flat receiver, similar to linear Fresnel receivers. Figure 37 left, shows modules of the collector being installed, and the right image shows a closeup of the mirror facets.
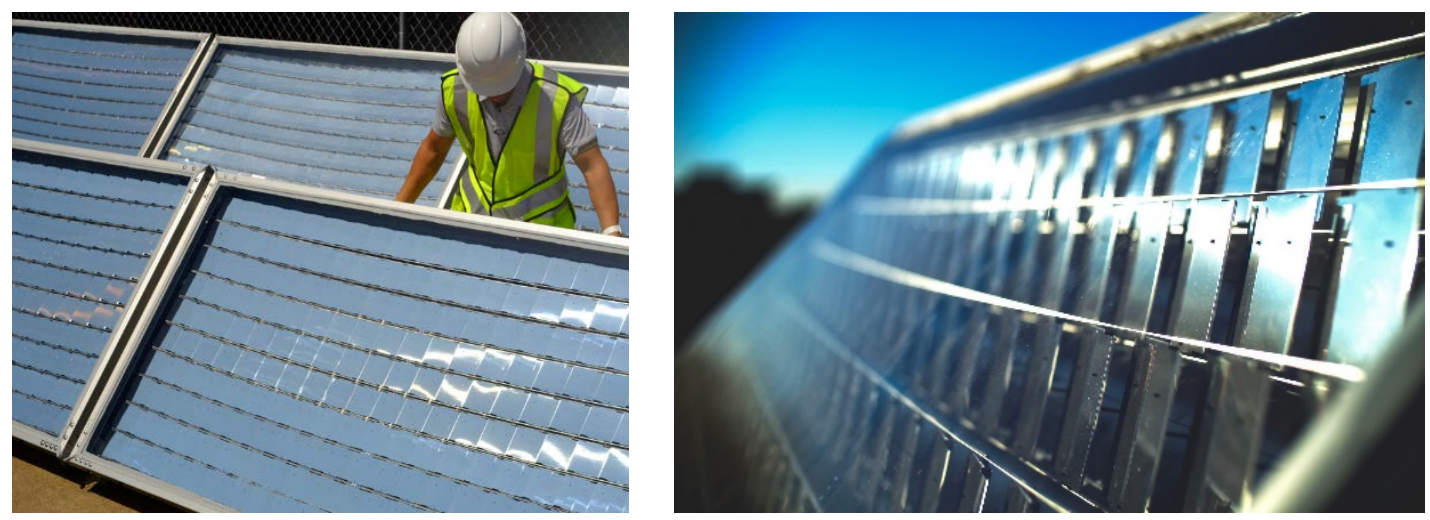

Figure 37. Skyven Technologies modular panels being installed (left), and close up (right). Photos from Skyven Technologies, credit: Skyven Technologies.

Innovations of Skyven Technologies include a very modular design for the collector, ease of installation (as the structure and mounting is based of PV panels), stamped aluminum mirror facets and injection molded facet backing structures (Protolabs 2016). This collector has potential to be low-cost (e.g. through the mass manufacturing modular approach of key components like the mirror facets). Performance data are yet to be published or reviewed by NREL.

\section{Hyperlight Energy}

Hyperlight Energy is a California-based solar thermal technology developer and manufacturer, who through the DOE COLLECTS program, have continued development of an innovative linear Fresnel collector and received a SunShot award of $\$ 1.5$ million (DOE EERE 2016). Hyperlight Energy recently completed a demonstration system in Brawley, CA at San Diego State University, which covers 0.5 acre (Mungas 2016). Hyperlight Energy have also received $\$ 750 \mathrm{k}$ from the California Energy Commission (CEC) for collector development (Hyperlight Energy 2016). Hyperlight Energy is aiming to reduce the installed collector cost to less than $\$ 100 / \mathrm{m}^{2}$ through the use of low-cost plastic extrusions and water replacing traditional CSP collector structural steel and concrete 
(Mungas 2016). The demonstration site in Brawley, CA can be seen in Figure 38 (left), and the right image shows the water support and plastic pipes which hold the mirrors.
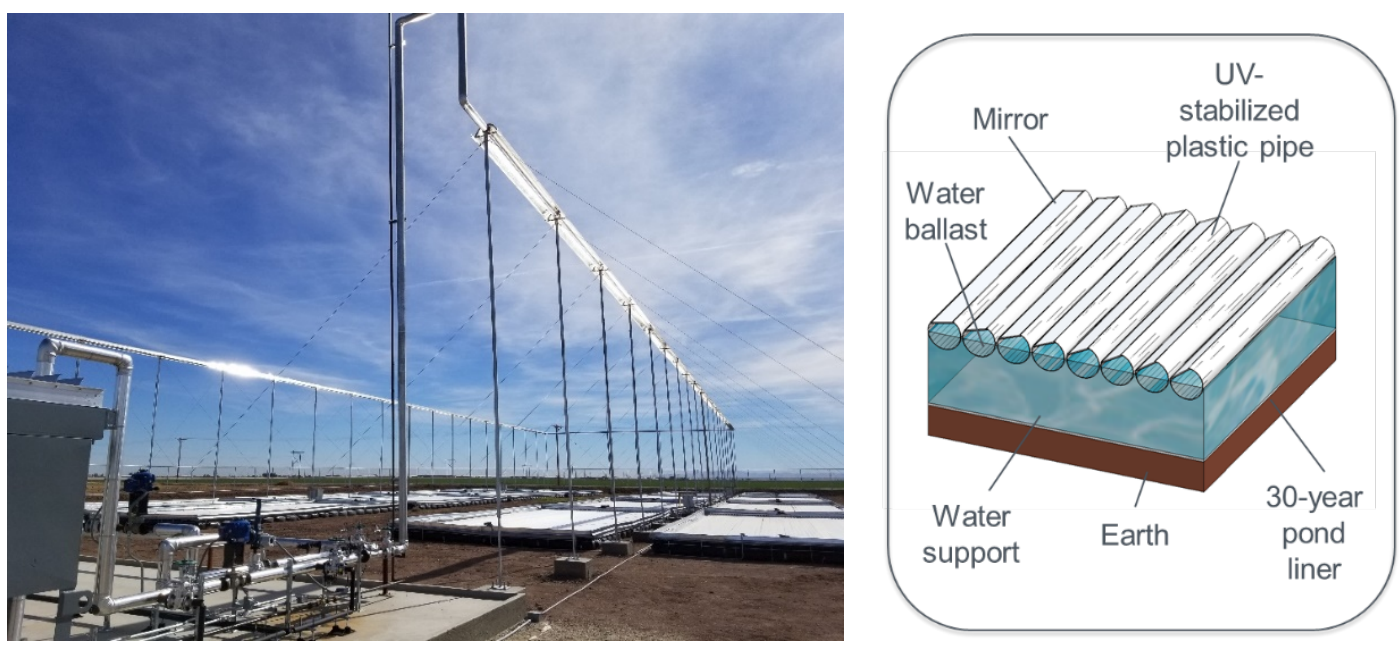

Figure 38. Hyperlight Energy $1 / 2$ acre demonstration at the San Diego State University in Brawley, CA (left), and illustration of the mirrors floating on the water support (right). Credit: Hyperlight.

Hyperlight are working with NREL in the further improvement of the collector design and modeling of the system (Zhu et al. 2016). An adaptive optimization approach for the secondary receiver has been developed, to then improve the optical performance of the system. The modelled results indicate that with an optimum secondary-reflector profile, the optical efficiency of the Hyperlight collector can be $90 \%$, for a wide range of transversal and longitudinal incidence angles (Zhu et al. 2016).

3. Heliac

Heliac is a Danish solar thermal developer, manufacturer and installer, and are targeting low-cost large-scale solar fields for heat generation, for example at industrial sites or for district heating. For cost effectiveness, solar fields are expected to be greater than 200$\mathrm{kW}_{\text {th }}$ (Heliac 2018a). The heat generated can either be used with a heat exchanger to integrate into a site's existing IPH needs or for electricity generation.

Rather than traditional linear Fresnel based on mirrors, their innovative system, uses a thin film which has a refractive microstructure to concentrate the light to heat an HTF dependent on the temperature needed. Water is the cheapest option for temperatures below $100^{\circ} \mathrm{C}$, and traditional synthetic HTFs like Therminol VP-1 or Dowtherm A would be used to reach $400^{\circ} \mathrm{C}$. As seen in Figure 39, the concentrated light heats up a relatively cold fluid, and a heated fluid exits each individual system. 

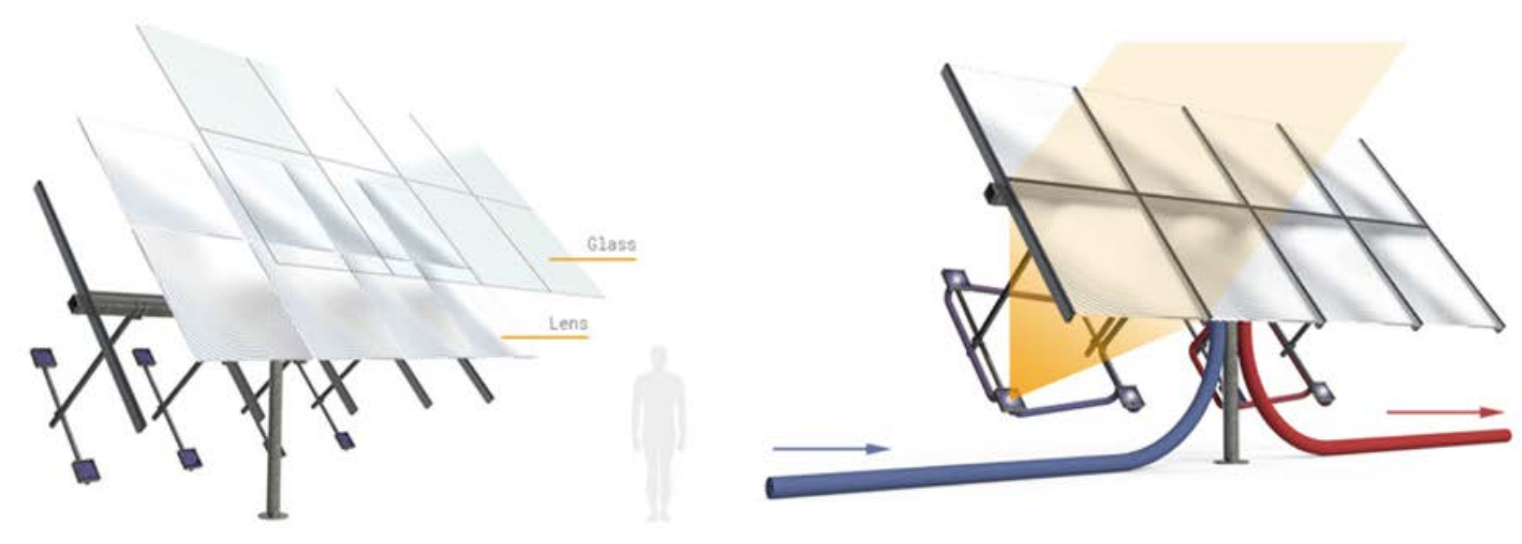

Figure 39. Heliac system design to concentrate light with thin film refractive les and produce heated fluid. Image provided by Heliac, credit: Heliac. (Heliac 2018c)

A demonstration of the solar technology is currently under construction. Heliac have been contracted to manufacture and install for E.ON (a large European power utility) a 2-MW th system. This is being integrated into the existing district heating network at Lendemarke, Denmark. The installation can be seen in Figure 40.

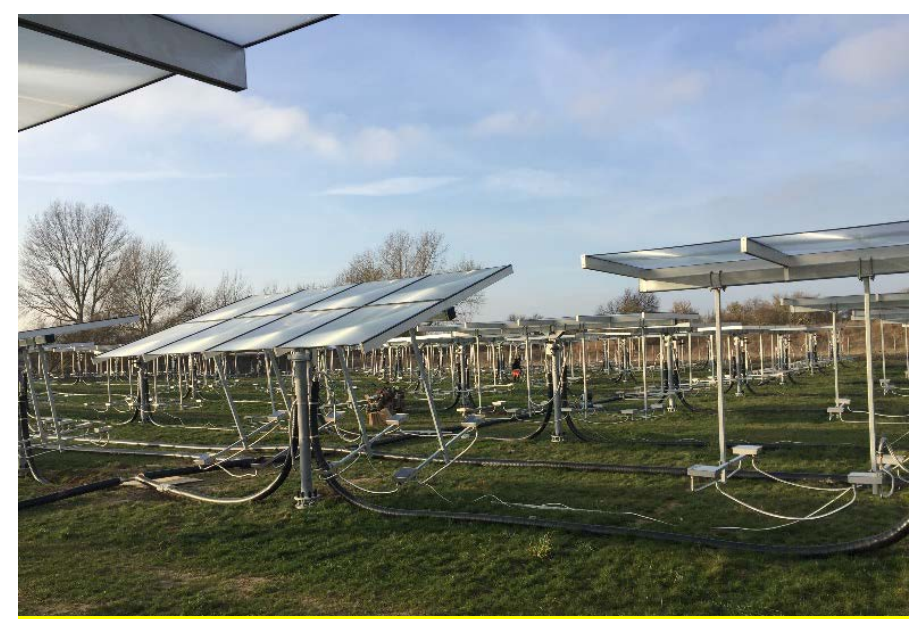

Figure 40. Heliac 2-MW $\mathrm{MW}_{\text {th }}$ demonstration for a district heat facility in Denmark. Photo provided by Heliac, credit Heliac.

The system is expected to produce 2,000-MWh annually, and the plant is expected to meet Lendemarke's heat demand during the summer months and $20 \%$ in the rest of the year (Heliac 2018b).

\section{DSG collectors}

Few existing solar IPH collector developers have designed for steam production in the solar field itself. One notable application is the use of the steam in solar EOR.

1. GlassPoint

GlassPoint, a California-based developer, has developed and deployed multiple generations of DSG trough technology, with focus on injecting solar steam into existing oil fields for solar EOR. The key GlassPoint innovation is to place the collector and receiver hardware inside a transparent glasshouse, enabling the use of lightweight 
structures in a zero-wind environment, see Figure 41 (Bierman, Treynor, et al. 2014; Bierman, O'Donnell, et al. 2014). GlassPoint reports the solar steam can decrease the onsite use of gas for EOR by $50-80 \%$ (Glasspoint 2018a).

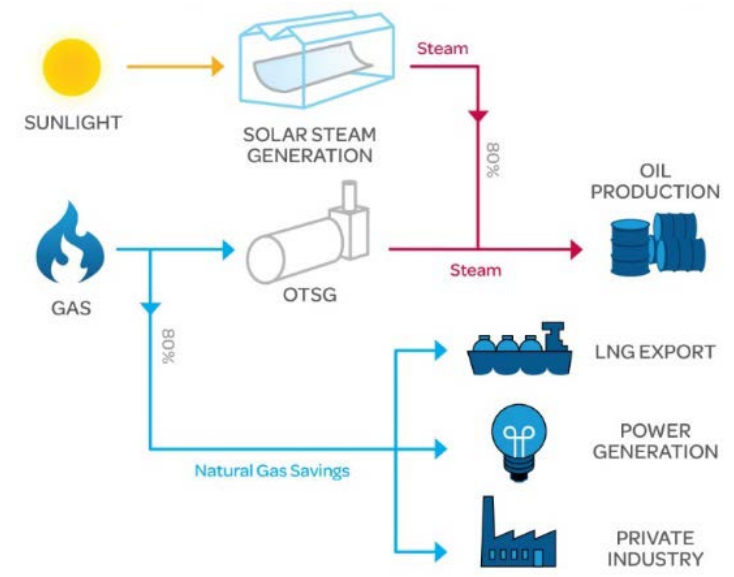

Figure 41. GlassPoint schematic for once-through steam generation for EOR and other industrial use.

The biggest and most progressed GlassPoint project is the 1,021 $\mathrm{MW}_{\text {th }}$ solar field in Amal, Oman, spanning nearly $3 \mathrm{~km}^{2}$ (Glasspoint 2018b). This is in construction, and as of February 2018, four of 36 planned glasshouse enclosures were in operation (SolarPaces 2018). Once the site is complete, a daily solar steam output of 6,000 tons/day could be reached, saving 5.6 trillion British Thermal Units (BTU) of gas per annum (Glasspoint 2018b). Progress of the site can be seen in Figure 42.
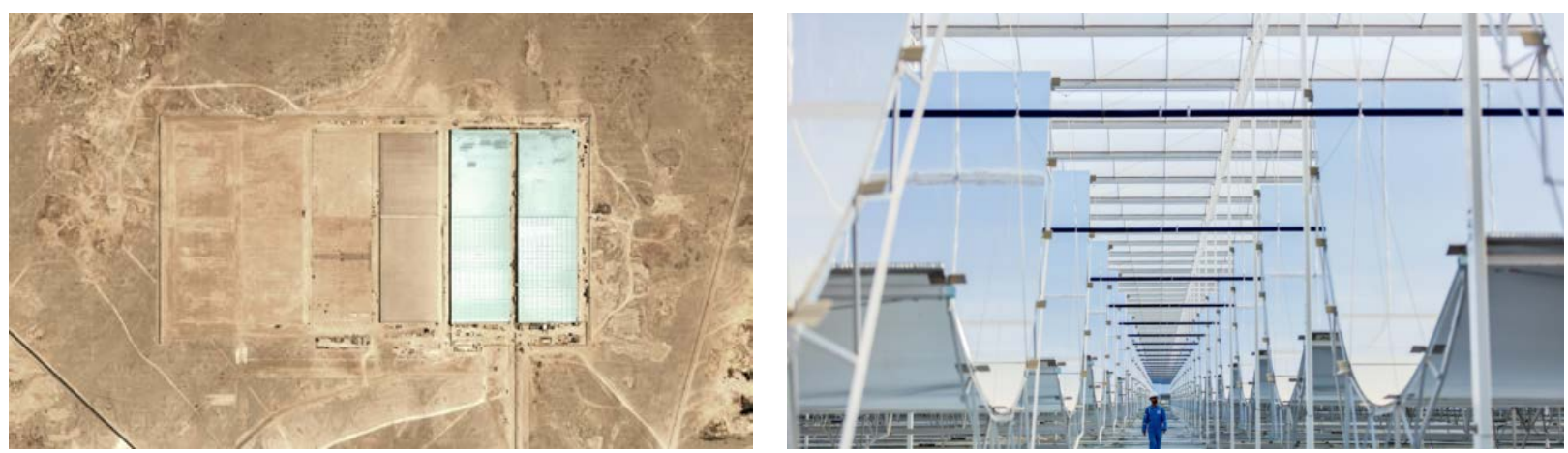

Figure 42. GlassPoint site Miraah. Construction as of September 2017. Credit: GlassPoint.

In 2017, GlassPoint also announced an 850-MW th solar EOR site in Belridge, California. When completed, this would be the largest concentrating solar site in the U.S. of any type. The site is expected to incorporate 26.5-MWe of PV to generate electricity for site needs (23 ABC News 2017; Business Wire 2017).

2. Solarlite

Solarlite is a German company offering DSG troughs. Solarlite's composite-facet DSG trough offers an innovative approach to reduce collector cost and enhance deployment of small-capacity systems. Most notably, composite-facet troughs are lighter and more rigid than the current state-of-the-art and composite facets allow a thinner, higher- 
reflectivity mirror (0.9 $\mathrm{mm}$ vs. $4 \mathrm{~mm}$ glass). Solarlite has developed composite-trough systems since 2001 and has deployed the 5-MWe TSE-1 power plant in Thailand (Solarlite 2011). The installation of the SL 4600 trough can be seen in Figure 43.
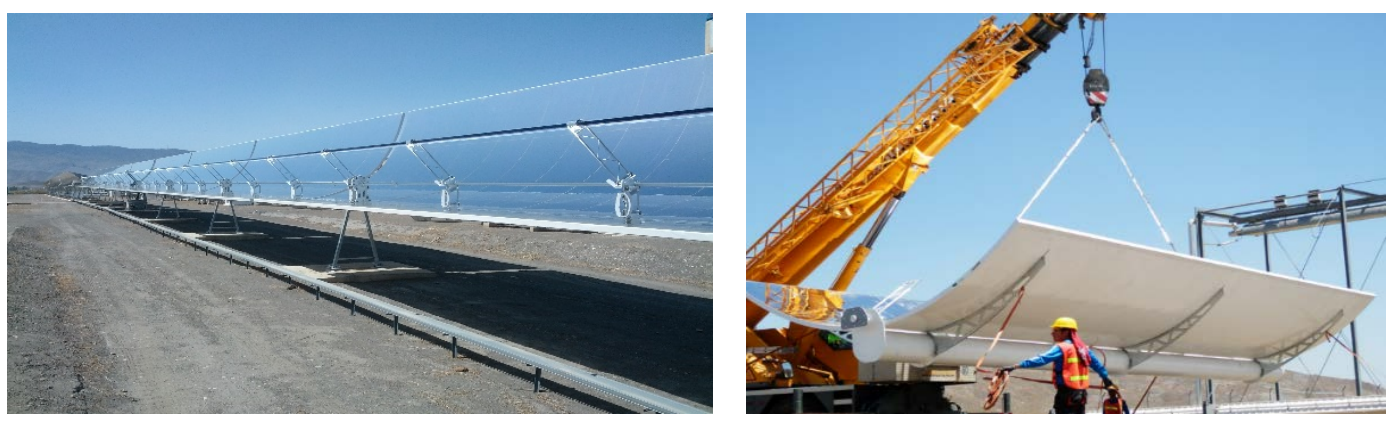

Figure 43. Solarlite DSG Trough (SL 4600) installed in Thailand. Photos from Solarlite, credit: Solarlite.

Solarlite DSG systems for solar IPH applications could be very suitable, though they have yet to deploy solar field sizes less than 2-MWth as such small projects may not be cost effective, at least in terms of the fast payback needed by industrial end-users.

3. Industrial Solar

Industrial Solar, a German company, has developed a modular DSG linear Fresnel collector for solar IPH. Industrial Solar's LF-11 is designed for industrial application and direct production of saturated or superheated steam, up to $400^{\circ} \mathrm{C}$. Roof mounting is available. The LF-11 collector with a $7.5 \mathrm{~m}$ collector width can be seen in Figure 44 .

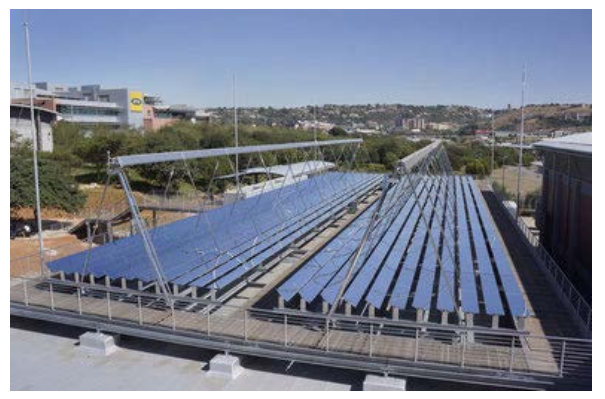

Figure 44. Industrial Solar DSG LF collector roof mounted in South Africa, where the heat is utilized for solar cooling (Industrial Solar 2016)

Industrial Solar are heavily working with the German Aerospace Center (DLR) for the development and deployment of their DSG collector into markets in Jordan (Berger et al. 2016). The solar field at the RAM Pharma pharmaceuticals processing plant in Jordan can be seen in Figure 45. The site uses fuel oil for steam generation, and the Industrial Solar integration feeds into the existing steam line, where the steam supply is controlled through a steam drum (Willwerth et al. 2017). 


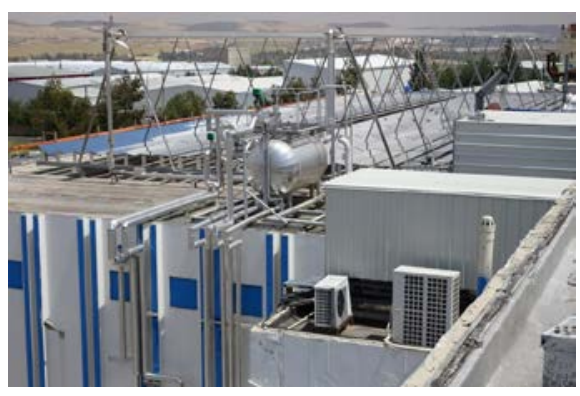

Figure 45. Industrial Solar collector integration at Ram Pharma in Jordan

The $394 \mathrm{~m}^{2}$ solar field produces $166^{\circ} \mathrm{C}$ steam at 6 bar (Berger et al. 2016), with a steam drum used for the integration to the pharmaceutical plant. Like most current IPH systems, there is no storage. Collaboration with DLR has shown that stable steam supply and control is achieved, both in winter and summer. During the spring and summer months, the solar field can produce sufficient steam to meet the requirements of the site for many hours. For example, on the $24^{\text {th }}$ of April 2016, the integrated solar field and control system supplied steam for 5.5 hours, allowing fuel use to be switched off and represented a $33 \%$ saving in fuel oil. On winter days, the steam supply can be delivered in intervals, where steam supply from the steam drum is alternated with steam supply from the fossil power to meet the site's needs. Throughout the testing and since the DSG solar field integration, there have been no technical issues, which is often a concern for operations staff (Krüger et al. 2017).

\section{SunCNIM}

SunCNIM, a French company, has developed a DSG linear Fresnel technology. The DSG collector and installation is designed to have high recyclable content (SunCNIM 2017). This novel technology has applications for power generation (with thermal storage), solar EOR, hybridizing conventional fossil generation plants, and for solar IPH, where steam is generated for process application. SunCNIM has built and tested their 500-kWth DSG solar field at the La-Seyne-Sur-Mer site since 2011 (SunCNIM 2017). Part of the novel aspect of the whole SunCNIM solution is a robotic, automatic cleaning system that ensures regular cleaning of the mirrors. The collector module and the robotic cleaning system at the test site can be seen in Figure 46 left and right respectively.
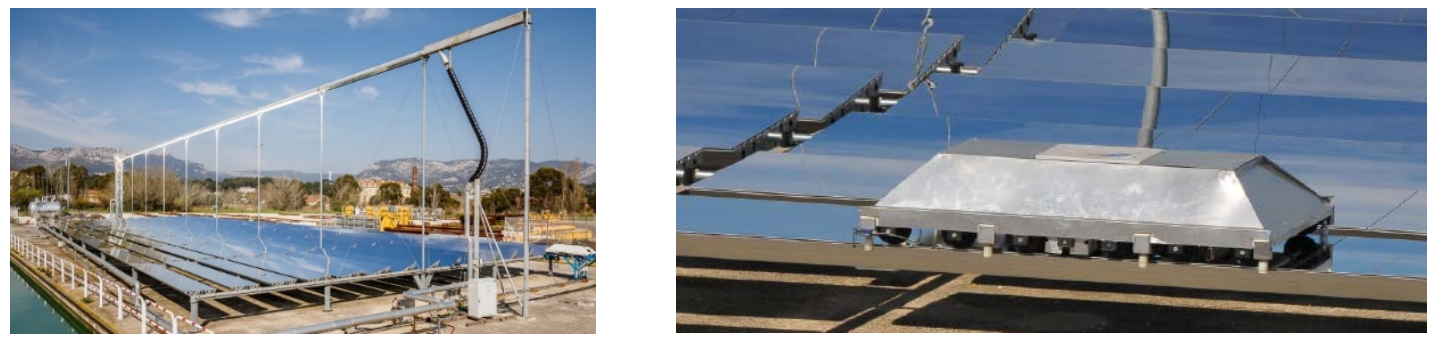

Figure 46: SUNCNIM DSG linear Fresnel collector module (left) and Robotic Cleaning System (right). Photos from SunCNIM, credit SunCNIM.

SunCNIM are in the construction phase of a 9-MWe DSG linear Fresnel power plant with 4 hours of storage, where $€ 60$ million has been raised in financing (CNIM 2016; SunCNIM 2016). The aperture of the field is $150,000 \mathrm{~m}^{2}$; steam is produced at $285^{\circ} \mathrm{C}$ at 70 bar (SunCNIM 2016). For France at least, SunCNIM can offer a vertically integrated solution to 
customers, which could help decrease EPC costs to allow small solar IPH projects to be more cost competitive. Figure 47 shows the on-site progress of the solar field for the 9MWe project.
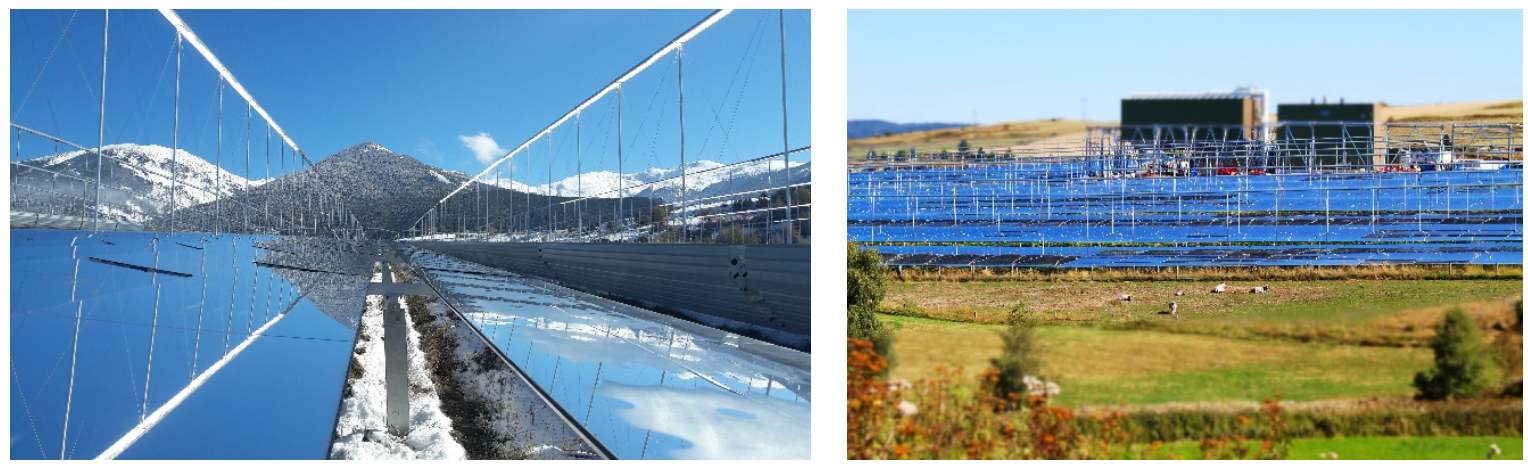

Figure 47. Site pictures of the solar field for the Ello project. Photos from SunCNIM, credit SunCNIM.

\section{Brewery Integration Case Study}

A case study of a potential $1-\mathrm{MW}_{\text {th }}$ solar field integration into an existing brewery in California was completed in project year three. The project was being pursued by developer Heat2Hydro Inc. (New York, NY), who shared information with NREL. Project finance sensitivities to solar field cost, natural gas price, project life, federal corporate tax rate, debt interest rate, and project incentives were explored. The biggest influences on project viability (measured by NPV) were the federal tax rate, the project life, and the solar field installed cost. For example, changing the tax rate from $35 \%$ to $21 \%$, flips the Base Case from NPV>0 $(+\$ 9 k)$ to economically unattractive NPV $=-\$ 7 \mathrm{k}$. The pronounced influence of the federal tax is due to the large upfront costs of solar IPH projects that lead to tax-deductible losses in the early years of the project period. A higher tax rate produces larger deductions. It is important to realize that the commercial application model (from SAM 2017.09.05) used in this study assumes that the project owner has sufficient income to allow for tax deductions. Developer Heat2Hydro acknowledged the importance of owner tax appetite for project economics.

Longer project life is also an important factor in project economics. After payoff of the project loan, project net income can be substantial. The importance of project life points to the need for development and demonstration of durable technologies for these applications-activities that may benefit from DOE R\&D. However, this contrasts with the next lesson.

Figure 48 shows a contour plot of NPV when installed solar field cost and project life are varied. The orange band highlights conditions where NPV transitions to positive values; thereby defining the border of economic viability for the given assumptions. As can be seen, the increase in life of the project significantly increases project NPV. A project with a 10 -year financial life requires a solar field cost of less than about $\$ 100 / \mathrm{m}^{2}$. 


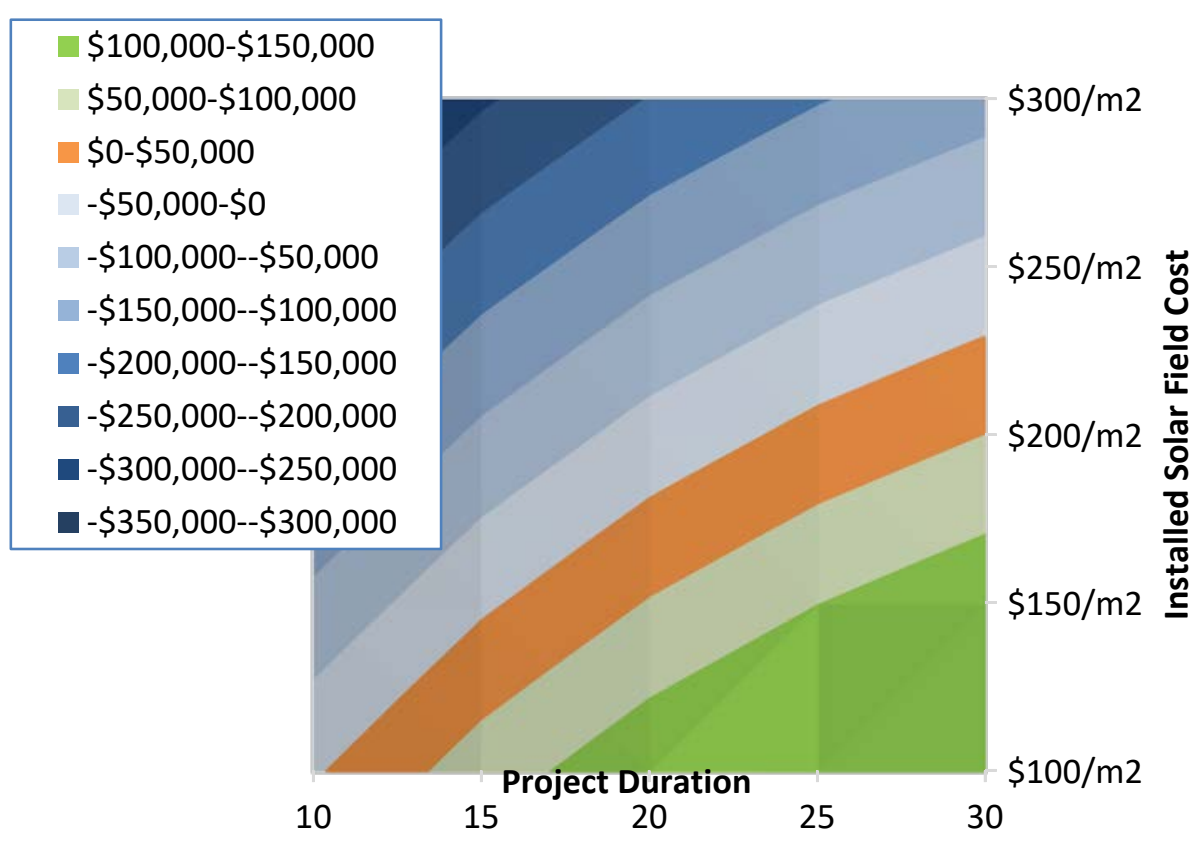

Figure 48. Contour plot of NPV, varying the solar field costs and the project life, with $21 \%$ federal tax rate.

The influence of tax rate and project life touch on the metric that is often most important to industrial users, namely payback period. Industrial users may require relatively short payback periods (e.g., less than 3-5 years), regardless of overall project NPV due to uncertainties in future cost and market projections. Under this constraint, sacrificing durability for lower upfront cost, may be the better economic choice. For example, lowcost collectors that last only 10 years, rather than 15 to 20 years, may be a more viable pathway for solar IPH.

Sensitivities to the loan interest rate, salvage value, and the use of $100 \%$ equity (i.e. no debt used for the project) had lesser effect on the NPV.

The federal investment tax credit (ITC) and California solar-thermal production-based incentive (PBI) were also investigated as part of the case study. Despite these incentives and, as illustrated by this study, the favorable economics they suggest, deployment of solar IPH in California has been weak, and time is running out on these incentives. If new projects are constructed by the end of 2019 , the project could at least gain the $30 \%$ ITC, and if they are built and finished in 2018, the California PBI also would apply in 2019.

The potential to receive the $\$ 800 \mathrm{k}$ California PBI credit for a solar IPH installation in two years, yielding a positive NPV even with relatively high solar field costs of $\$ 300 / \mathrm{m}^{2}$, seems to provide a strong incentive to end-users wanting to install solar IPH. It should be noted that the $\mathrm{PBI}$ requires at least one year of measurements to document natural gas reduction after the operation of the solar field.

Yet, currently no new solar IPH projects have been built in California, even with the very lucrative California incentive in place, and potentially the use of the incentive in conjunction with the $30 \%$ ITC. There are likely several reasons for this. Solar IPH projects present risk due to the relative newness of the technology and the technology providers. The incumbency of low-cost natural gas remains a hurdle. Research from the Climate 
Policy Institute indicates that large heat users like cement manufacturers, require a payback period of less than about three years before they will invest in carbon abatement options, even if the project can be profitable in the longer term (Zuckerman et al. 2014). This confirms what solar IPH developers are highlighting about the demand for quick ( $<3$ year) payback periods. Discussions with solar IPH developers like Heat2Hydro and Sunvapor (Livermore, CA), have found it is still very difficult to get projects closed and constructed, especially when gas prices the end users are paying can be as low as $\$ 3.3 / \mathrm{MMBTU}$ in some locations.

Part of this lack of new projects is also related to uncertainty associated with Bill AB-797, which extended the natural gas incentive for only two years, and was signed in late 2017 (California Legislative Information 2017). Solar developers working in 2017 with end users would have faced a situation where the original incentive could have been withdrawn by the end of 2017, and as such would have dissuaded the end users from committing to go ahead with the project. The extension of Bill AB-797 will make 2018 and 2019 the last years where this specific California natural gas incentive is available. But for end users to fully benefit from the incentive the project must be built by the end of 2018, to have the requisite year of operations data to show metered decreases in natural gas consumption.

In discussions with Heat2Hydro, it is clear the EPC costs in California can be a significant issue that can derail a project. Heat2Hydro has highlighted that EPC contractors in California are significantly over estimating prospective projects for relatively small solar fields (e.g., $1800 \mathrm{~m}^{2}$ or about $1-\mathrm{MW}_{\text {th }}$ ). This indicates that $1-\mathrm{MW}_{\text {th }}$ projects in California could be significantly more costly due to the EPC risk margin added to building these first projects. While the installed solar field cost assumed for the Base Case has been achieved for large power projects, smaller IPH projects do not benefit from those economies of scale, and newer technical and business models will be needed to allow solar IPH to proliferate.

Another reason for the high installed cost estimated by the EPC contractors could be the lack of experience with small IPH projects. Both the EPC contractors and the end-users are unfamiliar with the needs of solar IPH sites, and end-users also perceive solar IPH integrations as potentially high risk. This perception will be difficult to shake until there are multiple operating solar IPH plants in the region.

As of July 2017, the current $\mathrm{CO}_{2}$ Cap-and-Trade scheme for California was extended from 2020 to 2030, via Bill AB-398 (Nemec 2017a). In January 2018, the average price of carbon emissions per ton was approximately $\$ 15 /$ ton (CPI 2018), but currently the 'pain' of an emissions penalty is still quite low for most industrial users of natural gas. There is potential that by 2030 , the cost per ton of $\mathrm{CO}_{2}$ could reach $\$ 55 /$ ton (Nemec 2017b), which could force large industrial end-users to consider alternatives like solar thermal. The impact would need to be understood for small industrial sites like food processors. It is likely that California will continue to penalize $\mathrm{CO}_{2}$ emissions, which will raise the cost of natural gas usage and promote conservation and alternative heat sources such as solar $\mathrm{IPH}$.

\section{Modeling Solar Process Heat with PCM Storage}

Use of a solar collector for the DSG can be an efficient way of using solar energy for industrial steam supply. However, the intermittency of solar energy limits the capacity factor for the system, and hence, increases the cost of the steam produced. In project 
year three, NREL used SAM's solar DSG process heat model with a PCM-based TES system to simulate a DSG + TES system. The model examined the influence of PCM thermal conductivity and other system properties on overall performance and cost.

With enhancement in the PCM thermal conductivity, the design-point performance of the storage system increases considerably, but these enhancements are expensive. In addition, the performance of the storage depends on the heat supplied from the DSG collector, which varies considerably over a year compared to the design point. A detailed yearly simulation needs to be carried out to predict the optimal PCM thermal conductivity. A literature review showed limited information available for the PCM storage optimization based on annual simulation. The objective of the study was to minimize the $\mathrm{LCOH}$ for the steam generated from PCM integrated with the solar-thermal system for solar IPH. Different available PCM materials for process-heat applications are identified, and a suitable PCM, sodium formate $\left(\mathrm{T}_{\mathrm{mp}}=258^{\circ} \mathrm{C}\right)$, is selected based on cost and thermal properties. The optimal values of different design parameters (PCM thermal conductivity, hours of storage, pitch of the tubes, pipe diameter, and length of pipe) are calculated based on detailed annual simulation. Surface-area extending fins are modeled to improve heat transfer within the system and an approximate method for calculating the fin mass required to enhance the effective thermal conductivity is derived. Sensitivity analysis based on the solar installation cost is also carried out, and breakeven price for the solar field is calculated so that the cost of steam is comparable with steam produced from natural gas.

For this case study, the annual capacity factor for steam generation without storage is $30.9 \%$. PCM storage depends on several operating parameters, and detailed parametric analysis is done to calculate the optimal design parameters based on annual simulation. The thickness of the PCM surrounding the tube is inversely proportional to the cost of the storage. But with an increase in the PCM thickness, the resistance offered by the PCM increases significantly. To improve the heat transfer, either fins or some thermalconductivity enhancement technique for PCM is needed. To improve the heat transfer through PCMs, the use of longitudinal fins is proposed. But fins can be expensive, so a detailed technoeconomic analysis is done to minimize the levelized cost of heat for steam generation. The minimum LCOH for steam generation is 4.2 cents $/ \mathrm{kWh}$ th with four hours of storage, $38.5 \%$ capacity factor, and $1.5 \mathrm{~W} / \mathrm{mK}$ thermal conductivity for the PCM.

In a cost comparison with natural-gas-fired boilers, the steam generated from a solar thermal system is slightly more expensive for California, USA, but could be competitive if solar installation costs reduce to $220 \$ / \mathrm{m}^{2}$. To be competitive with other sunny regions of the United States, the solar installation cost needs to be less than about $100 \$ / \mathrm{m}^{2}$.

The complete study is being prepared for journal submission (Sharan, Kurup, and Turchi 2018).

\section{Task 5. SolarPACES Task I Status Updates}

Throughout the last two years of the three-year project, funding was provided to support NREL's participation as the operating agent for SolarPACES Task I. SolarPACES is an international association representing the CSP research and industrial community. SolarPACES Task I covers the design, testing, demonstration, evaluation, and application of CSP systems. For example: (i) the development and population of an international 
project database for commercial CSP plants and projects, (ii) the development of acceptance test procedures and standards for CSP systems, (iii) the development of best practice guidelines for modeling CSP systems, and (iv) the analysis of the value of CSP in electricity markets with variable energy sources. Substantial CSP research and deployment activity is occurring internationally and knowledge of these activities helps DOE assess the value to the U.S. CSP industry and DOE program objectives. Lessons from the international community are leveraged to improve U.S. plant performance and augment U.S. research objectives. The project reported SolarPACES activities to DOE on a quarterly basis.

In project year three, NREL completed the development of a model checklist for the SolarPACES Guidelines for Bankable STE Yield Assessment, also known as the GuiSmo project. Accurately modeling risks, costs, and electricity output is essential to the financing and advancement of concentrating solar power projects. To address this need, a group of CSP experts created a guideline document, titled SolarPACES Guideline for Bankable STE Yield Assessment (Hirsh et al. 2017). To make this information more accessible and allow stakeholders to test specific models against the recommendations, the guidelines have been condensed into a spreadsheet-based checklist. The checklist was applied to SAM, providing useful feedback to both the checklist group and the SAM development team. The study showed strong agreement between SAM and the guidelines, demonstrated the use of the guidelines in model validation, and resulted in several recommended improvements to SAM (Kesseli et al. 2018).

Task 6. Assessment of Advanced CSP Systems in the $600^{\circ} \mathrm{C}$ to $650^{\circ} \mathrm{C}$ Temperature Range In project year two, NREL examined the potential benefit of adopting the $\mathrm{sCO}_{2}$ Brayton cycle at $600^{\circ} \mathrm{C}$ to $650^{\circ} \mathrm{C}$ compared to the current state-of-the-art power tower operating a steam-Rankine cycle with solar salt at approximately $574^{\circ} \mathrm{C}$. The analysis compared a molten-salt power tower configuration using direct storage of solar salt $(60: 40$ weight $\%$ sodium nitrate : potassium nitrate) or single-component nitrate salts at $600^{\circ} \mathrm{C}$ or alternative carbonate- or chloride-based salts at $650^{\circ} \mathrm{C}$.

The increase in power cycle efficiency offered by the $\mathrm{sCO}_{2}$ Brayton cycle is expected to reduce the size and cost of the solar field required for a given thermal energy input. Power cycle capital cost is expected to decrease compared to the superheated steam-Rankine cycle, based on projections from $\mathrm{sCO}_{2}$ cycle developers. Maximizing the $\Delta \mathrm{T}$ of the storage system is required for viable deployment of sensible-salt TES. In this regard, the partialcooling $\mathrm{sCO}_{2}$ cycle is noted as a better option than the recompression $\mathrm{sCO}_{2}$ cycle. In the analysis it is assumed that a $\Delta \mathrm{T}=180 \mathrm{~K}$ can be achieved with the partial-cooling cycle. Even with $\Delta \mathrm{T}=180 \mathrm{~K}$, the potential benefits of the $\mathrm{sCO}_{2}$ Brayton cycle are partially or completely offset by increased thermal storage cost, albeit for reasons that differ for the different salts. An approximate $5 \%$ reduction in levelized cost of energy (LCOE) is achieved with either solar salt at $600^{\circ} \mathrm{C}$ or ternary chloride salt at $650^{\circ} \mathrm{C}$.

The potential of using pure sodium nitrate or potassium nitrate is considered because the cold tank temperature for the $\mathrm{sCO}_{2}$ power cycle is estimated at $420^{\circ} \mathrm{C}$, which would allow use of a salt with a higher melting point than solar salt. Sodium nitrate is the most cost effective, resulting in an overall LCOE reduction of $8.5 \%$; however, sodium nitrate is known to have lower thermal stability than potassium nitrate. 
The strong influence of salt cost and hot-tank cost on overall economics led to the analysis of single-tank thermocline options. The thermocline design significantly reduces salt inventory (by $50 \%$ or more) and in many cases also reduces the tank size versus the hot salt tank of the 2-tank system. It is speculated that integration of encapsulated phasechange material (PCM) in the thermocline could further increase the thermal-storage energy density and reduce storage tank volume. The thermocline cases led to three scenarios with relative LCOE reductions of approximately $10 \%$; however, this must be tempered by possible operational inefficiencies of the thermocline temperature profile.

The full results of this study are documented in a Solar Energy journal article published in 2018 (C. S. Turchi, Vidal, and Bauer 2018).

\section{Inventions, Patents, Publications, and Other Results}

\section{Patents and Patent Applications}

T. Neises, "Hybridized Low-Temperature and High-Temperature Power Cycle," U.S. provisional patent application 62/361,134.

\section{Journal Submittals}

C.S. Turchi, J. Vidal, and M. Bauer, "Molten salt power towers operating at $600-650{ }^{\circ} \mathrm{C}$ : Salt selection and cost benefits," Solar Energy, 164, 38-46 (2018).

G. Mohan, M. Venkataraman, J. Gomez-Vidal, J. Coventry. "Assessment of a novel ternary eutectic chloride salt for next generation high-temperature sensible heat storage," Energy Conversion and Management, 167, 156-165 (2018).

G. Mohan, M. Venkataraman, J. Gomez-Vidal, J. Coventry. "Thermo-economic analysis of hightemperature sensible thermal storage with different ternary eutectic alkali and alkaline earth metal chlorides," Solar Energy, 176, 350-357 (2018).

M.J. Wagner et al., "Optimizing Dispatch for a Concentrated Solar Power Tower," Solar Energy, 174, 1198-1211 (2018). (documents SolarPILOT upgrades)

J. Lilliestam, T. Barradi, N. Caldés, M. Gomez, S. Hanger ,J. Kern, N. Komendantova, M. Mehos, W.M. Hong, Z. Wang, A. Patt, "Policies to keep and expand the option of concentrating solar power for dispatchable renewable electricity," Energy Policy, 116, 193-197 (2018).

T. Neises and C. Turchi, "Supercritical Carbon Dioxide Power Cycle Design and Configuration Optimization to Minimize Levelized Cost of Energy of Molten Salt Power Towers Operating at $650^{\circ} \mathrm{C}$," Solar Energy, submitted, November 2018.

P. Sharan, P. Kurup, and C. Turchi, "Optimal System Design for Steam Production from Solar Collector and Phase-Change Material Storage," Solar Energy, in preparation.

\section{Conference Publications and NREL Reports}

Tse and T. Neises, "Analysis and Optimization for Off-design Performance of the Recompression $\mathrm{sCO}_{2}$ Cycles for High Temperature CSP Applications," 5th International Symposium - Supercritical CO2 Power Cycles, San Antonio, TX, March 29-31, 2016.

C. Turchi, P. Kurup, and G. Zhu, "Revisiting Parabolic Trough Concentrators for Industrial Process Heat in the United States," PowerEnergy2016-59621, ASME 2016 Power \& Energy Conference, Charlotte, NC, June 26-30, 2016. 
C. Turchi, J. Vidal, M. Bauer, "Intermediate-Temperature Molten Salt as a Pathway to CSP Performance and Cost Goals under the U.S. SunShot Initiative," SolarPACES, Santiago, Chile, September 25-29, 2017.

P. Kurup, A. Parikh, J. Möllenkamp, T. Beikircher, A. Samoli, and C. Turchi, "SAM Process Heat Model Development and Validation: Liquid-HTF Trough and Direct Steam Generation Linear Focus System," Solar World Congress, Abu Dhabi, United Arab Emirates, October 29 to November 2, 2017.

P. Sharan, T. Neises, and C. Turchi, "Thermal Desalination as Cooling for a Supercritical Carbon Dioxide Brayton Cycle," Paper 187, Supercritical $\mathrm{CO}_{2}$ Power Cycles Symposium Pittsburgh, PA, March 26-29, 2018.

C. Turchi, " $\mathrm{SCO}_{2}$ Power-Related Research at NREL," National Laboratory Panel Presentation Supercritical $\mathrm{CO}_{2}$ Power Cycles Symposium, Pittsburgh, PA, March 26-29, 2018.

T. Neises, "Supercritical Carbon Dioxide Recompression Cycle Integration with a Molten Salt Power Tower CSP Plant, ASME 2018 Energy Sustainability Conference, Lake Buena Vista, FL, June 25-28, 2018.

D. Kesseli, M. Wagner, R. Guédez, and C.S. Turchi, "CSP-Plant Modeling Guidelines and Compliance of the System Advisor Model (SAM), SolarPACES 2018, Casablanca, Morocco, October 2-5, 2018. 


\section{Path Forward}

NREL will continue to support the DOE program with development and improvement of analysis tools for estimating the performance and cost of CSP systems. Proposed work for future years includes:

- Bottoms up cost analysis for a next-generation parabolic trough collector and heliostat subsystems from a U.S.-based developer to be used for SAM solar field updates.

- Development of a cavity-receiver option for SAM's molten-salt power tower model and extension of the model library to include additional HTFs. Many designs for future hightemperature CSP systems rely on cavity-receiver designs to ensure good thermal efficiency. The proposed SAM model and underlying SolarPILOT code will provide the user a path to evaluate the efficiency of cavity designs.

- The dispatch optimization code in SAM's molten-salt power tower model will be converted for use in the other models that currently include TES, that is, the Physical Trough and Trough Process Heat models. This will allow the benefits of dispatch optimization to be extended to the trough-system models.

- The primary metrics for TES performance, e.g., thermal capacity, temperature profile, thermal loss rate, etc., will be provided as user input functions or tables to allow simulation of performance of novel TES systems.

- Continued support for NREL's role as the operating agent for SolarPACES Task I. The active international sector provides valuable markets for U.S. CSP developers and knowledge that can be applied to systems in the United States.

- Development of a general model of the latent-heat storage in SAM's C++ code base. Latent-heat TES offers unique opportunities for efficiency when integrated with the $\mathrm{sCO}_{2}$ Brayton cycle. Develop a CSP system model of a sensible-heat HTF power tower, cascaded latent-heat storage, and the reheat recompression cycle.

- Quantify the potential benefits of small-scale (e.g., less than $50 \mathrm{MWe}$ ) power tower designs featuring factory-fabricated power block and tower designs to drive down the cost of next-generation CSP technology deployment.

This scope will be discussed and refined with the DOE CSP program and is subject to funding availability and decisions of that office. 


\section{References}

23 ABC News. 2017. “Aera, GlassPoint to Build State's Largest Solar Energy Project in Kern County." 23ABC News. November 30, 2017. https://www.turnto23.com/news/localnews/aera-glasspoint-to-build-states-largest-solar-energy-project-in-kern-county.

Aalborg CSP. 2017. "50MWe SGS4 Steam Generation System for CSP Plant, China.” Aalborg CSP. 2017. https://www.aalborgcsp.com/projects/50mwe-sgs4-steam-generation-systemfor-csp-plant-china/.

Abengoa S.A. 2018. “Abengoa DEWA Solar Field Press Release.” Abengoa.

http://www.abengoa.com/export/sites/abengoa_corp/resources/pdf/gobierno_corporativo/ hr_y_otras_comunicaciones_cnmv/hechos_relevantes/2018/20180509-HR-Dewaeng.pdf.

Absolicon. 2011. "Hemab Energipark - Absolicon Solar Collector." June 13, 2011. http://www.absolicon.se/case/hemab-energipark/.

2012. "Smedjebacken - Absolicon Solar Collector." February 2012. http://www.absolicon.se/case/baverglantan-smedjebacken/.

. 2017. "Absolicon Collector - Steam and Process Heat for Industry." 2017. http://www.absolicon.se/absolicon-t160/.

- 2018a. "First Production Line Shipped to China!" 2018. http://www.absolicon.se/forstaproduktionslinan-skeppad-till-kina/.

—. 2018b. "Ongoing projects." 2018. http://www.absolicon.se/om-absolicon/pagaendeprojekt/.

—. 2018c. "Absolicon Magazine (Issue 4)." Absolicon. http://www.absolicon.se/wpcontent/uploads/2018/08/AM18EN_Small_Absolicon-Magazine-2018.pdf.

ACWA $\quad$ Power. 2017. - "Rēstone CSP IPP." 2017. http://www.acwapower.com/en/projects/assets/projects/redstone-csp-ipp/.

ADB. 2013. "Proposed Loan: People's Republic of China: Qinghai Delingha Concentrated Solar Thermal Power Project." 46058. Asian Development Bank. https://www.adb.org/sites/default/files/project-document/79585/46058-002-pam.pdf.

Adrian Farr, Randy Gee. 2009. "The SkyTrough ${ }^{\mathrm{TM}}$ Parabolic Trough Solar Collector." https://doi.org/10.1115/ES2009-90090.

AEE INTEC. 2017. "SHIP Plant: Agropecuaria Tarasca." 2017. http://ship-plants.info/solarthermal-plants/257-agropecuaria-tarasca-s-de-p-r-de-r-1-

mexico?name=Agropecuaria+Tarasca.

—. 2018. "Solar Heat for Industrial Processes (SHIP) Plants Database." 2018. http://shipplants.info/solar-thermal-plants.

Akar, Sertac, Chad Augustine, Parthiv Kurup, and Margaret Mann. 2018. "Global Value Chain and Manufacturing Analysis on Geothermal Power Plant Turbines." NREL/TP-6A2071128. Golden, CO: NREL. https://gdr.openei.org/files/1067/CEMAC\%20GTO_Technical\%20Report_Geothermal\% 20Power\%20Plant\%20Turbines_Final_06.01.2018.pdf.

Alanod Solar. 2014. "Efficiency. Solar. Surfaces." Alanod Solar. https://www.alanod.com/wpcontent/uploads/2014/12/Alanod_Solar_Image_12s_FINAL_E_11_14-1.pdf.

Artic Solar. 2019. "What Makes Us Different." ${ }^{-}$Artic Solar. 2019. http://articsolar.com/home/what-makes-us-different/.

Berger, M., M. Mokhtar, C. Zahler, M. M. R. Al-Najami, D. Krüger, and K. Hennecke. 2016. "Solar Process Steam for a Pharmaceutical Company in Jordan." In AIP Conference Proceedings, 1734:100001. Cape Town, South Africa. https://doi.org/10.1063/1.4949189. 
Bierman, B., J. O’Donnell, R. Burke, M. McCormick, and W. Lindsay. 2014. "Construction of an Enclosed Trough EOR System in South Oman." Energy Procedia, Proceedings of the SolarPACES 2013 International Conference, 49 (January): 1756-65. https://doi.org/10.1016/j.egypro.2014.03.186.

Bierman, B., C. Treynor, J. O’Donnell, M. Lawrence, M. Chandra, A. Farver, P. von Behrens, and W. Lindsay. 2014. "Performance of an Enclosed Trough EOR System in South Oman." Energy Procedia, Proceedings of the SolarPACES 2013 International Conference, 49 (January): 1269-78. https://doi.org/10.1016/j.egypro.2014.03.136.

BLS. 2017. "Occupational Employment and Wages, May 2017: 47-2061 Construction Laborers." Bureau of Labor Statistics. May 2017. https:/www.bls.gov/oes/current/oes472061.htm.

Business Wire. 2017. “Aera Energy and GlassPoint to Build California's Largest Solar Energy Project at Kern County's Belridge Oilfield," November 29, 2017. https://www.businesswire.com/news/home/20171129006025/en/Aera-EnergyGlassPoint-Build-California\%E2\%80\%99s-Largest-Solar.

California Legislative Information. 2017. "Bill Text - AB-797 Solar Thermal Systems." California Legislative Information. $\quad$ October $\quad 5,2017$. https://leginfo.legislature.ca.gov/faces/billTextClient.xhtml?bill_id=201720180AB797.

ChemEng Online. 2018. "Chemical Engineering Plant Cost Index (CEPCI)." September 2018. https://www.chemengonline.com/pci-home.

CNIM. 2016. "SUNCNIM Raises €60 Million.” October 13, 2016. https://cnim.com/en/media/suncnim-raises-eu60-million.

CNSTE. 2017. "Hangzhou Steam Turbine Co., Ltd. Wins the Bid of Turbine-Generator Set for Supcon Delingha 50MW Solar Tower Project - China National Solar Thermal Alliance." China National Solar Thermal Alliance. April 27, 2017. http://en.cnste.org/html/csp/2017/0427/243.html.

Coventry, Joe, Jon Campbell, Yunpeng Xue, Colin Hall, and John Pye. 2016. "Heliostat Cost Down Scoping Study - Final Report." STG-3261 Rev 01. https://www.researchgate.net/publication/312214094_Heliostat_Cost_Down_Scoping_St udy__Final_Report.

CPI. 2018. "California Carbon Dashboard." Climate Policy Initiative. 2018. calcarbondash.org.

CSP Focus. 2017a. "Bidding Update on SUPCON Delingha 50MW Solar CSP Tower Project in China." CSP Focus, February 14, 2017. http://www.cspfocus.cn/en/project/detail_68.htm. - 2017b. "SUPCON Offer USD180m Bidding Price (USD105/ $\mathrm{m}^{2}$ on Solar Field) for China 50MW CSP Tower Hybrid Project.” CSP Focus, August 22, 2017. http://www.cspfocus.cn/en/market/detail_272.htm.

- 2017c. "China Dahua Shangyi 50MW Tower CSP Project Starts next April.” CSP Focus, November 23, 2017. http://cspfocus.cn/en/project/detail_85.htm.

—. 2018a. "Shouhang Dunhuang 100MW Molten Salt Tower CSP Plant." http://www.cspfocus.cn/en/report/detail_43.htm.

. 2018b. "China 1st Large-Scale Commercial CSP Project-CGN Delingha 50MW Plant Commercially Operates on September 30," September 4, 2018. http://www.cspfocus.cn/en/market/detail_943.htm.

CSP Plaza. 2018a. "Brazil Plans to Build A New Concentrated Solar Plant of 12,000 $\mathrm{M}^{2}$." CSP $P L A Z A$, April 6, 2018. http://en.cspplaza.com/brazil-plans-to-build-a-new-concentratedsolar-plant-of-12000-m\%c2\%b2/. 
- 2018b. "SolarReserve's Aurora Solar Project Signs MOU for 13,000 Heliostats of Aurora Solar Energy Project.” September 20, 2018. http://en.cspplaza.com/solarreserves-aurorasolar-project-signs-mou-for-13000-heliostats-of-aurora-solar-energy-project/.

Digital Journal. 2018. "Solar Thermal Is Distilling Spirits in Jacksonville Florida. Four Fathers Has the Proof!" December 28, 2018. http://www.digitaljournal.com/pr/4088704.

Dixon, Drew. 2019. "Solar-Steam Process Distills Four Fathers Spirits." The Florida Times-Union - Jacksonville. January 18, 2019. https:/www.jacksonville.com/news/20190118/solarsteam-process-distills-four-fathers-spirits.

DOE. 2016. "PROJECT PROFILE: Sunvapor Inc. (CSP: COLLECTS)." Energy.Gov. 2016. https://energy.gov/eere/solar/project-profile-sunvapor-inc-csp-collects.

DOE EERE. 2016. "PROJECT PROFILE: Hyperlight Energy (CSP: COLLECTS)." 2016. https://www.energy.gov/eere/solar/project-profile-hyperlight-energy-csp-collects.

- 2017. "EERE Success Story - Concentrating Solar Power Transforms Food Processing with Solar Steam.” Energy.Gov. June 16, 2017. https://www.energy.gov/eere/successstories/articles/eere-success-story-concentrating-solar-power-transforms-food.

2018. "Solar Desalination." June 19, 2018. https:/www.energy.gov/eere/solar/solardesalination.

Dou, George, Fridolin Stary, and Erich Schaffer. 2017. "World's First Commercial Application for 'Heliosol \%A' New Silicone Based HTF - Royal Tech 50 MW TRough Project in Yumen, Sansu, China." presented at the SolarPaces 2017, October. https://www.solarpaces.org/wp-content/uploads/HELIOSOL-Presentation.pdf.

Dubai FAQs. 2018. "Salaries and Wages in Dubai." September 25, 2018. http:/www.dubaifaqs.com/salaries-dubai.php.

Economic Research Institute. 2018. "Construction Worker Salary in China.” Salary Expert. 2018. https://www.salaryexpert.com/salary/job/construction-worker/china.

Epp, Bärbel. 2018. "Parabolic Trough Collector Production Line Shipped to China." April 24, 2018. http://www.solarthermalworld.org/content/parabolic-trough-collector-productionline-shipped-china.

ESTELA. 2016. "The Value of Solar Thermal Electricity: Cost Vs. Value Approach.” 2016. http://www.estelasolar.org/Docs/2016_ESTELA_STE-CSP_Value_Final.pdf.

Frank, Elimar, Heinz Marty, Lucien Hangartner, and Stefan Minder. 2014. "Evaluation of Measurements on Parabolic Trough Collector Fields for Process Heat Integration in Swiss Dairies." Energy Procedia, 2013 ISES Solar World Congress, 57: 2743-51.

Glasspoint. 2018a. "Markets - Oman." GlassPoint. 2018. https://www.glasspoint.com/markets/oman/.

-. 2018b. "Miraah - Project Fact Sheet." https://www.glasspoint.com///wpcontent/uploads/GPS_MiraahFactSheet_v2.0_201802.pdf.

Government of Dubai. 2018. "Mohammed Bin Rashid Breaks Ground on World's Biggest Concentrated Solar Power Project." March 19, 2018. https://www.dewa.gov.ae/en/aboutdewa/news-and-media/press-and-news/latest-news/2018/03/mohammed-bin-rashidbreaks-ground.

Guide 2 Dubai. 2017. "Dubai Salary and Pay Scale." August 15, 2017. https://www.guide2dubai.com/living/expat-life/dubai-salary-and-pay-scale.

Heliac. 2018a. "FAQ." Heliac. 2018. https://www.heliac.dk/utility-scale/faq.html. . 2018b. "Home | Heliac." Heliac. 2018. https://www.heliac.dk/utility-scale/. 
HelioCSP. 2017. "SUPCON offer USD180m bidding price (USD105/mon solar field) for China 50MW Concentrated Solar Power Tower hybrid project." HELIOSCSP, August 22, 2017. http://helioscsp.com/supcon-offer-usd180m-bidding-price-usd $105 \% \mathrm{e} \% 8 \mathrm{e} \% \mathrm{al}$ on-solarfield-for-china-50mw-concentrated-solar-power-tower-hybrid-project/.

2018. "China's first batch of Concentrated Solar Power demonstration projects." HelioCSP, May 4, 2018. http://helioscsp.com/progress-of-chinas-first-batch-ofconcentrated-solar-power-demonstration-projects/.

Heliovis. 2017. "Technology - Inflatable Trough.” HELIOVIS AG. 2017. https://heliovis.com/technology/.

Hirsh, T., J. Dersch, T. Fluri, J. Garcia-Barberena, S. Giuliano, F. Hustig-Diethelm, R. Meyer, N. Schmidt, M. Seitz, and M. Eck. 2017. "SolarPACES Guideline for Bankable STE Yield Assessment." IEA Technology Collaboration Programme SolarPACES.

Hyperlight Energy. 2016. "Energy Commission Funds New Wastewater Treatment Process and Solar Power Collector." October 19, 2016. http://www.hyperlightenergy.com/wp/?p=897.

Industrial Solar. 2016. "Technical Data: Industrial Solar Linear Fresnel Collector LF-11." https://www.industrial-solar.de/en/products/fresnel-collector/.

Inventive Power. 2016. "Power Trough 110 Datasheet." http://www.inventivepower.com.mx/wpcontent/uploads/2016/02/Inventive-Power-Datasheet-2015.pdf.

2017a. "Proyectos: Agropecuaria Tarasca." 2017. http://inventivepower.com.mx/?us_portfolio=agropecuaria-tarasca-morelia-michoacanmexico\&lang=es.

$2017 \mathrm{~b}$

"Proyectos:

Howard

Johnson."

2017. http://inventivepower.com.mx/?us_portfolio=proyecto-cecoopal-capilla-de-guadalupejalisco-mexico\&lang=es.

—. 2017c. "Power Trough 250 Datasheet." http://inventivepower.com.mx/wpcontent/uploads/2017/03/MONOFOLLETO_POWER_250_2016.pdf.

_. 2018. "Projects." 2018. http://inventivepower.com.mx/?page_id=6296\&lang=en.

IRENA. 2016. "The Power to Change: Solar and Wind Cost Reduction Potential to 2025." International Renewable Energy Agency. /publications/2016/Jun/The-Power-to-ChangeSolar-and-Wind-Cost-Reduction-Potential-to-2025.

Jung, C., J. Dersch, A. Nietsch, and M. Senholdt. 2015. "Technological Perspectives of Silicone Heat Transfer Fluids for Concentrated Solar Power.” Energy Procedia, SolarPACES 2014, 69 (2015): 663-71.

Kazkaz, Labib. 2018. "Heliovis - Inflatable Collectors for CSP Made from Plastic Films." January.

Kelly, Bruce. 2010. "Advanced Thermal Storage for Central Receivers with Supercritical Coolants." 08GO18149. https://www.osti.gov/servlets/purl/981926.

Kesseli, Devon, Michael Wagner, Rafael Guedez, and Craig S. Turchi. 2018. "CSP-Plant Modeling Guidelines and Compliance of the System Advisor Model (SAM)." In SolarPACES 2018. Casablanca, Morocco.

Kistner, Rainer. 2016. "Update on Recent Developments in the CSP Technology.” Berlin: GIZ. https://www.giz.de/de/downloads/giz2016_en_CSP\%20Update_Abu\%20Dhabi.pdf.

Krüger, Dirk, Michael Berger, Marwan Mokhtar, Lisa Willwerth, Christian Zahler, Mahmoud AlNajami, and Klaus Hennecke. 2017. "Experiences with Industrial Solar Process Steam Generation in Jordan." In AIP Conference Proceedings, 1850:180003. American Institute of Physics. https://doi.org/10.1063/1.4984570.

Kurup, Parthiv, Abhishek Parikh, Jana Möllenkamp, Thomas Beikircher, Alexia Samoli, and Craig Turchi. 2018. "SAM Process Heat Model Development and Validation: Liquid-HTT 
Trough And Direct Steam Generation Linear Focus Systems." In . https://www.researchgate.net/publication/320907845_SAM_PROCESS_HEAT_MODEL _DEVELOPMENT_AND_VALIDATION_LIQUIDHTF_TROUGH_AND_DIRECT_STEAM_GENERATION_LINEAR_FOCUS_SYSTE MS.

Kurup, Parthiv, and Craig Turchi. 2015a. "Initial Investigation into the Potential of CSP Industrial Process Heat for the Southwest United States." NREL/TP-6A20-64709. NREL. http://www.nrel.gov/docs/fy16osti/64709.pdf.

- 2015b. "Parabolic Trough Collector Cost Update for the System Advisor Model (SAM)." NREL/TP-6A20-65228. NREL. http://www.nrel.gov/docs/fy16osti/65228.pdf.

Lilliestam, Johan, Mercè Labordena, Anthony Patt, and Stefan Pfenninger. 2017. "Empirically Observed Learning Rates for Concentrating Solar Power and Their Responses to Regime Change." Nature Energy 2 (7): 17094.

Lilliestam, Johan, and Robert Pitz-Paal. 2018. "Concentrating Solar Power for Less than USD 0.07 per KWh: Finally the Breakthrough?” Renewable Energy Focus 26 (September): 17-21. https://doi.org/10.1016/j.ref.2018.06.002.

Markham, Derek. 2017. "This Concentrated Solar Power Plant Is Totally Tubular \& Easily Transported." TreeHugger. October 9, 2017. https:/www.treehugger.com/solartechnology/concentrated-solar-power-plant-totally-tubular-easily-transported.html.

Mehos, Mark, Craig Turchi, Jennie Jorgenson, Paul Denholm, Clifford Ho, and Kenneth Armijo. 2016. "On the Path to SunShot: Advancing Concentrating Solar Power Technology, Performance, and Dispatchability.” NREL/TP-5500-65688. EERE Publication and Product Library. https://www.nrel.gov/docs/fy16osti/65688.pdf.

Minder, Stefan. 2013. "Example of Concentrated Solar Systems (PTC) in the Dairy Industry in Switzerland." presented at the SHC Workshop on Solar Process Heat for Industry, Zurich, Switzerland, March $\quad 15 . \quad$ http://www.rhcplatform.org/fileadmin/user_upload/Structure/Solar_Thermal/Download/130315_Worksh op_SPHI_Example_of_concentrated_solar_systems_PTC_in_the_dairy_industry_in_ Switzerland_S_Minder.pdf.

Muang, Zara. 2018. "Maximizing Concentrating Solar Heat's Potential in the Food Industry." MENA CSP KIP. October 31, 2018. https://cmimarseille.org/menacspkip/maximizingconcentrating-solar-heats-potential-food-industry/.

Mungas, Greg. 2016. "Low Cost Concentrated Solar Power (CSP) Collector: Hyperlight Energy." presented at the CSP Program Summit 2016. https://www.energy.gov/sites/prod/files/2016/08/f33/Collectors\%20AM\%2004-\%20CSPProgram-Summit-Hyperlight-Mungas\%20-\%20FINAL.pptx.

Neises, Ty, and Craig Turchi. 2018. "Supercritical Carbon Dioxide Power Cycle Design and Configuration Optimization to Minimize Levelized Cost of Energy of Molten Salt Power Towers Operating at $650^{\circ}$ C." Solar Energy submitted.

Nemec, Richard. 2017a. "California Bipartisan Vote Extends Cap-and-Trade Another Decade." Natural Gas Intel. July 18, 2017. http://www.naturalgasintel.com/articles/111121california-bipartisan-vote-extends-cap-and-trade-another-decade? $\mathrm{v}=$ preview.

_. 2017b. "Cost of California Carbon Credits Likely to Increase, Study Says." Natural Gas Intel. December 11, 2017. http://www.naturalgasintel.com/articles/112708-cost-ofcalifornia-carbon-credits-likely-to-increase-study-says? $\mathrm{v}=$ preview.

NEP Solar. 2013. "PolyTrough 1800 Technical Datasheet (V7)." NEP Solar. http://www.nepsolar.com/wp-content/uploads/2013/11/NEP-Solar-Polytrough1800_Datasheet.pdf. 
New Energy Update. 2018. “Abengoa Dubai Contract Valued at \$650mn; US to Inject \$72mn into High-Temperature Designs." May 16, 2018. http://analysis.newenergyupdate.com/csptoday/abengoa-dubai-contract-valued-650mn-us-inject-72mn-high-temperature-designs.

Novatec Biosol. 2011. "Puerto Errado II BOP 30 MW Thermal Power Station - Process Diagram Water/Steam Balance Load Point 100\%." Tubosol PE2.

Novatec Solar. 2011. "NOVATEC SOLAR: Concentrating Solar Power - Puerto Errado 2 in Spain.” Novatec Solar. 2011. http://www.novatecsolar.com/56-1-PE-2.html.

NREL. 2017a. "2017 Annual Technology Baseline." 2017. https://atb.nrel.gov/.

—. 2017b. "System Advisor Model (SAM)." NREL System Advisor Model. 2017. https://sam.nrel.gov/.

NREL and SolarPaces. 2016. "Concentrating Solar Power Projects - Gulang 100MW Thermal Oil Parabolic Trough Project." $\quad$ September 2016. https://www.nrel.gov/csp/solarpaces/project_detail.cfm/projectID=5309.

PayScale. 2018. "USA - Average Construction Worker Hourly Pay." 2018. https://www.payscale.com/research/US/Job=Construction_Worker/Hourly_Rate.

Pitchbook. 2018. "Skyven Technologies Company Profile: Valuation \& Investors." 2018. https://pitchbook.com/profiles/company/94853-17.

Pitz-Paal, Robert. 2017. "Status and Perspectives of CSP Technology." presented at the AGCS Expert Days. https://www.agcs.allianz.com/assets/Global\%20offices\%20assets/Germany/Expert\%20D ays\%202017/Pr\%C3\%A4sentationen/04_AGCS_Expert_Days_2017_CSP_Technology_ Robert_Pitz-Pall.pdf.

Pizá de Silva, $\bar{C}$ arlos. 2018. "Abengoa logra su mayor contrato tras el rescate: $480 \mathrm{M}$ con Acwa y Shanghai Electric. Noticias de Empresas." El Confidencial, May 2, 2018. https://www.elconfidencial.com/empresas/2018-02-05/abengoa-solar-dubai-acwaenergia-china_1517428/.

PR Newswire. 2018a. "EPC Contract with Shanghai Electric to Develop 700 MW DEWA CSP Project Signed in China," April 15, 2018. https:/www.prnewswire.com/newsreleases/epc-contract-with-shanghai-electric-to-develop-700-mw-dewa-csp-projectsigned-in-china-679802743.html.

. 2018b. "Preparing for the Next Big Drought: Sunvapor Receives \$1.5M Award from U. S. Department of Energy." June 25, 2018. https://www.prnewswire.com/newsreleases/preparing-for-the-next-big-drought-sunvapor-receives-1-5m-award-from-u-sdepartment-of-energy-300671429.html.

Protolabs. 2016. "Case Study: Skyven Technologies.” 2016. https://www.protolabs.com/resources/case-studies/skyven-technologies/.

Rackam. 2016. "S10 Parabolic Trough System - Data Sheet." Rackham. https://rackam.com/media/products/rackam_s10.pdf.

. 2017a. "Heat2Hydro, Inc. Selects Rackam Solar Thermal Equipment to Power an Advanced Technology Wastewater Treatment System for the City of Surprise, Arizona! News - Rackam.” Rackam. September 12, 2017. /en/news/heat2hydro-inc-selects-rackamsolar-thermal-equipm/.

- 2017b. "A Contract for Rackam with More than 5 MWth in Brazil." November 15, 2017. /en/news/contract-brazil-5MW/.

. 2018. "Projects - Rackam." 2018. https://rackam.com/en/studies/.

SBP. 2016. "Stellio Heliostat." 2016. https://www.sbp.de/en/project/stellio-heliostat/. 
Schaffer, Erich. 2016. "HELISOL®- Ein Siliconöl Basierter Wärmeträger Für CSP Kraftwerke.” June 7. https://www.dlr.de/sf/Portaldata/73/Resources/dokumente/soko/soko2016/DLRSonnenkolloquium2016_Schaffer_(Wacker)_HELISOL-

Ein_Siliconoel_fuer_CSP_Kraftwerke.pdf.

Sharan, Prashant, Parthiv Kurup, and Craig Turchi. 2018. "Optimal System Design for Steam Production from Solar Collector and Phase- Change Material Storage." In Preparation.

Shemer, Nadav. 2017. "CSP Heliostat Innovations Set to Deliver Big Cost Reductions." New Energy Update, November 1, 2017. http://newenergyupdate.com/csp-today/csp-heliostatinnovations-set-deliver-big-cost-reductions.

—. 2018a. "As CSP Bids Fall to Record Lows, Prices Diverge between Regions." February 20, 2018. http://newenergyupdate.com/csp-today/csp-bids-fall-record-lows-pricesdiverge-between-regions.

2018b. "CSP Capex Costs Fall by Almost Half as Developers Shift towards China and Middle East." New Energy Update, April 16, 2018. http://newenergyupdate.com/csptoday/csp-capex-costs-fall-almost-half-developers-shift-towards-china-and-middle-east.

Skyven Technologies. 2018a. “Applications." Skyven Technologies. 2018. http://www.skyven.co/uses/.

. 2018b. "Skyven Technologies Revolutionizes Industrial Heat with the Support of the National Science Foundation." Skyven Technologies. January 9, 2018. http://www.skyven.co/news/2018/1/9/skyven-technologies-revolutionizes-industrial-heatwith-the-support-of-the-national-science-foundation.

Solar Dynamics. 2018. "RE: CSP Tracker Updates: Abengoa to Supply Technology for 3 Dubai Projects; SolarReserve May Add PV to Aurora," May 15, 2018.

Solarlite. 2011. "TSE 1' Kanchanaburi Province, Thailand - 5 MWe Solar Thermal Power Plant." Solarlite. 2011. http://www.solarlite.de/en/project_kanchanaburi.cfm.

SolarPaces. 2018. "Glasspoint Inaugurates First Four Units of Miraah in Oman." SolarPACES, February 14, 2018. https://www.solarpaces.org/glasspoint-inaugurates-first-four-unitsmiraah-oman/.

SolarPACES. 2018. "Chile's 210 MW Cerro Dominador CSP-PV Project Signs Financing," May 18, 2018. http://www.solarpaces.org/chiles-cerro-dominador-csp-pv-project-signsfinancing/.

SRCC. 2018. "OG-100 ICSRCC - Certified Solar Collector \#10002069 - Artic Solar, Inc." $10002069 . \quad$ SRCC. https://secure.solarrating.org/Certification/Ratings/RatingsReport.aspx?device=7611\&units=METRICS.

Statista. 2018a. "Labor Productivity per Hour Worked in China from 2000 to 2018 (in 2017 U.S. Dollars*)." Statista. 2018. https:/www.statista.com/statistics/878164/china-laborproductivity-per-hour/.

2018b. "Pakistan: Labor Productivity per Hour 2018." Statista. 2018. https://www.statista.com/statistics/878186/pakistan-labor-productivity-per-hour/.

SunCNIM. 2016. "La Première Centrale Solaire Commerciale En France: Ello." https://www.equipex-socrate.fr/uploads/pdfs/actualites/microsolr/SUNCNIMR.Alliotte.27.09.16.pdf.

- 2017. "Solar Stean Generator Leaflet - Turnkey Concentrated Solar Thermal Plant for Steam and Electricity Production." SunCNIM. https://www.suncnim.com/sites/default/files/2017-06/SUNCNIM\%20leaflet\%20SSG.pdf.

The Corner. 2018. "Abengoa Will Participate in the Construction of the Biggest Solar Complex in the World in Dubai; a Contract Equivalent to 38\% of Its Portfolio.” The Corner, May 13, 
2018. http://thecorner.eu/financial-markets/abengoa-will-participate-in-the-constructionof-the-biggest-solar-complex-in-the-world-in-dubai-a-contract-equivalent-to-38-of-itsportfolio/72977/.

Turchi, Craig. 2010. "Parabolic Trough Reference Plant for Cost Modelling with the Solar Advisor Model (SAM)." NREL.

Turchi, Craig, and Garvin Heath. 2013. "Molten Salt Power Tower Cost Model for the System Advisor Model (SAM)." NREL/TP-5500-57625. Golden, CO: NREL. https://www.nrel.gov/docs/fy13osti/57625.pdf.

Turchi, Craig, Parthiv Kurup, and Guangdong Zhu. 2016. "Revisiting Parabolic Trough Concentrators for Industrial Process Heat in the United States." In ASME 2016 Power and Energy Conference PowerEnergy 2016, V001T08A018. North Carolina, USA: ASME. https://doi.org/10.1115/POWER2016-59621.

Turchi, Craig S, Judith Vidal, and Matthew Bauer. 2018. "Molten Salt Power Towers Operating at $600-650^{\circ} \mathrm{C}$ : Salt Selection and Cost Benefits." Solar Energy, 9.

Ultra Lite Solar. 2018a. "About Us - Technical Advantage." CSPUltraliteSolar. 2018. http://www.cspultralitesolar.com/about-us/technical-advanage.html. . 2018b. "Home Page - CSP Ultra Lite Trough and Point Focus Applications." 2018. http://www.cspultralitesolar.com/.

—. 2018c. "Technology - Concentrated Solar Power." CSPUltraliteSolar. 2018. http://www.cspultralitesolar.com/technology/concentrated-solar-power/.

Valenzuela, Loreto, and Rafael López-Martín. 2017. "Dual-Axis Solar Tracking Collector by Lucida Solar - Study of Annual Energy Performance.” USSC-TE-CS-49. Spain: CIEMATPSA.

Wagner, Michael, Mark Mehos, David Kearney, and Andrew McMahan. 2011. "Modeling of a Parabolic Trough Solar Field for Acceptance Testing: A Case Study." In Proceedings of ASME 2011 5th International Conference on Energy Sustainability \& 9th Fuel Cell Science, Engineering and Technology Conference. Washington, DC, USA.

Wang, Jun, Song Yang, Chuan Jiang, Yaoming Zhang, and Peter D. Lund. 2017. "Status and Future Strategies for Concentrating Solar Power in China." Energy Science \& Engineering 5 (2): 100-109. https://doi.org/10.1002/ese3.154.

Willwerth, Lisa, Svenja Müller, Joachim Krüger, Manuel Succo, Jan Fabian Feldhoff, Jörg Tiedemann, Yuvaraj Pandian, Dirk Krüger, and Klaus Hennecke. 2017. "Steam Drum Design for Direct Steam Generation.” In AIP Conference Proceedings. Abu Dhabi: AIP Publishing.

Winston, Roland. 2016. Solar thermal concentrator apparatus, system, and method. United States US9383120B1, filed March 20, 2015, and issued July 5, 2016. https://patents.google.com/patent/US9383120B1/en?oq=U.S.+Patent+\#9\%2c383\%2c120 $+\mathrm{B} 1$.

XE.com. 2018a. "XE - The World's Trusted Currency Authority: Money Transfers \& Free Exchange Rate Tools." June 2018. https://www.xe.com/.

- 2018b. "XE: Convert AED/USD. United Arab Emirates Dirham to United States Dollar." September $27, \quad 2018$. https://www.xe.com/currencyconverter/convert/?Amount=20600\&From=AED\&To=US D.

X-Rates. 2018a. "Historic Exchange Rates (Chinese Yuan Renminbi) in 2017." September 28, 2018. https://www.X-rates.com/historical/?from=CNY\&amount=18\&date=2017-09-29. 
—. 2018b. "Historic Exchange Rates (Euro) in 2016." September 29, 2018. https://www.Xrates.com/historical/?from $=$ EUR\&amount=15\&date $=2016-09-30$.

Yang, Shuxia, Xianguo Zhu, and Weishang Guo. 2018. "Cost-Benefit Analysis for the Concentrated Solar Power in China." Journal of Electrical and Computer Engineering 2018.

Zhu, Guangdong, Greg Mungas, Nick Kramer, and John King. 2016. "Optical Performance Prediction of Hyperlight Energy Collector With a New Optimized Secondary Reflector." In AIP Conference Proceedings. SolarPACES. https://www.researchgate.net/profile/Guangdong_Zhu/publication/301607980_Optimizati on_of_a_New_Linear_Fresnel_Collector_Using_WaterBorne_Reflectors/links/58309a5b08aef19cb817f726.pdf.

Zhu, Guangdong, and Ty Neises. 2015. "Third-Party Thermal Performance Validation of FLABEG's Ultimate Trough Test Loop Located at the SEGS VIII Plant." NREL/TP-550063522. National Renewable Energy Laboratory.

Zuckerman, Julia, Karen Laughlin, Dario Abramskiehn, and Xueying Wang. 2014. "Cap and Trade in Practice: Barriers and Opportunities for Industrial Emissions Reductions in California." Climate Policy Initiative. July 2014. https://climatepolicyinitiative.org/wpcontent/uploads/2014/07/Cap-and-Trade-in-Practice-Full-Report.pdf. 